\section{Constitutional WT1 mutations correlate with clinical features in children with progressive nephropathy}

EDITOR-The WT1 tumour suppressor gene encodes a transcriptional factor containing four zinc fingers. ${ }^{12}$ This gene has two alternative splicing regions, one consisting of 17 amino acids which are encoded by the whole of exon 5 and the other comprising three amino acids (lysine, threonine, and serine (KTS)) situated between the third and fourth zinc fingers encoded by the 3 ' end of exon 9. Four isoforms of the gene thus occur depending on the presence or absence of these regions. ${ }^{3}$ These isoforms are present in a fixed proportion in tissues where they are expressed. WT1 is expressed from the condensing mesenchyme to mature podocytes in fetal kidneys. The other sites are genital ridges and fetal gonads. Therefore, this gene is thought to play an important role in the development of the kidneys and gonads. ${ }^{45}$ Functional impairment of this gene is considered to give rise to urogenital abnormalities and Wilms tumours. Denys-Drash syndrome and Frasier syndrome, both of which are characterised by nephropathy with genital abnormalities, have been recognised as disorders related to WT1 mutations.

Denys-Drash syndrome consists of the triad of progressive nephropathy characterised by diffuse mesangial sclerosis (DMS), genital abnormalities, and Wilms tumour. ${ }^{6}$ The incomplete form consists of nephropathy with genital abnormalities or Wilms tumour. In virtually all patients with Denys-Drash syndrome, point mutations are detected in the zinc finger domain encoded by exons 7 to 10 of the WT1 gene. ${ }^{7}$ The mutations noted in Denys-Drash syndrome patients are frequently missense changes in exons 8 and 9 that encode the second and third zinc fingers.

Frasier syndrome is a clinical entity proposed by Moorthy $e t a l^{s}$ to be related to but distinguished from Denys-Drash syndrome. Frasier syndrome is characterised by a slowly progressing nephropathy, male pseudohermaphroditism, and no Wilms tumour. As for histological findings of the kidneys, focal segmental glomerular sclerosis (FSGS) or focal glomerular sclerosis (FGS) is often observed in cases of Frasier syndrome, whereas DMS is noted in Denys-Drash syndrome patients. Recent reports have shown that Frasier syndrome arises from heterozygous mutation at the intron 9 splicing donor site of the WT1 gene. ${ }^{9-11}$ This intron 9 mutation leads to impairment of exon 9 alternative splicing with a consequent decrease in the +KTS isoform, thereby eventually causing a quantitative $+\mathrm{KTS} /-\mathrm{KTS}$ isoform imbalance.

Recently, the presence of constitutional WT1 mutations has been documented in some patients with nephropathy alone, such as isolated DMS (IDMS). ${ }^{12}{ }^{13}$ IDMS presents the same clinical features of nephropathy as those seen in Denys-Drash syndrome, but is not accompanied by any other anomalies or Wilms tumours. ${ }^{14}$ The mutations were mostly located in exons 8 and 9 in these IDMS patients, and were thus similar to the mutations seen in DenysDrash syndrome.

As noted above, some progressive nephropathies in children are thought to be related to WT1 mutations. However, the clinical features of WT1 related nephropathy have not been fully elucidated at the molecular level, especially in patients with FSGS not accompanied by other abnormalities. Analysis of the WT1 gene in such progressive nephropathy is of value in clarifying the role of WT1 in urogenital organ development. In this study, we analysed constitutional WT1 mutations in patients with progressive nephropathies, such as FSGS, FGS, and DMS, which may be related to functional impairment of WT1, to investigate the correlation between the type of WT1 mutation and the phenotype of nephropathy.

The clinical features of the 42 patients with progressive nephropathy are summarised in table 1. Thirty four patients were analysed in the present study, eight of whom (patients 1-3 and 10-14) were reported in our previous study. $^{9}$

Of the 42 patients studied, 16 had nephropathy accompanied by genital abnormalities or Wilms tumours. Nine patients including a set of identical twins (patients 8 and 9) had been clinically diagnosed with incomplete DenysDrash syndrome. In all the Denys-Drash syndrome patients, except one (No 5) who lacked detailed clinical progress data, the nephropathy had progressed rapidly to renal failure by the age of 2 years. Six patients (Nos 2, 4, and 6-9) with a 46,XY karyotype had diverse genital anomalies ranging from hypospadias and cryptorchidism to complete female external genitalia. Three patients (Nos 1, 3, and 5) developed a Wilms tumour. In seven patients including another set of identical twins (Nos 10 and 11), Frasier syndrome was strongly suspected based on the following clinical features. The course of nephropathy was slowly progressive; in four patients (Nos 12 and 14-16), the nephropathy did not require dialysis until more than 6 years after the onset and in the other three (Nos 10, 11, and 13) nephropathy had not yet led to renal failure. All patients had female external genitalia despite a 46,XY karyotype. None showed evidence of a Wilms tumour.

Of the remaining 26 patients, none was noted to have genital anomalies or Wilms tumours. In seven patients with IDMS, the nephropathy had developed at or before 2 years of age and progressed rapidly to renal failure in all but one patient (No 21). The clinical picture was diverse in 19 patients with FSGS. Age at the onset of nephropathy varied widely, ranging from 0 months to 15 years, and the age at which the condition progressed to end stage renal failure also varied considerably, 1 to 17 years. There were no signs of renal failure in three patients (Nos 30, 34, and 42). In two patients (Nos 32 and 41), detailed clinical progress data pertaining to the nephropathy were not available.

DNA extraction from leucocytes was carried out by the SDS-proteinase $\mathrm{K}$ method as previously described ${ }^{15}$ or using the GFX genomic blood DNA purification kit (Amersham-Pharmacia Biotech). Amplification of exons 7 to 10 was performed using primers designed in the pre- and post-exon introns. The primers used included the following: for exon 7, 7D-S (5'-GACCTACGTGAATGTTCACATG-3') and 7C-A (5'-CTTAGCAGTGTGAGAGCCTG-3'); for exon 8, 8-S (5'-AGATCCCCTTTTCCAGTATC-3') and 8C'-A (5'-CAACAACAAAGAGAATCA-3'); for exon 9, 9C-S (5'-AAGTCAGCCTTGTGGGCCTC-3') and 9C-A (5'-TTTCCAATCCCCTCTCATCAC-3'); and for exon 10, 10C-S (5'-CACTCGGGCCTTGATAGTTG-3') and 10C-A (5'-GTCAGACTTGAAAGCAGTTC-3'). ${ }^{9}$ The 
cycling protocol consisted of incubation at $94^{\circ} \mathrm{C}$ for three minutes, followed by 30 cycles of $94^{\circ} \mathrm{C}$ for one minute, $55^{\circ} \mathrm{C}$ (exons 8 and 9 ) $/ 58^{\circ} \mathrm{C}$ (exons 7 and 10 ) for one minute, $72^{\circ} \mathrm{C}$ for one minute, and a final extension time of $72^{\circ} \mathrm{C}$ for five minutes. The resultant PCR products were purified through Microspin S-400 HR columns (Amersham-Pharmacia Biotech). The sequence reactions were carried out using either fluorescently labelled forward or reverse primers, a Thermo Sequenase fluorescently labelled primer cycle sequencing kit (AmershamPharmacia Biotech), and ALF DNA sequencer II (Amersham-Pharmacia Biotech). Whenever the sequence of the PCR product was ambiguous or mutated, the sequence reaction was repeated using the contradirected primer. The fluorescently labelled primers used were as follows: exon 7 forward: 7-S (5'AGCСTCCСTTCСTCTTACTC-3'), and reverse: 7-A (5'-GTTTGCCCAAGACTGGACAG-3'); exon 8 forward: 8-S (5'-AGATCCCCTTTTCCAGTATC-3'), and reverse: 8C-A (5'-AAATCAACCCTAGCCCAAGG-3'); exon 9 forward: 9B-S (5'-TAGGGCCGAGGCTAGACCTTC TCT-3'), and reverse: 9C-A (5'-TTTCCAATCCCT CTCATCAC-3'); and exon 10 forward: 10B-S (5'TGTGCCTGTCTCTTTGTTGC-3'), and reverse: 10B-A (5'-TGCTGCCTGGGACACTGAAC-3'). ${ }^{9}$

Of the 42 patients studied, 18 were found to have constitutional mutations in the WT1 gene (table 1). These mutations were heterozygous in all but one patient (No 1), in whom the mutation was homozygous. ${ }^{15}$

WT1 mutations were found in all 16 patients with genital abnormalities or Wilms tumour, the mutations being exonic in seven patients and intronic in nine patients. Of seven patients with exonic mutations, who had been clinically diagnosed as having Denys-Drash syndrome, six (Nos 1-3 and 5-7) carried missense mutations within exon 8 or 9. The conversions of the amino acids cysteine 355,385 , and 388, critical for the zinc finger structure, were found in patients 1,2 , and 5 , respectively. The mutations in patients 3,6 , and 7 were located in the amino acids arginine 366, asparagine 396, and arginine 394, respectively, which are essential for DNA binding. These mutations have frequently been seen in patients with Denys-Drash syndrome. ${ }^{16}$ In the other patient (No 4) with exonic mutations, there was a missense mutation in exon 7 which has not been reported previously. In this case, transversion of the nucleotide $T 1025$ to $G$ leading to replacement by arginine of the amino acid 342 methionine adjacent to the zinc coordinating histidine was identified. Of the nine patients with intronic mutations, the identical twins (Nos 8 and 9), who had been clinically considered to have DenysDrash syndrome and seven patients with Frasier syndrome (Nos 10-16), had point mutations at the intron 9 splicing donor site +2 (two cases), +4 (five cases), and +5 (two cases). These mutations, detected in patients in the present

Table 1 Clinical features and WT1 mutations in patients

\begin{tabular}{|c|c|c|c|c|c|c|c|c|c|c|c|}
\hline Patient & Age & $\begin{array}{l}\text { Nephropathy } \\
\text { onset }\end{array}$ & Renal failure & Histology & Karyotype & $\begin{array}{l}\text { Genital status external } \\
\text { E internal genitalia }\end{array}$ & $\begin{array}{l}\text { Wilms } \\
\text { tumour }\end{array}$ & \multicolumn{2}{|c|}{$\begin{array}{l}\text { WT1 mutation } \\
\text { (exon/intron) }\end{array}$} & $D N A$ & Amino acids \\
\hline \multicolumn{12}{|c|}{ Nephropathy with genital abnormalities or Wilms tumours } \\
\hline \multicolumn{12}{|c|}{ Clinical Denys-Drash syndrome } \\
\hline $1^{\star}$ & $1 \mathrm{y}$ & $1 \mathrm{y}$ & $1 \mathrm{y}$ & FGS & $46, \mathrm{XX}$ & Female & + & Exon 8 & 1064 & $\mathrm{G} \rightarrow \mathrm{A}$ & ${ }^{355} \mathrm{Cys} \rightarrow{ }^{355} \mathrm{Thr}$ \\
\hline $2^{\star}$ & $22 \mathrm{y}$ & Unclear & $2 \mathrm{y}$ & FGS & $46, X Y$ & Female, streak gonad & - & Exon 9 & 1154 & $\mathrm{~T} \rightarrow \mathrm{C}$ & ${ }^{385} \mathrm{Cys} \rightarrow{ }^{385} \mathrm{Arg}$ \\
\hline $3^{\star}$ & $5 \mathrm{y}$ & Unclear & $1 \mathrm{mth}$ & FGS & $46, \mathrm{XX}$ & Female & + & Exon 8 & 1097 & $\mathrm{G} \rightarrow \mathrm{A}$ & ${ }^{366} \mathrm{Arg} \rightarrow{ }^{366} \mathrm{His}$ \\
\hline 4 & $7 \mathrm{y}$ & Unclear & $1 \mathrm{y}$ & ESRD & $46, X Y$ & Female & - & Exon 7 & 1025 & $\mathrm{~T} \rightarrow \mathrm{G}$ & ${ }^{342} \mathrm{Met} \rightarrow{ }^{342} \mathrm{Arg}$ \\
\hline 5 & $5 \mathrm{y}$ & $<5 \mathrm{y}$ & Not followed & Not known & $\mathrm{NE}$ & Female & + & Exon 9 & 1163 & $\mathrm{G} \rightarrow \mathrm{T}$ & ${ }^{388} \mathrm{Cys} \rightarrow{ }^{388} \mathrm{Phe}$ \\
\hline 6 & $1 \mathrm{y}$ & 1 y 2 mth & 1 y $2 \mathrm{mth}$ & DMS & $46, \mathrm{XY}$ & $\begin{array}{l}\text { Hypospadias, } \\
\text { cryptorchidism }\end{array}$ & - & Exon 9 & 1186 & $\mathrm{G} \rightarrow \mathrm{A}$ & ${ }^{396} \mathrm{Asp} \rightarrow{ }^{396} \mathrm{Asn}$ \\
\hline 7 & $9 \mathrm{y}$ & Unclear & $11 \mathrm{mth}$ & DMS & $46, \mathrm{XY}$ & $\begin{array}{l}\text { Hypospadias, } \\
\text { cryptorchidism }\end{array}$ & - & Exon 9 & 1180 & $\mathrm{C} \rightarrow \mathrm{T}$ & ${ }^{394} \mathrm{Arg} \rightarrow{ }^{394} \operatorname{Trp}$ \\
\hline $8+$ & $18 \mathrm{y}$ & Unclear & $7 \mathrm{mth}$ & Dysplasia & $46, X Y$ & Female & - & Intron 9 & +4 & $\mathrm{c} \rightarrow \mathrm{t}$ & Disruption of splicing \\
\hline $9 \dagger$ & $18 \mathrm{y}$ & $7 \mathrm{mth}$ & $7 \mathrm{mth}$ & Dysplasia & $46, \mathrm{XY}$ & Female & - & Intron 9 & +4 & $c \rightarrow t$ & Disruption of splicing \\
\hline \multicolumn{12}{|c|}{ Clinical Frasier syndrome } \\
\hline $10^{\star} \ddagger$ & $18 \mathrm{y}$ & $3 \mathrm{y}$ & No & FGS & $46, X Y$ & Female, streak gonad & - & Intron 9 & +4 & $\mathrm{c} \rightarrow \mathrm{t}$ & Disruption of splicing \\
\hline $11^{\star} \ddagger$ & $18 \mathrm{y}$ & $3 y$ & No & FGS & $46, X Y$ & Female, streak gonad & - & Intron 9 & +4 & $\mathrm{c} \rightarrow \mathrm{t}$ & Disruption of splicing \\
\hline $12^{\star}$ & $19 \mathrm{y}$ & $5 \mathrm{y}$ & $16 \mathrm{y}$ & FGS & $46, X Y$ & Female, streak gonad & - & Intron 9 & +4 & $\mathrm{c} \rightarrow \mathrm{t}$ & Disruption of splicing \\
\hline $13^{\star}$ & $3 y$ & $3 y$ & No & Not known & $46, X Y$ & Female, streak gonad & - & Intron 9 & +5 & $\mathrm{~g} \rightarrow \mathrm{t}$ & Disruption of splicing \\
\hline $14^{\star}$ & $26 \mathrm{y}$ & $6 \mathrm{y}$ & $23 \mathrm{y}$ & FGS & $46, \mathrm{XY}$ & Female, streak gonad & - & Intron 9 & +2 & $t \rightarrow c$ & Disruption of splicing \\
\hline 15 & $19 \mathrm{y}$ & $6 \mathrm{y}$ & $12 \mathrm{y}$ & FSGS & $46, X Y$ & Female & - & Intron 9 & +5 & $\mathrm{~g} \rightarrow \mathrm{a}$ & Disruption of splicing \\
\hline 16 & $18 \mathrm{y}$ & $2 \mathrm{y}$ & $8 \mathrm{y}$ & FSGS & $46, X Y$ & Female & - & Intron 9 & +2 & $t \rightarrow c$ & Disruption of splicing \\
\hline \multicolumn{12}{|c|}{ Nephropathy without genital abnormalities and Wilms tumours } \\
\hline 17 & $3 \mathrm{y}$ & $2 \mathrm{y}$ & $2 \mathrm{y}$ & DMS & $46, \mathrm{XY}$ & Male & - & Exon 7 & 935 & $\mathrm{G} \rightarrow \mathrm{A}$ & ${ }^{312} \mathrm{Arg} \rightarrow{ }^{312} \mathrm{Gln}$ \\
\hline 18 & $2 \mathrm{y}$ & $1 \mathrm{y}$ & $1 \mathrm{y}$ & DMS & $46, \mathrm{XY}$ & Male & - & - & & & \\
\hline 19 & $7 \mathrm{y}$ & $2 \mathrm{y}$ & $2 \mathrm{y}$ & DMS & $46, \mathrm{XY}$ & Male & - & - & & & \\
\hline 20 & $18 \mathrm{y}$ & $0 \mathrm{y}$ & $1 \mathrm{y}$ & DMS & $46, \mathrm{XY}$ & Male & - & - & & & \\
\hline 21 & $3 \mathrm{y}$ & 2 y $8 \mathrm{mth}$ & No & DMS & $46, X Y$ & Male & - & - & & & \\
\hline 22 & $6 \mathrm{y}$ & $2 \mathrm{mth}$ & $2 \mathrm{mth}$ & DMS & $46, X Y$ & Male & - & - & & & \\
\hline 23 & Not known & $8 \mathrm{~d}$ & $1 \mathrm{y} 2 \mathrm{mth}$ & DMS & $46, \mathrm{XX}$ & Female & - & - & & & \\
\hline 24 & $18 \mathrm{y}$ & $2 \mathrm{y}$ & $4 y$ & FSGS & $46, \mathrm{XX}$ & Female, puberty(+) & - & Intron 9 & +4 & $\mathrm{c} \rightarrow \mathrm{t}$ & Disruption of splicing \\
\hline 25 & $8 \mathrm{y}$ & 1 y $9 \mathrm{mth}$ & $3 \mathrm{y}$ & FSGS & $\mathrm{NE}$ & Female & - & - & & & \\
\hline 26 & $13 \mathrm{y}$ & $7 \mathrm{y}$ & $8 \mathrm{y}$ & FSGS & $46, \mathrm{XX}$ & Female & - & - & & & \\
\hline 27 & $15 \mathrm{y}$ & 2 y $8 \mathrm{mth}$ & $7 \mathrm{y}$ & FSGS & $\mathrm{NE}$ & Male & - & - & & & \\
\hline 28 & $19 \mathrm{y}$ & $1 \mathrm{w}$ & 5 y $2 \mathrm{mth}$ & FSGS & $46, \mathrm{XX}$ & Female & - & - & & & \\
\hline 29 & $30 \mathrm{y}$ & Unclear & $11 \mathrm{y}$ & FSGS & $46, \mathrm{XX}$ & Female & - & - & & & \\
\hline 30 & $24 \mathrm{y}$ & $7 \mathrm{y}$ & No & FSGS & $\mathrm{NE}$ & Male & - & - & & & \\
\hline 31 & $11 \mathrm{y}$ & 4 y $6 \mathrm{mth}$ & $7 \mathrm{y}$ & FSGS & $\mathrm{NE}$ & Not known & - & - & & & \\
\hline 32 & Not known & $15 \mathrm{y}$ & Not followed & FSGS & $\mathrm{NE}$ & Male & - & - & & & \\
\hline 33 & $9 \mathrm{y}$ & 2 y $10 \mathrm{mth}$ & 3 y $11 \mathrm{mth}$ & FSGS & $46, X Y$ & Male & - & - & & & \\
\hline 34 & Not known & $13 \mathrm{y}$ & No & FSGS & NE & Male & - & - & & & \\
\hline 35 & $8 \mathrm{y}$ & 1 y $6 \mathrm{mth}$ & 1 y $7 \mathrm{mth}$ & FSGS & $\mathrm{NE}$ & Male & - & - & & & \\
\hline 36 & $4 \mathrm{y}$ & 1 y $7 \mathrm{mth}$ & 2 y $10 \mathrm{mth}$ & FSGS & $\mathrm{NE}$ & Male & - & - & & & \\
\hline 37 & $16 \mathrm{y}$ & 3 y $2 \mathrm{mth}$ & 4 y $4 \mathrm{mth}$ & FSGS & $\mathrm{NE}$ & Male & - & - & & & \\
\hline 38 & $19 \mathrm{y}$ & 3 y $2 \mathrm{mth}$ & $17 \mathrm{y}$ & FSGS & $\mathrm{NE}$ & Male & - & - & & & \\
\hline 39 & $9 \mathrm{y}$ & 3 y $1 \mathrm{mth}$ & 7 y 6 mth & FSGS & $\mathrm{NE}$ & Male & - & - & & & \\
\hline 40 & $19 \mathrm{y}$ & 5 y $5 \mathrm{mth}$ & $7 \mathrm{y}$ & FSGS & $\mathrm{NE}$ & Male & - & - & & & \\
\hline 41 & $12 \mathrm{y}$ & 6 y $2 \mathrm{mth}$ & Not followed & FSGS & $\mathrm{NE}$ & Male & - & - & & & \\
\hline 42 & $5 \mathrm{y}$ & $3 y$ & No & FSGS & $\mathrm{NE}$ & Not known & - & - & & & \\
\hline
\end{tabular}

${ }^{\star}$ Patients $1-3$ and $10-14$ have been reported before ${ }^{9} \dagger 8$ and 9 , and $\ddagger 10$ and 11 are identical twins. FGS, focal glomerular sclelrosis; ESRD, end stage renal disease; DMS, diffuse mesangial sclerosis; FSGS, focal segmental glomerular sclerosis; NE, not examined. 
study (Nos 15 and 16), were consistent with those which have been reported in patients with Frasier syndrome. ${ }^{9-11}$

Of the 26 patients with nephropathy alone, only two (No 17 with IDMS and No 24 with FSGS) were noted to have WT1 point mutations. The WT1 mutation detected in patient 17 has been reported in cases without nephropathy, Wilms tumours with genital anomalies, or sporadic Wilms tumours. The amino acid 312 arginine was replaced by glutamine as a result of alteration of the nucleotide $\mathrm{T} 935$ to $\mathrm{A}$, and this mutation occurred upstream from the zinc finger domain. In patient 24, who had FSGS, a WT1 mutation situated at position +4 of the intron 9 splicing donor site was detected; this mutation was the same as those reported in Frasier syndrome patients. ${ }^{9-11}$

The published constitutional WT1 mutations in patients with nephropathy are thought to be classifiable into two groups: one is mutations occurring within the zinc finger domain, especially within exon 8 or 9 , most of which are missense mutations, and the other is point mutations at the intron 9 splicing donor site. ${ }^{16}$ In the present analyses in patients with nephropathy as well as our previous studies, ${ }^{9}$ we identified WT1 mutations in 18 such cases, that is, missense mutations at exons 7 to 9 in eight cases and mutations at the intron 9 splicing donor site in 10 cases (table 1). Depending on whether they had the exonic or intronic mutations, differences in clinical features were noted among these patients.

The eight patients with exonic mutations clinically had either Denys-Drash syndrome or IDMS. In six patients with Denys-Drash syndrome (Nos 1-3 and 5-7), WT1 mutations were missense mutations within the second or the third zinc finger encoded by exon 8 or 9 , respectively, whereas in one Denys-Drash syndrome patient (No 4), a missense mutation was detected in a rarely involved site, the first zinc finger encoded by exon 7 . In patient 4 , a point mutation with replacement of 342 methionine by arginine was detected. This replacement of a hydrophobic amino acid by a basic amino acid may disrupt the conformation of the first zinc finger. This mutant protein would potentially affect $W T 1$ gene functions, like the mutant proteins resulting from injury to the second or the third zinc finger that are often noted in Denys-Drash syndrome and IDMS patients.

The clinical features of patients with the exonic mutations studied may be summarised as follows. Nephropathy progressed rapidly to renal failure in all but one patient (No 5) whose clinical course was uncertain. Genital abnormalities were diverse, ranging from little if any impairment to 46,XY female. A Wilms tumour developed in three of the eight patients; the potential risk of Wilms tumour development in patients with exonic WT1 mutations was thus reconfirmed.

The missense mutation observed in patient 17 was situated in exon 7 but upstream from the zinc finger domain. In published nephropathy cases, the mutation upstream from the zinc finger domain was rarely detected. ${ }^{12}{ }^{16}$ This mutation may exert an effect on WT1 gene functions different from that of the mutations located within the zinc finger domain. To understand the mechanism of nephropathy development, further studies are needed to clarify the function of the resulting mutant protein.

Among 10 patients with intron 9 splicing donor site mutations, the clinical features of seven patients (Nos 10-16) were consistent with Frasier syndrome. Patient 24 actually had features concordant with nephropathy in Frasier syndrome. The patient developed nephropathy at the age of 2 that had progressed to renal failure by the age of 4 . Renal biopsies showed findings characteristic of FSGS. The patient's karyotype was $46, \mathrm{XX}$, however. The conventional disease concept of Frasier syndrome has not been applicable to this patient since cases with a $46, \mathrm{XX}$ karyotype were not described in the definition of Frasier syndrome proposed by Moorthy et al. ${ }^{8}$ In this regard, we consider this case with a $46, \mathrm{XX}$ karyotype to represent a variant form of Frasier syndrome based on both the clinical features of nephropathy and the types of WT1 mutations. This patient, No 24, had normal female external genitalia and presented secondary female sex characteristics. Besides this patient, three other cases with a $46, \mathrm{XX}$ karyotype accompanied by intron 9 splicing donor site mutations have been reported. ${ }^{11}{ }^{12}{ }^{17}$ All these patients had nephropathy and normal sex differentiation, as did our case 24. They can be considered to have "genotypic female Frasier syndrome". It would be reasonable to assume that the intron 9 splicing donor site mutation does not interfere with feminisation in patients with a 46,XX karyotype, whereas this mutation strongly interferes with masculinisation since patients with a 46,XY karyotype who have intron 9 mutations invariably have female external genitalia. ${ }^{9-11}$

As mentioned above, the intron 9 mutation leads to impairment of exon 9 alternative splicing, thereby eventually causing a quantitative +KTS/-KTS isoform imbalance. Many studies have suggested functional differences among the isoforms, with or without KTS. These isoforms have different DNA binding properties ${ }^{18}$; the -KTS isoform has greater binding affinity for growth related genes. ${ }^{19}$ In addition, two of these isoforms have been shown to vary in subnuclear localisation. The +KTS isoform appears to be involved in post-transcriptional RNA processing in association with splicing factors, while the -KTS isoform is situated in the transcriptional factor domain. ${ }^{20}{ }^{21}$ In the patients with Frasier syndrome, in whom masculinisation is impaired, the amount of the +KTS isoform diminishes relative to the $-\mathrm{KTS}$ isoform owing to the intron 9 mutation. Therefore, it appears probable that the $+\mathrm{KTS}$ isoform plays a significant role in masculinisation. The clinical features of patients with a 46 , XX karyotype nevertheless indicate that the +KTS isoform probably has little significance in feminisation.

The clinical features of the patients with intron 9 mutations discussed so far are summarised as follows. The patients exhibited slowly progressive nephropathy, as reported for Frasier syndrome, as compared to those with exonic mutations. Whereas all 46,XY cases presented female external genitalia, normal sex differentiation was evident in the 46,XX cases. There was no evidence of Wilms tumour in the patients with intron 9 mutations analysed in this study. The incidence of Wilms tumour is considered to be markedly lower in patients with intron 9 mutations than in those with exonic mutations, since Wilms tumour had occurred in only one of the 27 cases analysed in this and previous studies. ${ }^{9-12} 17$ 22-25

In the two patients with an intron 9 mutation (Nos 8 and 9), who were identical twins, the clinical manifestations also overlapped in part with those of Frasier syndrome, that is, 46, XY female external genitalia without the development of Wilms tumour. However, nephropathy progressed to renal failure as early as 7 months after onset. Because of the rapidity with which nephropathy progressed, the disease state was clinically considered to represent DenysDrash syndrome rather than Frasier syndrome. Histological findings were those of dysplastic kidney and were not characteristic of either Denys-Drash or Frasier syndrome. An IDMS case with an intron 9 splicing donor site mutation with early onset and rapid progression of nephropathy was reported (patient P4 in the study by Jeanpierre et $a l^{12}$ ). The twin cases described here, and the case documented by Jeanpierre et $a l,{ }^{12}$ had a nephropathy course consistent with the clinical features of Denys-Drash syndrome. It follows that the nephropathy associated with WT1 intron 9 
mutations is more heterogeneous than was previously thought. The rapid progress of nephropathy in these cases might be the consequence, in part, of a possible influence of additional genes related to development of the kidneys.

In conclusion, this review of the clinical features of nephropathy in patients with WT1 gene mutations indicates that differences exist in the progression of nephropathy, the degree of genital abnormalities, and the incidence of Wilms tumours between two types of mutations, that is, exonic and intronic mutations, although in a few cases (patients 8 and 9) features occasionally overlap. Thus, detecting and clarifying types of WT1 mutations is considered to be useful for prognostic estimation of the clinical course in children with progressive nephropathy. The authors are grateful to Dr K Yamamoto (Osaka Medical Center and
Research Institute for Maternal and Child Health) and Dr O Motoyama (Toho Research Institute for Maternal and Child Health) and Dr O Motoyama (Toho
University School of Medicine) for providing materials. This work was University School of Medicine) for providing materials. This work was supported by a Grant-in-Aid for Scientific Research on Priority Areas Ministry of Education, Science, Sports and Culture to JH, the Grant-in-Aid for
Mind Ministry of Education, Science, Sports and Culture to $\mathrm{JH}$, the Grant-in-Aid for
Cancer Research from the Ministry of Health and Welfare to $\mathrm{JH}$, and Keio University Grant-in-Aid for Encouragement of Young Medical Scientists to AT

AYAKO TAKATA* HARUHITO KIKUCHI*† RYUJI FUKUZAWA* SHUICHI ITO

MASATAKA HONDA

JUN-ICHI HATA*

*Department of Pathology, Keio University School of Medicine, 35 Shinanomachi, Shinjuku-ku, Tokyo 160-8582, fapan

†Department of Laboratory Medicine, Keio University School of

Medicine, 35 Shinanomachi, Shinjuku-ku, Tokyo 160-8582, Japan

$\ddagger$ Department of Paediatric Nephrology, Tokyo Metropolitan Kiyose

Children's Hospital, Tokyo, Fapan

Correspondence to: Dr Hata, jhata@med.keio.ac.jp

1 Call KM, Glaser T, Ito CY, Buckler AJ, Pelletier J, Haber DA, Rose EA, Kral $\mathrm{A}$, Yeger $\mathrm{H}$, Lewis WH, Jones $\mathrm{C}$, Housman DE. Isolation and characterization of a zinc finger polypeptide gene at the human chromosome 11 Wilms' tumor locus. Cell 1990;60:509-20.

2 Gessler M, Poustka A, Cavenee W, Neve RL, Orkin SH, Bruns GA. Homozygous deletion in Wilms tumours of a zinc-finger gene identified by chrozygous deletion in Wilms tumours of a zinc-

mosome jumping. Nature 1990;343:774-8.
3 Haber DA, Sohn RL, Buckler AJ, Pelletier J, Call KM, Housman DE. Alternative splicing and genomic structure of the Wilms tumor gene WT1. Proc native splicing and genomic structure
Natl Acad Sci USA 1991;88:9618-22.

4 Pritchard-Jones K, Fleming S, Davidson D, Bickmore W, Porteous D, Gosden C, Bard J, Buckler A, Pelletier J, Housman D, van Heyningen V, Hastie $\mathrm{N}$. The candidate Wilms' tumour gene is involved in genitourinary development. Nature 1990;346:194-7.

5 Pritchard-Jones K, Fleming S. Cell types expressing the Wilms' tumour gene (WT1) in Wilms' tumours: implications for tumour histogenesis. Oncogene 1991;6:2211-20.

6 Habib R, Loirat C, Gubler MC, Niaudet P, Bensman A, Levy M, Broyer M. The nephropathy associated with male pseudohermaphroditism and Wilms' tumor (Drash syndrome): a distinctive glomerular lesion - report of 10 cases. Clin Nephrol 1985;24:269-78.
7 Pelletier J, Bruening W, Kashtan CE, Mauer SM, Manivel JC, Striegel JE, Houghton DC, Junien C, Habib R, Fouser I, Fine RN, Silverman BL, Haber DA, Housman D. Germline mutations in the Wilms' tumor suppressor gene are associated with abnormal urogenital development in Denys-Drash syndrome. Cell 1991;67:437-47.

8 Moorthy AV, Chesney RW, Lubinsky M. Chronic renal failure and XY gonadal dysgenesis: "Frasier" syndrome - a commentary on reported cases. Am ₹ Med Genet Suppl 1987;3:297-302.

9 Kikuchi H, Takata A, Akasaka Y, Fukuzawa R, Yoneyama H, Kurosawa Y, Honda M, Kamiyama Y, Hata J. Do intronic mutations affecting splicing of WT1 exon 9 cause Frasier syndrome? $\mathcal{F}$ Med Genet 1998;35:45-8.

10 Barbaux S, Niaudet P, Gubler MC, Grunfeld JP, Jaubert F, Kuttenn F, Fekete CN, Souleyreau-Therville N, Thibaud E, Fellous M, McElreavey $\mathrm{K}$. Donor splice-site mutations in WT1 are responsible for Frasier syndrome. Nat Genet 1997;17:467-70.

11 Klamt B, Koziell A, Poulat F, Wieacker P, Scambler P, Berta P, Gessler M. Frasier syndrome is caused by defective alternative splicing of WT1 leading to an altered ratio of WT1 +/-KTS splice isoforms. Hum Mol Genet 1998; 7:709-14.

12 Jeanpierre C, Denamur E, Henry I, Cabanis MO, Luce S, Cecille A, Elion J, Peuchmaur M, Loirat C, Niaudet P, Gubler MC, Junien C. Identification of constitutional WT1 mutations, in patients with isolated diffuse mesangial sclerosis, and analysis of genotype/phenotype correlations by use of a computerized mutation database. Am f Hum Genet 1998;62:824-33.

13 Schumacher V, Scharer K, Wuhl E, Altrogge H, Bonzel KE, Guschmann M, Neuhaus TJ, Pollastro RM, Kuwertz-Broking E, Bulla M, Tondera AM, Mundel P, Helmchen U, Waldherr R, Weirich A, Royer-Pokora B. Spectrum of early onset nephrotic syndrome associated with WT1 missense mutations. Kidney Int 1998;53:1594-600.

14 Habib R, Gubler MC, Antignac C, Gagnadoux MF. Diffuse mesangial sclerosis: a congenital glomerulopathy with nephrotic syndrome. Adv Nephrol Necker Hosp 1993;22:43-57.

15 Kikuchi H, Akasaka Y, Kurosawa Y, Yoneyama H, Kato S, Hata J. A critical mutation in both WT1 alleles is not sufficient to cause Wilms' tumor. FEBS Lett 1995;360:26-8.

16 Little M, Wells C. A clinical overview of WT1 gene mutations. Hum Mutat 1997;9:209-25.

17 Tsuda M, Owada M, Tsuchiya M, Murakami M, Sakiyama T. WT1 nephropathy in a girl with normal karyotype (46,XX). Clin Nephrol 1999;51:62-3.

18 Bickmore WA, Oghene K, Little MH, Seawright A, van Heyningen V, Hastie ND. Modulation of DNA binding specificity by alternative splicing of the Wilms tumor wt 1 gene transcript. Science 1992;257:235-7.

19 Drummond IA, Madden SL, Rohwer-Nutter P, Bell GI, Sukhatme VP, Rauscher FJ III. Repression of the insulin-like growth factor II gene by the Wilms tumor suppressor WT1. Science 1992;257:674-8.

20 Larsson SH, Charlieu JP, Miyagawa K, Engelkamp D, Rassoulzadegan M, Ross A, Cuzin F, van Heyningen V, Hastie ND. Subnuclear localization of WT1 in splicing or transcription factor domains is regulated by alternative splicing. Cell 1995;81:391-401.

21 Davies RC, Calvio C, Bratt E, Larsson SH, Lamond AI, Hastie ND. WT1 interacts with the splicing factor U2AF65 in an isoform-dependent manner and can be incorporated into spliceosomes. Genes Dev 1998;12:3217-25.

22 Bruening W, Bardeesy N, Silverman BL, Cohn RA, Machin GA, Aronson AJ, Housman D, Pelletier J. Germline intronic and exonic mutations in the Wilms' tumour gene (WT1) affecting urogenital development. Nat Genet 1992;1:144-8.

23 König A, Jakubiczka S, Wieacker P, Schlosser HW, Gessler M. Further evidence that imbalance of WT1 isoforms may be involved in Denys-Drash syndrome. Hum Mol Genet 1993;2:1967-8.

24 Bardeesy N, Zabel B, Schmitt K, Pelletier J. WT1 mutations associated with incomplete Denys-Drash syndrome define a domain predicted to behave in a dominant-negative fashion. Genomics 1994;21:663-4.

25 Barbosa AS, Hadjiathanasiou CG, Theodoridis C, Papathanasiou A, Tar A, Merksz M, Gyorvari B, Sultan C, Dumas R, Jaubert F, Niaudet P, MoreiraFilho CA, Cotinot C, Fellous M. The same mutation affecting the splicing of WT1 gene is present on Frasier syndrome patients with or without Wilms' tumor. Hum Mutat 1999;13:146-53.

\section{Interstitial deletion of chromosome 17 (del(17)(q22q23.3)) confirms a link with oesophageal atresia}

EDITOR-There have been five previously described cases with a de novo interstitial deletion within the distal long arm of chromosome $17 .{ }^{1-5}$ We describe a sixth case, 46,XY,del(17)(q22q23.3)de novo. Three patients, including the proband in this report, presented with tracheooesophageal fistula (TOF)/oesophageal atresia, highlighting a potential genetic locus for this significant congenital anomaly.

The patient was born at 32 weeks' gestation by Caesarean section for fetal distress and intrauterine growth retardation. The liquor volume was low. He was the first child of a 20 year old mother and 22 year old father who were non- consanguineous and healthy. The birth weight was $1420 \mathrm{~g}$ (9th centile) and head circumference was $27 \mathrm{~cm}$ (2nd centile). Apgar scores were 7 at one minute and 9 at five minutes. The patient was noted to be dysmorphic at birth and oesophageal atresia was diagnosed at 2 days of age (fig 1). The patient had a small fontanelle, a sloping forehead with wrinkled skin, a round facial appearance, hypertelorism, small eyes with upward slanting palpebral fissures, a broad nasal tip with a short philtrum, a downturned mouth, and thin lips. His palate and ears were normal. He had small nails, proximally placed thumbs, and a deep crease between his first and second toes. He had knee contractures and a fixed flexion deformity of his hips. There was no palpable hip instability and ultrasound confirmed this.

Echocardiography showed a ventricular septal defect with an overriding aorta, pulmonary valve stenosis, and a left to right shunt. Cranial ultrasound was normal, as was renal ultrasound. At surgery oesophageal atresia was 


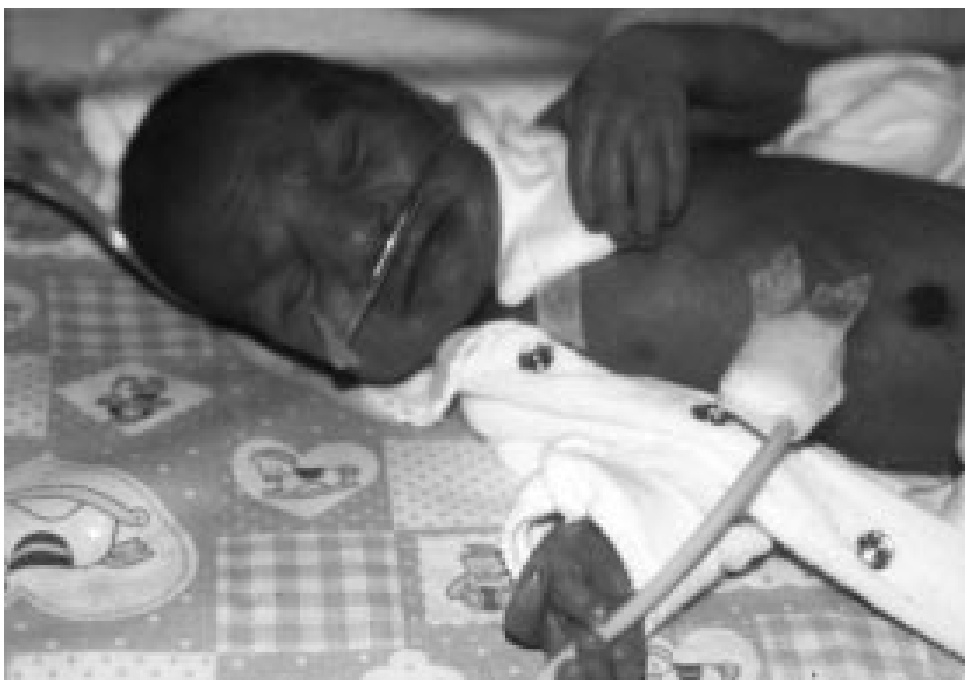

Figure 1 The proband aged 3 days. Note the wrinkled forehead, hypertelorism, small, upward slanting palpebral fissures, broad nasal tip, and downturned mouth. Proximal placement of the thumb is shown on the right.

confirmed with tracheo-oesophageal fistulae communicating with both the upper and lower oesophageal pouches. A successful oesophagostomy and gastrostomy were performed. Anal stenosis was noted and required repeated dilatations and eventually an anoplasty was performed.

The baby's recovery was complicated by several episodes of sepsis but he was discharged at 2 months of age. He made little developmental progress. Readmission was required for cyanotic episodes related to a deterioration in his cardiac condition. He developed bronchiolitis and died at $31 / 2$ months.

Short term peripheral blood cultures were initiated and harvested by standard protocols. G banded analysis was carried out using trypsin digestion followed by Leishman staining. All metaphases examined showed a male karyotype with an apparent interstitial deletion of the region $17 q 22 \rightarrow q 23.3$ (fig 2). Parental karyotypes were normal. The patient's karyotype was therefore 46,XY,del(17)(q22q23.3)de novo.

Five cases of interstitial deletions within the distal long arm of chromosome 17 have been described with a similar phenotype, including microcephaly, facial dysmorphism, proximal placement of the thumbs, and developmental delay. ${ }^{1-5}$ The features are shown in table 1 . Congenital heart disease has been reported in all the cases that have died prematurely including the present case and those of Levin et $a l^{4}$ and Dallapiccola et $a l^{2}{ }^{2}$ The cardiac malformations described in these latter two cases differ from the present case and include bicuspid aortic valve, atrial septal defect, patent ductus arteriosus, and dilated left atrium and ventricle. Both of the other patients have a more distal breakpoint, involving $17 \mathrm{q} 24$. The patient in this report has similar breakpoints to that of Mickelson et $a l,{ }^{5}$ who reported a female with no cardiac defects. Our finding is

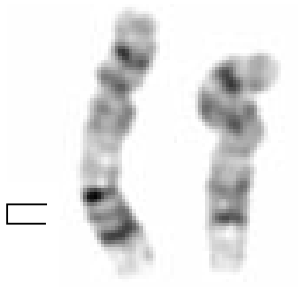

$17 \operatorname{del}(17)$
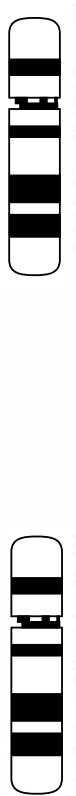

$17 \operatorname{del}(17)$

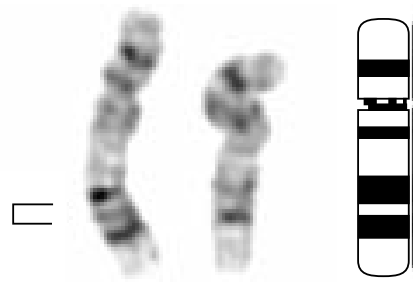

17 del(17)

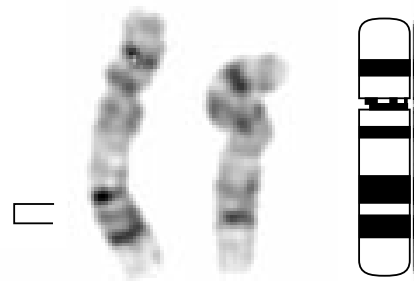

17 del(17)

Figure 2 A partial $G$ banded karyotype indicating the normal chromosome 17 (on the left) and the deleted chromosome 17 (in the centre). A chromosome 17 ideogram is also shown (on the right). The bracket indicates the deleted region. 
Table 1 Clinical features of the six cases with deletions of chromosome 17(q21-24)

\begin{tabular}{|c|c|c|c|c|c|c|}
\hline & Park et al ${ }^{1}$ & Dallapiccola et al ${ }^{2}$ & Khalifa et $a l^{3}$ & Levin et $a l^{4}$ & Mickelson et al ${ }^{5}$ & Present case \\
\hline \multicolumn{7}{|l|}{ Birth details } \\
\hline Gestation & $41.5 \mathrm{wk}$ & Term & $41.5 \mathrm{wk}$ & $35 \mathrm{wk}, 3 \mathrm{~d}$ & $39 \mathrm{wk}$ & $32 \mathrm{wk}$ \\
\hline Delivery & Caesarean & SVD & SVD & Caesarean & SVD & Caesarean \\
\hline Birth weight (g) & 2370 & 2780 & 3425 & 1160 & 2590 & 1430 \\
\hline Birth OFC $(\mathrm{cm})$ & 30.5 & 33 & 32 & 27 & - & 27 \\
\hline Birth length (cm) & 47 & 47 & 52 & 36 & 49 & - \\
\hline Sex & $\mathrm{F}$ & M & M & $\mathrm{F}$ & $\mathrm{F}$ & M \\
\hline \multicolumn{7}{|l|}{ Craniofacial } \\
\hline Microbrachycephaly & + & + & + & - & + & - \\
\hline Round face & + & ? & + & - & + & + \\
\hline Hypertelorism & + & + & + & + & - & + \\
\hline Upward slanting palpebral fissures & + & + & + & - & + & + \\
\hline Posteriorly rotated and low set ears & + & - & + & + & - & - \\
\hline Long philtrum & + & + & - & - & - & - \\
\hline Downturned mouth & + & - & - & - & + & + \\
\hline Abnormal palate & - & + & - & + & + & - \\
\hline Abnormal uvula & + & - & - & + & - & - \\
\hline Micrognathia & + & $+/-$ & + & - & Mild & - \\
\hline \multicolumn{7}{|l|}{ CNS } \\
\hline Radiological cerebral abnormalities & + & + & - & - & - & - \\
\hline \multirow{2}{*}{\multicolumn{7}{|c|}{ Skeletal }} \\
\hline & & & & & & \\
\hline Proximal placement of the thumbs & + & + & + & + & + & + \\
\hline Symphalangism & ? & + & + & - & + & - \\
\hline \multicolumn{7}{|l|}{ Other } \\
\hline TOF & + & + & - & - & - & + \\
\hline Oesophageal atresia & - & + & - & - & - & + \\
\hline Congenital heart defect & - & + & - & + & - & + \\
\hline Death & - & $4 \mathrm{mth}$ & - & $17 \mathrm{~d}$ & - & $3.5 \mathrm{mth}$ \\
\hline \multicolumn{7}{|l|}{ Cytogenetics } \\
\hline \multirow[t]{2}{*}{ Karyotype } & $46, \mathrm{XX}, \operatorname{del}(17)$ & $46, \mathrm{XY}, \operatorname{del}(17)$ & $46, X Y, \operatorname{del}(17)$ & $46, \mathrm{XX}, \operatorname{del}(17)$ & $46, \mathrm{XX}, \operatorname{del}(17)$ & 46,XY,del(17) \\
\hline & $(\mathrm{q} 21.3 \mathrm{q} 23)$ & (q21.3q24.2) & $(\mathrm{q} 21.3 \mathrm{q} 23)$ & $(\mathrm{q} 23.2 \mathrm{q} 24.3)$ & $(\mathrm{q} 23.1 \mathrm{q} 23.3)$ & $(\mathrm{q} 22 \mathrm{q} 23.3)$ \\
\hline Parental karyotype & Normal & Normal & Normal & Normal & Normal & Normal \\
\hline
\end{tabular}

SVD - spontaneous vaginal delivery

OFC - occipitofrontal circumference

thus consistent with a candidate region for cardiac malformations being more proximal to $17 \mathrm{q} 24$ and is against the hypothesis put forward by Mickelson et al, ${ }^{5}$ who suggested a more distal locus for cardiac abnormalities.

$\mathrm{TOF} /$ oesophageal atresia is rarely associated with a consistent chromosome abnormality. Brunner and Winter ${ }^{6}$ commented that an abnormal karyotype can be detected in $6 \%$ of patients with oesophageal atresia and associated anomalies. Schinzel ${ }^{7}$ noted that oesophageal atresia and TOF occur uncommonly in at least 10 different chromosomal abnormalities. These have been isolated cases in all instances except for two, where two out of 15 patients with $\operatorname{dup}(3)($ pter-p21) had a TOF as did two out of three cases with $\operatorname{del}(6)(\mathrm{q} 13-\mathrm{q} 15)$; there were no cases associated with chromosome 2 abnormalities. The discovery therefore of three patients with an interstitial $17 \mathrm{q}$ deletion and TOF is significant and unlikely to be coincidental. The breakpoints seen in our patient (q22-23.3) fall within the same region as reported in the two other patients ${ }^{12}$ and define a possible critical region. This is emphasised by two of the three cases without TOF having more distal breakpoints. ${ }^{45}$ The one case with no TOF and breakpoints in our critical region may confound this hypothesis, but is more likely to be because of variable expression and should not deter further research into this region. There are many other examples of deletion syndromes with a different clinical outcome in the presence of haploinsufficiency to support this. ${ }^{12}$

It is of note that the clinical findings have some overlap with Feingold syndrome, ${ }^{8}$ where oesophageal/duodenal atresia is commonly reported along with microcephaly and mesobrachyphalangy. However, the hand and foot findings seen in the $17 \mathrm{q}$ deletion cases such as symphalangism and thumb anomalies are not specific for Feingold syndrome and none of the patients have 4,5 toe syndactyly which is characteristic of this inherited condition. A recent report from Celli et $a l^{10}$ showing linkage to $2 \mathrm{p} 22.3$ would confirm these differences.

Human Nog has been shown by Gong et $a l^{11}$ to map to 17q22. Noggin encodes a bone morphogenetic protein
(BMP) antagonist which is expressed in the node, notochord, and dorsal somite. In mice lacking Noggin, cartilage condensations initiated normally but developed hyperplasia. In humans, heterozygous Nog mutations have been shown in multiple synostoses syndrome (SYNS1, OMIM 186500) and proximal symphalangism (SYM1, OMIM 185800). Our patient did not have similar joint abnormalities, nor is TOF a feature of either of these syndromes. Cartilage is, however, present in the oesophagus which could represent a rather tenuous link between these findings.

We believe that this case provides further evidence of a distinct phenotype associated with deletions of 17q22-q23 and confirms an association between haploinsufficiency of this region and oesophageal atresia. This is of particular interest as familial oesophageal atresia is rare ${ }^{9}$ and there are no other clues to genomic locations of importance for this malformation.

We would like to acknowledge the help of the family with this publication.

$$
\begin{array}{r}
\text { AIDAN J MARSH* } \\
\text { DIANA WELLESLEY } \\
\text { DAVID BURGE† } \\
\text { MARK ASHTON } \\
\text { CAROLINE E BROWNES } \\
\text { NICHOLAS R DENNIS } \\
\text { I KAREN TEMPLE* }
\end{array}
$$

*Wessex Clinical Genetics Service, The Princess Anne Hospital, Southampton University NHS Hospitals Trust, Coxford Road, Southampton SO16 5YA, UK

†Department of Paediatric Surgery, Southampton General Hospital, Southampton University NHS Hospitals Trust, Southampton, UK $\ddagger$ Paediatric Department, St Mary’s Hospital, Milton Road, Portsmouth, UK $\$$ Wessex Regional Genetics Laboratory, Salisbury District Hospital, Odstock, Salisbury SP2 8BF, UK

Correspondence to Dr Temple, itemple@hgmp.mrc.ac.uk

1 Park JP, Moeschler JB, Berg SZ, Bauer RM, Wurster-Hill DH. A unique de novo interstitial deletion del(17)(q21.3q23) in a phenotypically abnormal novo interstitial deletion del(17)(

2 Dallapiccola B, Mingarelli R, Digilio C, Obregon MG, Giannotti A. Interstitial deletion del (17)(q21.3q23 or 24.2) syndrome. Clin Genet 1993; 43:54-5. 
3 Khalifa MM, MacLeod PM, Duncan AMV. Additional case of de novo interstitial deletion del (17) (q21.3q23) and expansion of the phenotype.

4 Levin ML, Shaffer LG, Lewis RA, Gresik MV, Lupski JR. Unique de novo interstitial deletion of chromosome 17, $\operatorname{del}(17)(\mathrm{q} 23.2 \mathrm{q} 24.3)$ in a female newborn with multiple congenital anomalies. Am f Med Genet 1995;55:30-2.

5 Mickelson ECR, Robinson WP, Hrynchak MA, Lewis MES. Novel case of $\operatorname{del}(17)(\mathrm{q} 23.1 \mathrm{q} 23.3)$ further highlights a recognizable phenotype involving deletions of chromosome (17)(q21q24). Am F Med Genet 1997;71:275-9.

6 Brunner HG, Winter RM. Autosomal dominant inheritance of abnormalities of the hands and feet with short palpebral fissures, variable microcephaly with learning disability, and oesophageal/duodenal atresia. $\mathcal{F}$ Med Genet 1991;28:389-94.

7 Schinzel A. Catalogue of unbalanced chromosome aberrations in man. Berlin: De Gruyter, 1983:854.

8 Courtens W, Levi S, Verbelen F, Verloes A, Vamos E. Feingold syndrome: report of a new family and review. Am ₹ Med Genet 1997;73:55-60.
9 Van Staey M, De Bie S, Matton MT, De Roose J. Familial congenital esophageal atresia: personal case report and review of the literature. Hum Genet 1984;66:260-6

10 Celli J, van Steensel M, van Beusekom E, van Bokhoven H, Brunner HG. Familial oesophageal atresia is linked to chromosome 2. Eur f Hum Genet 1999;7:46.

11 Gong Y, Krakow D, Marcelino J, Wilkin D, Chityat D. Heterozygous mutations in the gene encoding noggin affect human joint morphogenesis. Nat Genet 1999;21:302-4

12 Ryan AK, Goodship JA, Wilson DI, Philip N, Levy A, Seidel H, Schuffenhauer S, Oechsler H, Belohradsky B, Prieu M, Aurias A, Raymond FL, Clayton-Smith J, Hatchwell E, McKeown C, Beemer FA, Dallapiccola B, Novelli G, Hurst JA, Ignatius J, Patton M, Paterson J, Scambler PJ. Spectrum of clinical features associated with interstitial chromosome 22q11 deletions: a European collaborative study. F Med Genet 1997;34: 798-804.

\section{Mutational analysis of Sanfilippo syndrome type A (MPS IIIA): identification of 13 novel mutations}

EDITOR-Sanfilippo syndrome or mucopolysaccharidosis type III (MPS III) encompasses a group of four lysosomal storage disorders resulting from a failure to break down the glycosaminoglycan heparan sulphate. Each of the four subtypes, A, B, C, and D, is caused by the deficiency of a different enzyme in the degradative pathway of heparan sulphate: heparan-N-sulphatase (EC 3.10.1.1), $\alpha-\mathrm{N}$ acetylglucosaminidase (EC 3.2.1.50), acetyl-CoA N-acetyl transferase (EC 2.3.1.3), and N-acetylglucosamine-6sulphatase (EC 3.1.6.14), respectively. ${ }^{1}$ Clinical symptoms usually occur after two years of apparently normal development and include hyperactivity, aggressive behaviour, delayed development (particularly in speech), sleep disturbances, coarse hair, hirsutism, and diarrhoea. There are only relatively mild somatic manifestations. There then follows a period of progressive mental retardation with death usually between the second and third decade of life. In a small number of patients with Sanfilippo syndrome type $\mathrm{B}$, there is a more slowly progressive form of the disease with later onset known as the attenuated phenotype..$^{2-4}$ A late onset phenotype has also been described for Sanfilippo syndrome type A. ${ }^{5}$

Sanfilippo syndrome type A (MPS IIIA) is caused by a deficiency in the enzyme heparan-N-sulphatase (sulphamidase). The disease is autosomal recessive and the gene encoding the enzyme is situated on chromosome 17q25.3, contains eight exons, and encodes a protein of 502 amino acids. ${ }^{67}$ To date, 46 different mutations have been identified in Sanfilippo A patients, ${ }^{6-13}$ several of which have been found at high frequencies in particular populations. The $\mathrm{R} 245 \mathrm{H}$, R74C, 1091delC, and S66W were the most frequent mutations in the Dutch (56.7\%), ${ }^{11}$ Polish (56\%), ${ }^{8}$ Spanish $(45.5 \%),{ }^{13}$ and Italian $(33 \%)^{12}$ populations, respectively. Several polymorphisms have been identified in the sulphamidase gene including $\mathrm{R} 456 \mathrm{H}$, which has a high frequency of $55 \%$ in the normal Australian population. ${ }^{9}$ In this study, mutational analysis has been carried out on the sulphamidase gene from 23 patients with Sanfilippo syndrome type A in the UK. Twenty three different mutations have been found, 13 of which have not been reported previously. The novel mutations comprise one insertion (1156ins6), two nonsense mutations (R233X, E369X), and 10 missense mutations (D32G, H84Y, R150W, D235N, D273N, I322S, E355K, Y374H, R433W, V486F).

All except one of the 23 Sanfilippo A patients under investigation had the classical Sanfilippo phenotype. The one milder patient had slight developmental delay but no hyperactivity or sleep problem. Sulphamidase enzyme activity in leucocytes from the patients ranged from 0 to $5 \mathrm{pmol} /$ $\mathrm{h} / \mathrm{mg}$ protein (reference range $52-458 \mathrm{pmol} / \mathrm{h} / \mathrm{mg}$ protein). ${ }^{14}$ The average age at diagnosis was 5 years 6 months. A modified version of the ammonium acetate salting out method was used to extract genomic DNA from either venous blood or fibroblast cell lines of the patients. ${ }^{15} 16$

Each of the eight exons and intron/exon boundaries of the sulphamidase gene was amplified by PCR using intronic primers (table 1). Exon 8 was amplified as two overlapping fragments (exons $8 \mathrm{a}$ and $8 \mathrm{~b}$ ). An M13(-21) forward primer sequence (5'-TGTAAAACGACGGCC AGT-3') and an M13 reverse primer sequence (5'CAGGAAACAGCTATGACC-3') were tagged at the 5' end of the sense and antisense primers, respectively. These sites were used as universal primer binding sites in the fluorescent DNA sequencing procedure.

A typical PCR reaction using 100 ng of genomic DNA contained $25 \mathrm{pmol}$ of each primer, $1 \times \mathrm{NH}_{4}$ reaction buffer (Bioline), $4 \%$ (v/v) DMSO (dimethylsulphoxide), $0.2 \mathrm{mmol} / 1$ dNTPs, and $0.5 \mu \mathrm{l}$ (2.5 units) BioPro ${ }^{\mathrm{TM}}$ DNA polymerase (Bioline) (added after a hot start). Details of annealing temperatures and $\mathrm{MgCl}_{2}$ concentrations for each particular amplification reaction are provided in table 1 . Cycling conditions were typically $96^{\circ} \mathrm{C}$ for 10 minutes, followed by 35 cycles of one minute at $96^{\circ} \mathrm{C}$, one minute at $60-64^{\circ} \mathrm{C}$, one minute at $72^{\circ} \mathrm{C}$, and a final extension at $72^{\circ} \mathrm{C}$ for 10 minutes.

Following amplification, the PCR products were subjected to SSCP (single strand conformation polymorphism) analysis using $\mathrm{MDE}^{\mathrm{TM}}$ gel (Mutation Detection Enhancement) (FMC Bioproducts). The nine PCR products were digested with a restriction enzyme before SSCP analysis (table 1). To $5 \mu$ of digestion mix, $2 \mu$ of loading dye $(95 \%(\mathrm{v} / \mathrm{v})$ formamide, $10 \mathrm{mmol} / \mathrm{l} \mathrm{NaOH}$, $0.25 \%$ (w/v) bromophenol blue, $0.25 \%(\mathrm{w} / \mathrm{v})$ xylene cyanol) was added. Samples were denatured at $94^{\circ} \mathrm{C}$ for four minutes before loading on a $0.5 \times \mathrm{MDE}^{\mathrm{TM}}$ gel. Electrophoresis was carried out in $0.5 \times \mathrm{TBE}$ at $15 \mathrm{~W}$ overnight at $4^{\circ} \mathrm{C}$ or at $45 \mathrm{~W}$ for four hours at room temperature. Bands were detected by silver staining. ${ }^{17}$

Fragments of interest were concentrated and separated from excess primers and dNTPs by ultrafiltration through Microcon ${ }^{\mathrm{TM}}-100$ columns (Millipore) before sequencing. Products were sequenced in both the forward and reverse direction using the appropriate M13 dye labelled primer kits (Perkin Elmer Applied Biosystems). Reactions were performed as instructed and samples were analysed on an ABI Prism ${ }^{\mathrm{TM}} 377$ DNA Sequencer (Perkin Elmer Applied Biosystems).

Sequence changes were confirmed either by digestion with a restriction enzyme or by ACRS (amplification created restriction site) PCR. ${ }^{18}$ Primer sequences, annealing 
Table 1 Primers and PCR conditions used for the amplification of the sulphamidase gene

\begin{tabular}{|c|c|c|c|c|c|c|c|}
\hline Fragment & Primer & $\begin{array}{l}\text { Nucleotide } \\
\text { position }\end{array}$ & Sequence & $\begin{array}{l}\text { Product size } \\
(b p)\end{array}$ & $\begin{array}{l}\mathrm{MgCl}_{2} \operatorname{conc} \\
(\mathrm{mmol} / \mathrm{l})\end{array}$ & $\begin{array}{l}\text { Annealing } \\
\text { temp }\left({ }^{\circ} \mathrm{C}\right)\end{array}$ & $\begin{array}{l}\text { Restriction enzyme } \\
\text { before SSCP (fragment } \\
\text { sizes }(b p))\end{array}$ \\
\hline \multirow[t]{2}{*}{1} & SFA1(+) & $3-19^{\star}$ & M13 (-21)- GCGGGAGACCAGAGAGC & & & & \\
\hline & SFA1(-) & $267-251$ & M13 rev-CAGCGGGGGATACAAGG & 301 & 1.5 & 64 & Bst NI (118+183) \\
\hline \multirow[t]{2}{*}{2} & SFA2(+) & $11-30 \dagger$ & M13 (-21)- ACAGTCCCAGCCTCCCTACT & & & & \\
\hline & SFA2(-) & $336-319$ & M13 rev-ATGGGAGACGTGGCAGAG & 362 & 1.5 & 60 & HaeII $(142+220)$ \\
\hline \multirow[t]{2}{*}{3} & SFA3 $(+)$ & $79-95 \ddagger$ & M13 (-21)- GGGCCATGGGAGAACAG & & & & \\
\hline & SFA3(-) & $348-330$ & M13 rev- CGTGCCTTGGTACAAGGTG & 306 & 1.5 & 62 & ApaLI $(129+177)$ \\
\hline \multirow[t]{2}{*}{4} & SFA4 $(+)$ & $426-442 \ddagger$ & M13 (-21)- CGAGAACCCACAGTGCG & & & & \\
\hline & SFA4(-) & $727-711$ & M13 rev- GTGCTCTGGTACCGGCC & 338 & 1.5 & 64 & BsaAI $(138+200)$ \\
\hline \multirow[t]{2}{*}{5} & SFA5 $(+)$ & $27-43 \$$ & M13 (-21)- CCTTCCTGTGCCACGTG & & & & \\
\hline & SFA5 (-) & $344-323$ & M13 rev- ТСТTTCTTCATCATCTAGGGCC & 354 & 1.0 & 62 & RsaI (139+215) \\
\hline \multirow[t]{2}{*}{6} & SFA6(+) & $493-511 \int$ & M13 (-21)- TGTTCTAAGCCTGGCTCCC & & & & \\
\hline & SFA6(-) & $718-701$ & M13 rev- CTGCCACACTGGACCCTC & 262 & 1.0 & 62 & StyI $(130+132)$ \\
\hline \multirow[t]{2}{*}{7} & SFA7 $(+)$ & $40-56$ & M13 (-21)- GGATGCAGCAGCAGGTG & & & & \\
\hline & SFA7(-) & $425-406$ & M13 rev- AGGTAATGGGTGTGGAGCAG & 422 & 1.5 & 64 & RsaI (219+203) \\
\hline \multirow[t]{2}{*}{$8 \mathrm{a}$} & SFA8a $(+)$ & $1286-13049$ & M13 (-21)- TTGGATTGGAGAAGGGAGC & & & & \\
\hline & SFA8a(-) & $1742-1721$ & M13 rev- CCGGTAGTAGTAATGACGGAGG & 493 & 1.5 & 66 & HaeII $(230+263)$ \\
\hline \multirow[t]{2}{*}{$8 \mathrm{~b}$} & SFA8b $(+)$ & $1632-16519$ & M13 (-21)- CCCATCGACCAGGACTTCTA & & & & \\
\hline & SFA8b $(-)$ & $2002-1984$ & M13 rev- GGATGTGTCTGGGACATGC & 407 & 1.0 & 62 & SacI $(143+264)$ \\
\hline
\end{tabular}

${ }^{\star}+\ddagger \$$ \$Positions of primers are numbered according to Genbank database entry u60107, u60108, u60109, u60110, and u60111, respectively. ${ }^{7}$

temperatures, and $\mathrm{MgCl}_{2}$ concentrations for the ACRS PCR reactions are provided in table 2. All other PCR parameters were as described previously.

The eight exons of the sulphamidase gene from 23 patients with Sanfilippo syndrome type A were amplified as nine fragments by PCR using intronic primers. Exon 8 is $559 \mathrm{bp}$ in length and was amplified as two overlapping fragments of $493 \mathrm{bp}$ and $407 \mathrm{bp}$. The PCR products were digested with a restriction enzyme before SSCP analysis at $4^{\circ} \mathrm{C}$. Fragments showing a shift were purified and sequenced directly in both the forward and reverse direction using fluorescent DNA sequencing technology (Perkin Elmer Applied Biosystems). In six patient samples where no or only one heterozygous shift was observed, restricted PCR products were also subjected to SSCP analysis at room temperature (RT). Two of the mutations identified only showed a shift at RT. In four patients where no SSCP shifts were observed at either $4^{\circ} \mathrm{C}$ or RT, the mutations were identified by directly sequencing all nine PCR products. In this study, 23 different mutations were found, 13 of which have not been reported previously (table 3). Of the 23 mutations found, $82.6 \%$ could be detected by SSCP under the conditions used, comparable to the expected detection rate of SSCP. The previously known mutations found in this study include three deletions (1307de19, 1091delC, and 1284del11), one insertion (1039insC), and six missense mutations (S66W, R74C, T79P, G122R, R245H, and S298P). Three of the known mutations, R74C, R245H, and $1091 \mathrm{delC}$, accounted for $8.7 \%, 13.1 \%$, and $15.2 \%$ of the mutant alleles, respectively, and together accounted for $37 \%$. The 13 novel mutations comprised one insertion (1156ins6), two nonsense mutations (R233X, E369X), and 10 missense mutations (D32G, H84Y, R150W, D235N, D273N, I322S, E355K, Y374H, R433W, and V486F). A second PCR fragment was generated to confirm the presence of the mutation in the patient sample. Restriction digests were performed for 18 of the mutations (table 3 ) and for the remaining five sequence changes region specific primers were designed that would lead to the creation or loss of restriction sites at those known mutation sites, a technique known as ACRS PCR (table 3). Table 2 details the amplification conditions for the reactions and subsequent restriction enzyme analysis.

Both putative mutations were found in all 23 Sanfilippo A patients (table 4). Nine of the patients were homozygous for the sequence change and the remaining 14 were compound heterozygotes. The patients were also screened for the $\mathrm{R} 456 \mathrm{H}$ polymorphism ${ }^{9}$ by $B s t \mathrm{UI}$ enzyme digestion and the frequency of the " $\mathrm{A}$ " allele (CAC encoding histidine) was $41.3 \%$. Six of the 23 mutations, $1091 \mathrm{delC}$, R74C, R245H, V486F, S66W, and 1156ins6, were found in more than one unrelated family. For patients 1, 3, 5, 8, and 23 (table 4), parent samples were available and all were shown to be carriers of one of the mutant alleles found in their affected child.

In this study, 10 novel missense mutations were found but their pathogenic effect on enzyme function has yet to be investigated. However, 100 control chromosomes were screened for all of these changes. SSCP analysis was used to screen for four of the changes (H84Y, R150W, D273N, and I322S). Digestion with the restriction enzymes $B s p 1286 \mathrm{I}, B s r \mathrm{I}$, and $B s a \mathrm{HI}$ was used to detect $\mathrm{E} 355 \mathrm{~K}$, R433W, and V486F, respectively. ACRS PCR and HincII, TaqI, or Sau96I digestion were used to screen for D32G, $\mathrm{D} 235 \mathrm{~N}$, and $\mathrm{Y} 374 \mathrm{H}$, respectively. None of the missense mutations was found in any of the 100 control chromosomes. A rare polymorphism which has not been previously reported was found in heterozygous form in exon 4 of one control, A137A (GCG $\rightarrow$ GCA: 423G $>$ A).

Mutational analysis on 23 patients from the UK with Sanfilippo syndrome type A has resulted in the identification of both putative mutations in all of the patients. Twenty three different mutations, including 13 which have not been reported previously, were detected.

One of the novel mutations is an insertion of $6 \mathrm{bp}$ (AGCGCC) in exon 8. The insertion is a duplication of six nucleotides upstream of the insertion site and the presence of direct repeat elements (GCAC) in the vicinity of the mutation suggests that it has arisen because of slippage

Table 2 Primers and PCR conditions used for the ACRS PCR reactions

\begin{tabular}{|c|c|c|c|c|c|c|}
\hline Mutation & Sense primer (nucleotide position) & $\begin{array}{l}\text { Antisense } \\
\text { primer (table 1) }\end{array}$ & $\begin{array}{l}\text { Product size } \\
(b p)\end{array}$ & $\begin{array}{l}\text { Annealing } \\
\text { temp }\left({ }^{\circ} \mathrm{C}\right)\end{array}$ & $\begin{array}{l}\mathrm{MgCl}_{2} \text { conc } \\
\text { (mmol/l) }\end{array}$ & $\begin{array}{l}\text { Restriction enzyme } \\
\text { (fragment sizes (bp)) }\end{array}$ \\
\hline $\mathrm{D} 32 \mathrm{G}$ & 5'ACTCTCTGTCTCCCACCTCACGCAGCGGTT3' (67-96*) & SFA2(-) & 288 & 64 & 1.5 & $-H i n c I I(288)$ \\
\hline G122R & 5'GCCAGGCCTCTCTTCCCGCCCAGGCATCCT3' (503-532†) & SFA4(-) & 243 & 62 & 1.0 & $+D d e I(29+133+81)$ \\
\hline $\mathrm{D} 235 \mathrm{~N}$ & 5'TTCGTCCCCAACACCCCGGCAGCCCGAGTC3' (536-565‡) & SFA6(-) & 201 & 64 & 1.5 & $-T a q \mathrm{I}(201)$ \\
\hline $\mathrm{D} 273 \mathrm{~N}$ & 5'CCTGAACGACACACTGGTGATCTTCACGAC3' (170-199\$) & SFA7(-) & 274 & 64 & 1.5 & $-B s i \mathrm{EI}(274)$ \\
\hline Y374H & 5'CAGCCAGAGCCACCACGAGGTCACCATGGC3' (1532-1561ฐ) & SFA8a $(-)$ & 229 & 64 & 1.5 & $\begin{array}{l}+ \text { Sau96I } \\
(28+111+48+42)\end{array}$ \\
\hline
\end{tabular}

${ }^{\star}+\ddagger \S$ Positions of primers are numbered according to Genbank database entry u60108, u60109, u60110, and u60111, respectively. ${ }^{7}$ 
Table 3 Mutations found in the sulphamidase gene from patients with MPS IIIA in this study

\begin{tabular}{|c|c|c|c|c|c|c|}
\hline Exon (fragment) & Mutation * & Nucleotide alteration * & Protein alteration & SSCP shift & $R E$ test & ACRS test (table 2) \\
\hline $2(2)$ & D32G† & GAC $\rightarrow$ GGC $107 \mathrm{~A}>\mathrm{G}$ & Asp $\rightarrow$ Gly & - & & -HincII \\
\hline $2(2)$ & S66W & $\mathrm{T} \underline{\overline{\mathrm{C}} \mathrm{G}} \rightarrow \mathrm{T} \overline{\bar{G}} \mathrm{G} 209 \mathrm{C}>\mathrm{G}$ & Ser $\rightarrow$ Trp & - & $+B s t \mathrm{NI}$ & \\
\hline $2(2)$ & $\mathrm{R} 74 \mathrm{C}$ & $\underline{\mathrm{C}} \overline{\mathrm{G}} \mathrm{C} \rightarrow \underline{\mathrm{T}} \overline{\mathrm{G}} \mathrm{C} 232 \mathrm{C}>\mathrm{T}$ & $\mathrm{Arg} \rightarrow \mathrm{Cys}$ & $+4^{\circ} \mathrm{C}$ & $-B s t \mathrm{UI}$ & \\
\hline $2(2)$ & T79P & $\overline{\mathrm{A}} \mathrm{CT} \rightarrow \overline{\mathrm{C}} \mathrm{CT} 247 \mathrm{~A}>\mathrm{C}$ & $\mathrm{Thr} \rightarrow$ Pro & $+4^{\circ} \mathrm{C}$ & $+B s t \mathrm{NI}$ & \\
\hline $3(3)$ & $\mathrm{H} 84 \mathrm{Y} \dagger$ & $\overline{\mathrm{C}} \mathrm{AT} \rightarrow \overline{\mathrm{T}} \mathrm{AT} 262 \mathrm{C}>\mathrm{T}$ & $\mathrm{His} \rightarrow \mathrm{Tyr}$ & $+4^{\circ} \mathrm{C}$ & $-F n u 4 \mathrm{HI}$ & \\
\hline $4(4)$ & G122R & $\underline{\overline{\mathrm{G}}} \mathrm{GG} \rightarrow \overline{\mathrm{A}} \mathrm{GG} 376 \mathrm{G}>\mathrm{A}$ & Gly $\rightarrow$ Arg & $+4^{\circ} \mathrm{C}$ & & $+D d e \mathrm{I}$ \\
\hline $4(4)$ & R150W† & $\underline{\overline{\mathrm{C}} G G} \rightarrow \underline{\mathrm{T}} G G \mathrm{~d} 60 \mathrm{C}>\mathrm{T}$ & Arg $\rightarrow$ Trp & $+4^{\circ} \mathrm{C}$ & $-A c i \mathrm{I}$ & \\
\hline $6(6)$ & $\mathrm{R} 233 \mathrm{X} \dagger$ & $\overline{\mathrm{C}} \mathrm{GA} \rightarrow \overline{\mathrm{T}} \mathrm{GA} 709 \mathrm{C}>\mathrm{T}$ & Arg $\rightarrow$ Stop & $+4^{\circ} \mathrm{C}$ & $-A v a \mathrm{I}$ & \\
\hline $6(6)$ & $\mathrm{D} 235 \mathrm{~N} \dagger$ & $\overline{\mathrm{G}} \mathrm{AC} \rightarrow \overline{\mathrm{A}} \mathrm{AC} \quad 715 \mathrm{G}>\mathrm{A}$ & Asp $\rightarrow$ Asn & $+\mathrm{RT}$ & & $-T a q \mathrm{I}$ \\
\hline $6(6)$ & $\mathrm{R} 245 \mathrm{H}$ & $\overline{\mathrm{C}} \underline{\mathrm{G}} \mathrm{C} \rightarrow \overline{\mathrm{C}} \underline{\mathrm{AC}} 746 \mathrm{G}>\mathrm{A}$ & $\mathrm{Arg} \rightarrow \mathrm{His}$ & $+4^{\circ} \mathrm{C}$ & $-E a g \mathrm{I}$ & \\
\hline $7(7)$ & $\mathrm{D} 273 \mathrm{~N}+$ & $\mathrm{G} \overline{\mathrm{A}} \mathrm{C} \rightarrow \mathrm{A} \overline{\mathrm{AC}} 829 \mathrm{G}>\mathrm{A}$ & Asp $\rightarrow$ Asn & $+4^{\circ} \mathrm{C}$ & & $-B s i \mathrm{EI}$ \\
\hline $7(7)$ & S298P & $\overline{\mathrm{T}} \mathrm{CC} \rightarrow \overline{\mathrm{C}} \mathrm{CC} 904 \mathrm{~T}>\mathrm{C}$ & Ser $\rightarrow$ Pro & $+4^{\circ} \mathrm{C}$ & + MaeIII & \\
\hline $8(8 a)$ & $\mathrm{I} 322 \mathrm{~S} \dagger$ & $\overline{\mathrm{ATC}} \rightarrow \overline{\mathrm{AGC}} 977 \mathrm{~T}>\mathrm{G}$ & $\mathrm{Ile} \rightarrow \mathrm{Ser}$ & $+4^{\circ} \mathrm{C}$ & $+A l u \mathrm{I}$ & \\
\hline $8(8 a)$ & 1039insC & $1 \bar{b} p$ ins - & 158 altered aa, term & $+4^{\circ} \mathrm{C}$ & $-B s t \mathrm{XI}$ & \\
\hline $8(8 a)$ & E355K† & $\underline{\mathrm{GAG}} \rightarrow \underline{\mathrm{A} A G} 1075 \mathrm{G}>\mathrm{A}$ & Glu $\rightarrow$ Lys & $+4^{\circ} \mathrm{C}$ & $-B s p 1286 \mathrm{I}$ & \\
\hline $8(8 a)$ & $1091 \mathrm{delC}$ & $\overline{1} \mathrm{bp} \mathrm{de} \bar{l}$ & 51 altered aa, term & $+4^{\circ} \mathrm{C}$ & $+B s t \mathrm{XI}$ & \\
\hline $8(8 a)$ & $\mathrm{E} 369 \mathrm{X} \dagger$ & $\mathrm{GAG} \rightarrow \mathrm{TAG} 1117 \mathrm{G}>\mathrm{T}$ & Glu $\rightarrow$ Stop & $+4^{\circ} \mathrm{C}$ & $+B f a \mathrm{I}$ & \\
\hline $8(8 a)$ & $\mathrm{Y} 374 \mathrm{H} \dagger$ & $\underline{\overline{\mathrm{T}} \mathrm{AC}} \rightarrow \underline{\overline{\mathrm{C}} \mathrm{AC}} 1132 \mathrm{~T}>\mathrm{C}$ & $\mathrm{Tyr} \rightarrow \mathrm{His}$ & - & & $+\operatorname{Sau} 96 \mathrm{I}$ \\
\hline $8(8 a)$ & 1156ins6† & $\overline{6}$ bp ins $\mathrm{AGCGCC}$ & ins Gln Arg & $+4^{\circ} \mathrm{C}$ & +HaeII & \\
\hline $8(8 b)$ & 1284 del1 1 & $11 \mathrm{bp} \mathrm{del}$ & 1 altered aa, term & $+4^{\circ} \mathrm{C}$ & $-R s a \mathrm{I}$ & \\
\hline $8(8 b)$ & 1307 del9 & 9 bp del & del 3 aa & $+4^{\circ} \mathrm{C}$ & $-B s t \mathrm{UI}$ & \\
\hline $8(8 b)$ & R433W† & $\underline{\mathrm{CGG}} \rightarrow \underline{\mathrm{TGG}} 1309 \mathrm{C}>\mathrm{T}$ & Arg $\rightarrow$ Trp & $+\mathrm{RT}$ & $+B s r I$ & \\
\hline $8(8 b)$ & $\mathrm{V} 486 \mathrm{~F} \dagger$ & $\underline{\overline{\mathrm{G}} \mathrm{TC}} \rightarrow \underline{\mathrm{T}} \mathrm{TC} 1468 \mathrm{G}>\mathrm{T}$ & $\mathrm{Val} \rightarrow \mathrm{Phe}$ & - & $-B s a \mathrm{HI}$ & \\
\hline
\end{tabular}

^Number of codons and nucleotides according to ref 6 .

†Novel mutations.

during DNA replication. ${ }^{19}{ }^{20}$ However, the 6 bp insertion is not an identical copy of the previous six nucleotides because the fourth base has been changed from A to $G$ (normal = AGCACC, mutant = AGCGCC). The insertion does not lead to a frameshift but results in the introduction of two additional amino acids into the protein chain (glutamine and arginine). This is likely to have a detrimental effect on the functioning of the protein and the absence of the insertion in 100 control chromosomes supports the likelihood that it is disease causing. Three unrelated British patients were found to be heterozygous for the insertion and since it has not been reported previously, it may have a founder effect in the UK population.

The two novel nonsense mutations that were found, R233X and E369X, will both be disease causing because of the production of a truncated product. All of the 10 novel missense mutations result in non-conservative amino acid substitutions and their absence in 100 control chromosomes further supports their suspected pathogenicity. Comparison of sulphamidase to $\mathrm{O}$ - and $\mathrm{N}$-sulphatases has highlighted two highly conserved regions, residues 70-80 containing the CTPSR active site motif and residues $115-124 .{ }^{6}$ None of the 10 novel missense mutations in this study is situated within these regions, although $\mathrm{H} 84 \mathrm{Y}$ is

Table 4 Genotype and national origin of the MPS IIIA patients in this study

\begin{tabular}{|c|c|c|c|c|}
\hline Patient & Allele 1 & Allele 2 & $\begin{array}{l}R 456 \mathrm{H} \text { poly } \\
C \mathbf{G} C \rightarrow C \mathbf{A} C\end{array}$ & National origin \\
\hline 1 & $1091 \mathrm{delC}$ & E355K & G/A & UK \\
\hline 2 & $\mathrm{R} 74 \mathrm{C}$ & S298P & G/A & UK \\
\hline 3 & R433W & $\mathrm{R} 245 \mathrm{H}$ & G/A & UK \\
\hline 4 & $\mathrm{H} 84 \mathrm{Y}$ & H84Y & $\mathrm{G} / \mathrm{G}$ & Pakistan \\
\hline 5 & G122R & G122R & $\mathrm{G} / \mathrm{G}$ & Pakistan \\
\hline 6 & R74C & R74C & $\mathrm{G} / \mathrm{G}$ & UK \\
\hline 7 & V486F & V486F & $\mathrm{A} / \mathrm{A}$ & Czech Rep \\
\hline 8 & I322S & $\mathrm{I} 322 \mathrm{~S}$ & $\mathrm{~A} / \mathrm{A}$ & Pakistan \\
\hline 9 & $\mathrm{R} 245 \mathrm{H}$ & S66W & G/A & UK \\
\hline 10 & E369X & T79P & $\mathrm{G} / \mathrm{G}$ & UK \\
\hline 11 & $\mathrm{R} 245 \mathrm{H}$ & $\mathrm{R} 245 \mathrm{H}$ & $\mathrm{A} / \mathrm{A}$ & UK \\
\hline 12 & R233X & 1156ins6 & $\mathrm{G} / \mathrm{A}$ & UK \\
\hline 13 & $1091 \mathrm{delC}$ & $\mathrm{D} 235 \mathrm{~N}$ & G/A & Spain \\
\hline 14 & 1307del9 & D32G & $\mathrm{G} / \mathrm{G}$ & UK \\
\hline 15 & $1091 \mathrm{delC}$ & 1091delC & $\mathrm{G} / \mathrm{G}$ & Malta \\
\hline 16 & S66W & 1091delC & $\mathrm{G} / \mathrm{G}$ & UK \\
\hline 17 & V486F & V486F & $\mathrm{A} / \mathrm{A}$ & Greece \\
\hline 18 & D273N & Y374H & $\mathrm{G} / \mathrm{G}$ & Turkey/UK \\
\hline 19 & $\mathrm{R} 245 \mathrm{H}$ & 1156ins6 & $\mathrm{A} / \mathrm{A}$ & UK \\
\hline 20 & R150W & 1039insC & $\mathrm{G} / \mathrm{A}$ & UK \\
\hline 21 & 1284del11 & 1156ins6 & G/A & UK \\
\hline 22 & R74C & $\mathrm{R} 245 \mathrm{H}$ & G/A & UK \\
\hline 23 & 1091delC & 1091delC & $\mathrm{G} / \mathrm{G}$ & UK \\
\hline
\end{tabular}

four amino acids downstream of the conserved CTPSR region and may have an effect on the active site environment. Five glycosylation sites have been proposed in the sulphamidase enzyme ${ }^{6}$ and although none of the missense mutations directly affects the NXS/T motif, $\mathrm{R} 150 \mathrm{~W}$ is immediately upstream of the third proposed glycosylation sequence and the basic to hydrophobic amino acid change may have a detrimental effect on the local conformation. For many of the novel mutations there is a significant change in the charge of the amino acid side chain and this is likely to affect the conformation, stability, or catalytic function of the sulphamidase enzyme.

Interestingly, three of the novel mutations in this study have occurred at amino acid sites in the sulphamidase protein where other mutations have been reported. In our study, R150W, D235N, and E369X occur at the same codons as the previously reported mutations R150Q, D235V, and E369K, respectively. Mutations at different nucleotides within the specific codon are responsible for the variation in the mutant amino acid but these results suggest that certain codons in the sulphamidase gene may be mutational hotspots. CpG dinucleotides are known to be mutational hotspots within many genes ${ }^{21}$ and six of the 13 novel mutations in our study, R150W, R233X, D235N, D273N, E355K, and R433W, are at such sites.

All except one of the Sanfilippo patients in this study showed the classical Sanfilippo phenotype and had very low or no detectable sulphamidase enzyme activity in their leucocytes. The one patient who did have a milder phenotype was homozygous for I322S. The amino acid change from a neutral hydrophobic to a neutral polar residue may allow the production of some residual enzyme but when sulphamidase enzyme activity was measured in leucocytes from this patient using the natural substrate [N-sulphonate$\left.{ }^{35} \mathrm{~S}\right]$ heparin, ${ }^{14}$ no activity was detectable. In contrast, two patients who were homozygous for the V486F novel mutation had very similar residual enzyme activities of 3 and 3.8 $\mathrm{pmol} / \mathrm{h} / \mathrm{mg}$ protein (reference range $52-458 \mathrm{pmol} / \mathrm{h} / \mathrm{mg}$ protein) but they both had the classical Sanfilippo phenotype associated with no detectable enzyme activity. Consequently, it is difficult to provide evidence of a genotype/ phenotype correlation in Sanfilippo syndrome type A. Further expression work on the I322S, V486F, and the other novel missense mutations is required to confirm their pathogenicity and to investigate their effect on enzyme function. In MPS I where there are three phenotypes, 
Hurler (severe), Hurler-Scheie (intermediate), and Scheie (mild), polymorphisms in the $\alpha$-L-iduronidase gene are thought to modify expression and affect enzyme function. ${ }^{22}$ In Sanfilippo syndrome type A, despite the high frequency of the $\mathrm{R} 456 \mathrm{H}$ polymorphism $(41.3 \%$ in our study), there is no evidence yet that it modifies the sulphamidase enzyme. However, expression of this polymorphism in isolation and in combination with known pathogenic mutations is necessary to investigate the possibility of such an effect.

Six mutations identified in this study, S66W, R74C, R245H, 1091delC, 1156ins6, and V486F, were found in more than one unrelated family. The $6 \mathrm{bp}$ insertion has not been reported previously and appears to be unique to the British Sanfilippo A population. The novel V486F mutation was found in homozygous form in a Greek and a Czech patient and although these patients were unrelated, haplotype analysis for three common polymorphisms (R456H, IVS5+17, and IVS2-26) showed that the mutant alleles were identical, suggestive of a common ancestor. The remaining four mutations, R74C, R245H, S66W, and $1091 \mathrm{delC}$, are known to be prevalent in Polish, Dutch, Italian, and Spanish populations, respectively. ${ }^{81-13}$ In our study, although the majority of patients with these four mutations were British, the haplotype of the mutant alleles corresponds to that associated with the mutations and suggests that they are all ancient mutations. The most common mutation in the 15 British patients was $\mathrm{R} 245 \mathrm{H}$ with a frequency of $20 \%$ (6/30 alleles). Two patients heterozygous and homozygous for the 1091delC mutation originated from Spain and Malta, respectively, confirming the prevalence of the mutation in this population. Altogether, the six mutations accounted for $56.5 \%$ of the mutant alleles in this study and this information in combination with knowledge of the ethnic background of patients will be important for future mutational analysis on newly diagnosed Sanfilippo A patients in the UK. However, 17 of the mutations found in this study were unique to a particular family, further highlighting the extensive heterogeneity of Sanfilippo syndrome type A at the genetic level.

The authors would like to thank the Enzyme Laboratory of the Chemical Pathology Services at GOSH NHS Trust for carrying out the enzymic diagnosis of the Sanfilippo A patients. We are grateful for the help and support of the parents from The Society for Mucopolysaccharide Diseases in the UK. Financial support was provided by The Society for Mucopolysaccharide Diseases with funds raised by the charity Jeans For Genes. Funding for the ABI Prism ${ }^{\mathrm{TM}} 377$ DNA sequencer was provided by The Wellcome Trust. Part of this work was undertaken by Great Ormond Street Hospital for Children NHS Trust who received a proportion of its funding from the NHS Executive; the views expressed in this publication are those of the authors and not necessarily those expressed in this publicative.
of the NHS Executive.
CLARE E BEESLEY ELISABETH P YOUNG ASHOK VELLODI BRYAN G WINCHESTER

Biochemistry, Endocrinology, and Metabolism Unit, Institute of Child

Health, 30 Guilford Street, London, WC1N 1EH, UK

Correspondence to: Dr Beesley, C.Beesley@ich.ucl.ac.uk

1 Neufeld EF, Muenzer J. The mucopolysaccharidoses. In: Scriver CR, Beaudet AL, Sly WS, Valle D, eds. The metabolic and molecular bases of inherited disease. New York: McGraw-Hill, 1995:2465-94.

2 Andria G, Di Natale P, Del Giudice E, Strisciuglio P, Murino P. Sanfilippo B syndrome (MPS III B): mild and severe forms within the same sibship. B syndrome (MPS III B):

3 van de Kamp JJ, Niermeijer MF, von Figura K, Giesberts MA. Genetic heterogeneity and clinical variability in the Sanfilippo syndrome (types A, B, and C). Clin Genet 1981;20:152-60.

4 Ballabio A, Pallini R, Di Natale P. Mucopolysaccharidosis III B: hybridization studies on fibroblasts from a mild case and fibroblasts from severe patients. Clin Genet 1984;25:191-5.

5 Lindor NM, Hoffman A, O'Brien JF, Hanson NP, Thompson JN. Sanfilippo syndrome type A in two adult sibs. Am f Med Genet 1994;15:241-4

6 Scott HS, Blanch L, Guo XH, Freeman C, Orsborn A, Baker E, Sutherland GR, Morris CP, Hopwood JJ. Cloning of the sulfamidase gene and identification of mutations in Sanfilippo A syndrome. Nat Genet 1995;11:465-7.

7 Karageorgos LE, Guo XH, Blanch L, Weber B, Anson DS, Scott HS, Hopwood JJ. Structure and sequence of the human sulphamidase gene. DNA Res 1996;3:269-71.

8 Bunge S, Ince H, Steglich C, Kleijer WJ, Beck M, Zaremba J, van Diggelen OP, Weber B, Hopwood JJ, Gal A. Identification of 16 sulfamidase gene OP, Weber B, Hopwood J, Gal A. Identification of 16 sulfamidase gene
mutations including the common R74C in patients with mucopolysacchamutations including the common R74C in patients with mucopc
ridosis type IIIA (Sanfilippo A). Hum Mutat 1997;10:479-85.

9 Blanch L, Weber B, Guo XH, Scott HS, Hopwood JJ. Molecular defects in Sanfilippo syndrome type A. Hum Mol Genet 1997;6:787-91

10 Weber B, Guo XH, Wraith JE, Cooper A, Kleijer WJ, Bunge S, Hopwood JJ. Novel mutations in Sanfilippo A syndrome: implications for enzyme function. Hum Mol Genet 1997;6:1573-9.

11 Weber B, van de Kamp JJP, Kleijer WJ, Guo XH, Blanch L, van Diggelen $\mathrm{OP}$, Wevers R, Poorthuis BJHM, Hopwood JJ. Identification of a common mutation (R245H) in Sanfilippo A patients from The Netherlands. F Inherit Metab Dis 1998;21:416-22.

12 Di Natale P, Balzano N, Esposito S, Villani GRD. Identification of molecular defects in Italian Sanfilippo A patients including 13 novel mutations. Hum Mutat 1998;11:313-20.

13 Montfort M, Vilageliu L, Garcia-Giralt N, Guidi S, Coll MJ, Chabás A, Grinberg D. Mutation 1091delC is highly prevalent in Spanish Sanfilippo syndrome type A patients. Hum Mut 1998;12:274-9.

14 Whiteman P, Young E. The laboratory diagnosis of Sanfilippo disease. Clin Chim Acta 1977;76:139-47.

15 Miller MA. A simple salting out procedure for extracting DNA from human nucleated cells. Nucleic Acids Res 1988;16:1215.

16 Davies JP, Winchester BG, Malcolm S. Sequence variations in the first exon of $\alpha$-galactosidase. Am F Med Genet 1993;30:658-63.

17 Tyson J, Ellis D, Fairbrother U, King RHM, Muntoni F, Jacobs J, Malcolm $\mathrm{S}$, Harding AE, Thomas PK. Hereditary demyelinating neuropathy of infancy. A genetically complex syndrome. Brain 1997;120:47-63.

18 Haliassos A, Chomel JC, Tesson L, Baudis M, Kruh J, Kaplan JC, Kitzis A. Modification of enzymatically amplified DNA for the detection of point mutations. Nucleic Acids Res 1989;17:3606.

19 Cooper DN, Krawczak M. Mechanisms of insertional mutagenesis in human genes causing genetic disease. Hum Genet 1991;87:409-15.

20 Krawczak M, Cooper DN. Gene deletions causing human genetic disease: mechanisms of mutagenesis and the role of the local DNA sequence environment. Hum Genet 1991;86:425-41.

21 Cooper DN, Krawczak M, Antonarakis SEM. The nature and mechanisms of human gene mutation. In: Scriver CR, Beaudet AL, Sly WS, Valle D, eds. The metabolic and molecular bases of inherited disease. New York: McGraw-Hill, 1995:259-92.

22 Scott HS, Nelson PV, Litjens T, Hopwood JJ, Morris CP. Multiple polymorphisms within the $\alpha$-L-iduronidase gene (IDUA): implications for a role in modification of MPS-1 disease phenotype. Hum Mol Genet 1993;2:1471-3.

\section{Genotype-phenotype relationship of Niemann-Pick disease type C: a possible correlation between clinical onset and levels of NPC1 protein in isolated skin fibroblasts}

EdIToR-Niemann-Pick disease type C (NP-C, MIM 257220) is a fatal autosomal recessive disorder characterised by progressive neurological deterioration and hepatosplenomegaly. NP-C patients can be classified into four major groups according to the onset of neurological symptoms, that is, early infantile, late infantile, juvenile, and adult forms, and the earlier the clinical onset the more quickly progressive are the symptoms and the shorter is the life span. ${ }^{1-4}$ Complementation analysis using cultured skin fibroblasts indicated the presence of at least two subgroups of NP-C, NPC1 (the major subgroup that comprises $>90 \%$ of NP-C patients) and NPC2 (the minor subgroup). ${ }^{2-4}$ In 1997, the NPC1 gene (NPC1) (accession No AF002020) that is responsible for the NPC1 subgroup was identified by positional cloning. ${ }^{5}{ }^{6}$ The number of NPC1 mutations known to date is not far off $100,{ }^{7-11}$ taking into account the accumulated data from seven groups presented in a recent international workshop (International Workshop, The Niemann-Pick C Lesion and the Role of Intracellular Lipid Sorting in Human Disease, Bethesda, USA, October 1999).

Because the genomic structure of NPC1 was unknown, initial mutation screening was performed on RT-PCR 
Table 1 Primers for PCR amplification of the NPC1 gene exons

\begin{tabular}{|c|c|c|c|c|}
\hline & Name & Sequence & Localisation* & PCR products $(b p)$ \\
\hline \multirow[t]{2}{*}{ ex1 } & $1 \mathrm{FW}$ & 5'-CTG AAA CAG CCC GGG GAA GTA G-3' & -87 & 232 \\
\hline & 57RV & 5'-GCC TGA GCC GTC GCT GGG CC-3' & +88 & \\
\hline \multirow[t]{2}{*}{ ex2 } & $58 \mathrm{FW}$ & 5'-ACC ATT GAG ACC CTG GTA AC-3' & -47 & 207 \\
\hline & 180RV & 5'-CAT TTT GTG TTC CCA GTG CC-3' & +37 & \\
\hline \multirow[t]{2}{*}{ ex3 } & $181 \mathrm{FW}$ & 5'-GAC CTT ACT CTA ACT GTT GCC-3' & -53 & 230 \\
\hline & 287RV & 5'-CAC AAG TAT CTA CAG CCC AG-3' & +43 & \\
\hline \multirow[t]{2}{*}{ ex 4} & $288 \mathrm{FW}$ & 5'-CTT GCT GGC CCT ATT ATG TGT G-3' & -56 & 292 \\
\hline & 463RV & 5'-CAA TTT GCT CTG CTG TCC TG-3' & +60 & \\
\hline \multirow[t]{2}{*}{ ex5 } & $464 \mathrm{FW}$ & 5'-CCT CGT GAA TTA CAG CAA GC-3' & -57 & 337 \\
\hline & $631 \mathrm{RV}$ & 5'-GCA ATT CTC TTG CCT CAG TC-3' & +112 & \\
\hline \multirow[t]{2}{*}{ ex6a } & $632 \mathrm{FW}$ & 5'-ATT CCA TAG GAC GAA GCA GC-3' & -173 & 350 \\
\hline & 808RV & 5'-CAT ACA TGG CGT CCA AGC CAA G-3' & nt 808 & \\
\hline \multirow[t]{2}{*}{ ex6b } & $724 \mathrm{FW}$ & 5'-GAC TGC TCT ATT GTC TGT GGC-3' & nt 724 & 286 \\
\hline & $881 \mathrm{RV}$ & 5'-CCA TGC AAT GGT ATT CAT GGA GG-3' & +128 & \\
\hline \multirow[t]{2}{*}{ ex7 } & $882 \mathrm{FW}$ & 5'-GAA GGC AGT AAT TAG GGA GG-3' & -130 & 284 \\
\hline & 955RV & 5'-TGC AAC CCA CTG AGG AAA CG-3' & +80 & \\
\hline \multirow[t]{2}{*}{ ex8a } & $956 \mathrm{FW}$ & 5'-GTT CCG ACT TTC AGG AAC GGC-3' & -66 & 159 \\
\hline & 1049RV & 5'-GGG TTT CGG ACG CAG AAA GAC-3' & nt 1049 & \\
\hline \multirow[t]{2}{*}{ ex $8 b$} & $986 \mathrm{FW}$ & 5'-CAG CAT TTG AGG GCT GCT TGA G-3' & nt 986 & 312 \\
\hline & $1297 \mathrm{RV}$ & 5'-GTC CAA AGG GTA CAT CAG CTC C-3' & nt 1297 & \\
\hline \multirow[t]{2}{*}{ ex8c } & $1235 \mathrm{FW}$ & 5'-CCC CTC TCA CTG ACA AAC AC-3' & nt 1235 & 186 \\
\hline & $1326 \mathrm{RV}$ & 5'-AGC CCC AAA TCC CCA TCT AGC-3' & +94 & \\
\hline \multirow[t]{2}{*}{ ex9a } & $1327 \mathrm{FW}$ & 5'-ATT CTC TCC CTC ATC TTA GG-3' & -137 & 309 \\
\hline & 1390RV & 5'-CTT TCT TGT GGT CCA GCA CG-3' & nt 1390 & \\
\hline \multirow[t]{2}{*}{ ex9b } & $1498 \mathrm{FW}$ & 5'-CTT CAA GAC ATC TGC TTG GC-3' & nt 1498 & 294 \\
\hline & 1553RV & 5'-GTA AAC TTC ACA GGG CAA GG-3' & +130 & \\
\hline \multirow[t]{2}{*}{ ex10 } & $1554 \mathrm{FW}$ & 5'-AGG GCC CAT GTT GTC CTT AG-3' & -119 & 285 \\
\hline & 1654RV & 5'-TGA TGC TAA TGA CAA AAC CGA G-3' & +65 & \\
\hline \multirow[t]{2}{*}{ ex11 } & $1655 \mathrm{FW}$ & 5'-GAG ATA CAG TCC ATA GCT CC-3' & -115 & 288 \\
\hline & $1787 \mathrm{RV}$ & 5'-AAG TGC TTG CCG CAA GTG TC-3' & +70 & \\
\hline \multirow[t]{2}{*}{ ex12 } & $1758 \mathrm{FW}$ & 5'-AAG TTT CTT ACT TAG CTG TCA G-3' & -62 & 315 \\
\hline & $1947 \mathrm{RV}$ & 5'-GAC GTT ACA CTG TGC ACT GC-3' & +63 & \\
\hline \multirow[t]{2}{*}{ ex13 } & $1948 \mathrm{FW}$ & 5'-AAG TGG GAC AGA CAA CCC TG-3' & -56 & 303 \\
\hline & $2130 \mathrm{RV}$ & 5'-GGA GCC ATT CAC AGT CCC TG-3' & +64 & \\
\hline ex14 & $2131 \mathrm{FW}$ & 5'-CAA GGC AGC AAG AAA TGG CG-3' & -70 & 261 \\
\hline & $2245 \mathrm{RV}$ & 5'-CAT GTT CAG GTA GCC AGC TC-3' & +76 & \\
\hline ex15 & $2246 \mathrm{FW}$ & 5'-GAA CAT AAG ACC TGC AGA GAG C-3' & -69 & 263 \\
\hline & 2373RV & 5'-CCG CTA GCT GCT TCC TCT AG-3' & +66 & \\
\hline ex16 & $2374 \mathrm{FW}$ & 5'-CTA GAG GAA GCA GCT AGC GG-3' & -51 & 279 \\
\hline & 2514RV & 5'-TCC TTC CCA GGC TGT CTG GC-3' & +87 & \\
\hline $\operatorname{ex} 17$ & $2515 \mathrm{FW}$ & 5'-TGT ACT CCC TAT TAG CCT GTC-3' & -137 & 316 \\
\hline & $2604 \mathrm{RV}$ & 5'-CTT GCT TGA AAC ACC TAC GTG C-3' & +90 & \\
\hline ex18 & $2605 \mathrm{FW}$ & 5'-CTT ATT CTC CGT GAT CCT CGC-3' & -80 & 355 \\
\hline & $2795 \mathrm{RV}$ & 5'-CAG TGA GAC ATT TCA GGC CTG-3' & +84 & \\
\hline ex19 & $2796 \mathrm{FW}$ & 5'-AGA CTT CCT CCC TGT GGA GC-3' & -49 & 257 \\
\hline & $2911 \mathrm{RV}$ & 5'-GGT ATA AAC TGA GGC ACG ATG C-3' & +92 & \\
\hline $\operatorname{ex} 20$ & $2912 \mathrm{FW}$ & 5'-GTA ATG CCC CTC ACT GTC AG-3' & -94 & 306 \\
\hline & $3041 \mathrm{RV}$ & 5'-GTC TTA GCC CAG TCC TCT CC-3' & +82 & \\
\hline $\operatorname{ex} 21$ & $3042 \mathrm{FW}$ & 5'-AAT GTA CAG CTG GGT CTG ACC-3' & -124 & 378 \\
\hline & 3245RV & 5'-CAG TGT AGG CCC TTT GCT GG-3' & +50 & \\
\hline $\mathrm{ex} 22$ & $3246 \mathrm{FW}$ & 5'-TGT TCG GGA GTG AGA GCG AGC-3' & -50 & 357 \\
\hline & $3477 \mathrm{RV}$ & 5'-ATG GAA TCT AAG ACA GCC AAT CC-3' & +75 & \\
\hline ex23 & $3478 \mathrm{FW}$ & 5'-AGC ACC CAT CCT CAG AAC GG-3' & -81 & 265 \\
\hline & $3591 \mathrm{RV}$ & 5'-CTC TTC AGT CAC TGA GGA GG-3' & +69 & \\
\hline ex24 & $3592 \mathrm{FW}$ & 5'-CAA TTA CAG GTT GGT AAA AGT GG-3' & -50 & 255 \\
\hline & $3754 \mathrm{RV}$ & 5'-ATG TCC TTC CAT TGT GCC ACC-3' & +43 & \\
\hline ex25 & $3755 \mathrm{FW}$ & 5'-TGA GCC ACT ATG CCC AGC CAA C-3' & -81 & 188 \\
\hline & 3870RV & 5'-GAC ACA GTT CAG TCA GGA TG-3' & nt 3870 & \\
\hline
\end{tabular}

^The location of primers refers to intronic position from exon, and those shown by nt refer to cDNA sequences (AF002020), 1st ATG as nt 1.

products or partial genomic amplicons. In our previous study using RT-PCR products, we identified 14 different mutations in 19 alleles from 11 patients, and failed to detect mutations in the remaining three alleles. ${ }^{8}$ Mutation screening using RT-PCR products has several drawbacks compared with screening using genomic amplicons. For example, mutations that reduce the mRNA stability may escape the screening. ${ }^{12} 13$ To refine the screening method, we screened a CITB human BAC library (Research Genetics, Huntsville, AL) and isolated a clone $386 \mathrm{~K} 10$ that contained all the 25 exons of NPC1 and a $2 \mathrm{~kb}$ fragment of 5'UTR. Our analysis using $386 \mathrm{~K} 10$ confirmed the exon/intron boundary sequences reported by Morris $e t a l^{14}$ and complements their data by showing the lengths of introns $1(20 \mathrm{~kb})$ and $6(3 \mathrm{~kb})$. Thus, NPC1 spans over $70 \mathrm{~kb}$ in the genome.

Sets of primers to amplify each of the 25 exons of NPC1 were designed according to the corresponding intron sequences (table 1). To include cis acting elements that participate in pre-mRNA splicing, the 3' nucleotide of nearly all the primers was placed $>20$ bp away from the splice junctions. For SSCP, exons 6, 8, and 9 were divided into two to three fragments by primers based on each exon sequence and named exon $6 \mathrm{a}$ and $6 \mathrm{~b}$ and so on (table 1 ). The clinical features of the 15 Japanese and two white NPC1 subjects are summarised in table 2 . All the patients were diagnosed by cholesterol accumulation in their skin fibroblasts. ${ }^{15}$ Informed consent for gene research was obtained from all the families. Two NPC1 cell lines (GM03123 and GM110) were obtained from the Human Genetic Mutant Cell Depository, Coriell Institute for Medical Research (Camden, NJ). Fibroblasts from one healthy volunteer and three NPC2 patients were used as controls.

By SSCP analysis of genomic amplicons, we surveyed the 34 alleles from the 17 patients (including the 11 subjects in our previous study ${ }^{8}$ ), confirmed the 14 mutations that had been identified by RT-PCR SSCP, and identified one recurrent and seven novel mutations (table 3 ). None of the recurrent or the seven new mutations were found in over 100 normal samples, and they were thus considered to be disease causing. Mutation S954L identified in 431-1 is a recurrent mutation that has been reported by Greer et $a l^{7}$ and also by Bauer et al (International Workshop, The Niemann-Pick C Lesion and the Role of Intracellular Lipid Sorting in Human Disease, Bethesda, 
Table 2 Clinical features of NP-C patients

\begin{tabular}{|c|c|c|c|c|c|c|c|}
\hline Clinical type & Cell strain & $\begin{array}{l}\text { Ethnic group } \\
\text { origin }\end{array}$ & Sex & $\begin{array}{l}\text { Onset of } \\
\text { neurological signs }\end{array}$ & Neurological signs & $\begin{array}{l}\text { Hepato- spleno- } \\
\text { megaly }\end{array}$ & Outcome \\
\hline \multirow[t]{14}{*}{ Late infantile } & OHS & JPN & M & $1.5 \mathrm{y}$ & Epilepsy, psychomotor delay & HSM & $1.5 \mathrm{y}$ (alive) \\
\hline & KUR & JPN & $\mathrm{F}$ & $2.5 \mathrm{y}$ & Epilepsy, deterioration & HSM & $?$ \\
\hline & INO & JPN & M & $2.5 \mathrm{y}$ & Epilepsy, deterioration & HSM & $4.5 \mathrm{y}$ (dead) \\
\hline & TAN & JPN & $\mathrm{M}$ & $2.5 \mathrm{y}$ & Epilepsy, ataxia, deterioration & Mild SM & ? \\
\hline & $\mathrm{UCH}$ & JPN & $\mathrm{F}$ & $2.5 \mathrm{y}$ & Ataxia, deterioration & HSM & 5 y (dead) \\
\hline & AMA & JPN & $\mathrm{F}$ & $3 y$ & Epilepsy, psychomotor delay & HSM & $4 \mathrm{y}$ (alive) \\
\hline & YON & JPN & $\mathrm{F}$ & $2.5 \mathrm{y}$ & Epilepsy, ataxia, deterioration & HSM & $12 \mathrm{y}$ (alive) \\
\hline & SHI & JPN & $\mathrm{F}$ & $2.5 \mathrm{y}$ & Epilepsy, deterioration & SM & $4 \mathrm{y}$ (alive) \\
\hline & MUR & JPN & M & $5 \mathrm{y}$ & Epilepsy, deterioration & HSM & $15 \mathrm{y}$ (dead) \\
\hline & YAN & JPN & $\mathrm{F}$ & $5 \mathrm{y}$ & Epilepsy, ataxia, deterioration & No & 19 y (alive) \\
\hline & SAK & JPN & ? & ? & ? & ? & ? \\
\hline & $431-1$ & JPN & ? & ? & ? & ? & ? \\
\hline & GM03123 & White & $\mathrm{F}$ & ? & ? & ? & $9 \mathrm{y}$ (alive) \\
\hline & GM110 & White & $\mathrm{M}$ & $5 \mathrm{y}$ & Epilepsy, deterioration & ? & $10 \mathrm{y}$ (alive) \\
\hline \multirow[t]{2}{*}{ Juvenile } & SAS & JPN & $\mathrm{F}$ & $13 \mathrm{y}$ & Epilepsy, ataxia, deterioration & Mild SM & $17 \mathrm{y}$ (alive) \\
\hline & END & JPN & M & $15 \mathrm{y}$ & Dystonia, ataxia, VSO & Mild SM & $17 \mathrm{y}$ (alive) \\
\hline Adult & KAI & JPN & M & $25 \mathrm{y}$ & Dementia, ataxia, dystonia, epilepsy, VSO & SM & 42 y (dead) \\
\hline
\end{tabular}

JPN: Japanese, HSM: hepatosplenomegaly, SM: splenomegaly, VSO: vertical supranuclear ophthalmoplegia.

Table 3 Mutations of NPC1 gene in Niemann-Pick C families

\begin{tabular}{|c|c|c|c|c|c|c|}
\hline Clinical type & Cell strain & & Genomic mutation & cDNA change & Amino acid change & Genotype \\
\hline \multirow[t]{24}{*}{ Late infantile } & OHS & Exon 19 & G2867A & Missense transition & C956Y & Cmpd hetero? \\
\hline & KUR & Exon 9 & G1553A & Missense transition \& splicing error & R518Q & Homo \\
\hline & INO & Exon 9 & G1553A & Missense transition \& splicing error & $\mathrm{R} 518 \mathrm{Q}$ & Homo \\
\hline & TAN & Exon 9 & G1553A & Missense transition \& splicing error & R518Q & Cmpd hetero \\
\hline & & Exon 24 & ${ }^{\star} \mathrm{C} 3614 \mathrm{G}$ & Missense transversion & T1205R & \\
\hline & $\mathrm{UCH}$ & Exon 9 & A1529C & Missense transversion & H510P & Homo \\
\hline & AMA & Exon 4 & 350 (or 351$) \mathrm{AG}$ (orGA) del & $2 \mathrm{bp}$ del & aa 119 frameshift-aa126/stop & Cmpd hetero \\
\hline & & Exon 5 & T529G & Missense transversion & $\mathrm{C} 177 \mathrm{G}$ & \\
\hline & YON & Exon 20 & ${ }^{\star} \mathrm{T} 2987 \mathrm{G}$ & Missense transversion & M996R & Cmpd hetero \\
\hline & & Exon 24 & $\star 3615[-3618] \mathrm{A}$ del & $1 \mathrm{bp}$ del & aa 1205 frameshift-aa $1241 /$ stop & \\
\hline & SHI & Exon 13 & ${ }^{\star} \mathrm{T} 2108 \mathrm{C}$ & Missense transition & F703S & Cmpd hetero \\
\hline & & Exon 16 & ${ }^{\star} \mathrm{C} 2438 \mathrm{G}$ & Missense transversion & S813X & \\
\hline & MUR & Exon 5 & C629A & Nonsense transversion & S210X & Cmpd hetero \\
\hline & & Exon 9 & $\mathrm{~T} 1417 \mathrm{C}$ & Missense transition & S473P & \\
\hline & YAN & Exon 24 & ${ }^{\star} \mathrm{G} 3707 \mathrm{~A}$ & Missense transition & G1236E & Cmpd hetero? \\
\hline & SAK & Exon 19 & G2867A & Missense transition & $\mathrm{C} 956 \mathrm{Y}$ & Cmpd hetero \\
\hline & & Exon 24 & $\star 3615[-3618] \mathrm{A}$ del & $1 \mathrm{bp}$ del & aa 1205 frameshift-aa $1241 /$ stop & \\
\hline & $431-1$ & Exon 24 & $\star 3615[-3618] \mathrm{A}$ del & $1 \mathrm{bp}$ del & aa 1205 frameshift-aa $1241 /$ stop & Cmpd hetero \\
\hline & & Exon 19 & †C2861T & Missense transition & S954L & \\
\hline & GM03123 & Exon 6 & C709T & Missense transition & $\mathrm{P} 237 \mathrm{~S}$ & Cmpd hetero \\
\hline & & Exon 21 & $\mathrm{~T} 3182 \mathrm{C}$ & Missense transition & $\mathrm{I} 1061 \mathrm{~T}$ & \\
\hline & GM110 & Exon 21 & $\mathrm{~T} 3182 \mathrm{C}$ & Missense transition & $\mathrm{I} 1061 \mathrm{~T}$ & Cmpd hetero \\
\hline & & Exon 14 & $\star 2215$ (or2217) & $6 \mathrm{bp}$ del & 2 aa deletion $(740 \mathrm{~F}, 741 \mathrm{~S})$ (in frame) & \\
\hline & & & ТССТTT(orCTTTTC) del & & & \\
\hline \multirow[t]{3}{*}{ Juvenile } & SAS & Exon1 & 44 (or45) TG(orGT) del & 2 bp del & aa 16 frameshift-aa56/stop & Cmpd hetero? \\
\hline & END & Exon 22 & A3263G & Missense transition & Y1088C & Cmpd hetero \\
\hline & & Exon 24 & G3639C & Missense transversion & L1213F & \\
\hline \multirow[t]{2}{*}{ Adult } & KAI & Exon 18 & G2665A & Missense transition & V889M & Cmpd hetero \\
\hline & & Intron 20 & IVS $20-2 \mathrm{~A}$ del & Splicing error (54 bp del) & 18 aa deletion $(1015-1032)$ (in frame) & \\
\hline
\end{tabular}

*: new mutation, $\uparrow:$ recurrent mutation, Cmpd hetero: compound heterozygous, Homo: homozygous, (): not confirmed, del: deletion.

USA, October 1999). Of the seven novel mutations, five were found in new subjects whereas the remaining two were found in one allele of TAN (C3614G) and of SAK (3615 (-3618) A del), respectively. It is not known why these two mutations escaped RT-PCR SSCP. Allelic mutations were not detected in three patients (OHS, SAS, and YAN) (table 3). In summary, SSCP analyses of genomic amplicons showed 21 disease causing mutations in 31 out of 34 alleles from 17 patients. Additionally, six different variants were identified (table 4 ).

The 22 mutations included 15 missense mutations, two nonsense mutations, two in frame deletions, and three deletions that cause a frameshift and a premature stop codon. In accordance with our identification of T3182C (I1061T substitution) as a frequent mutant allele in patients of western

Table 4 New polymorphisms of NPC1 gene

\begin{tabular}{lll}
\hline & Nucleotide location & Influence on amino acids \\
\hline Exon 1 & A-22C & Silent \\
Exon 8a & G1014T & Silent \\
Intron 12 & IVS12+8 +10GGG del & Silent \\
Exon 18 & T2618C & Missense transition (V873A) \\
Exon 18 & C2775T & Silent \\
Exon 21 & C3159T & Silent \\
\hline
\end{tabular}

European descent, ${ }^{13}$ this mutation was found in the genome of two white cell lines. None of the Japanese patients possessed this mutant allele, clearly highlighting an ethnic difference in the mutation frequency. Instead of T3182C, G1553A appears to be a relatively frequent mutation in Japanese patients, found in five alleles in three patients. This mutation is unique for two reasons; one is that it is predicted to cause both an amino acid substitution (R518Q) and an alternative exon skipping $^{8}$ and the other is that the skin fibroblasts from patients homozygous for this mutation (KUR and INO) retained considerable levels of NPC1 protein (see below).

With regard to the structure-function relationship of NPC1, mutagenesis studies have shown several functionally important domains of NPC1 protein including an NPC domain and a sterol sensing domain (SSD). ${ }^{16}{ }^{17}$ In addition, Greer et al suggested the functional importance of the cysteine rich extracellular loop between TM9 and TM10 based on the segregation of point mutations in this region. The 14 missense mutations and the one in frame deletion found in the present survey are widely distributed on NPC1 cDNA and appeared to be classified into five groups according to their location (fig 1A). Each group of mutations gives some insight into the structure-function relationship of NPC1. First, two mutations (F703S and del 740-741) in 
A

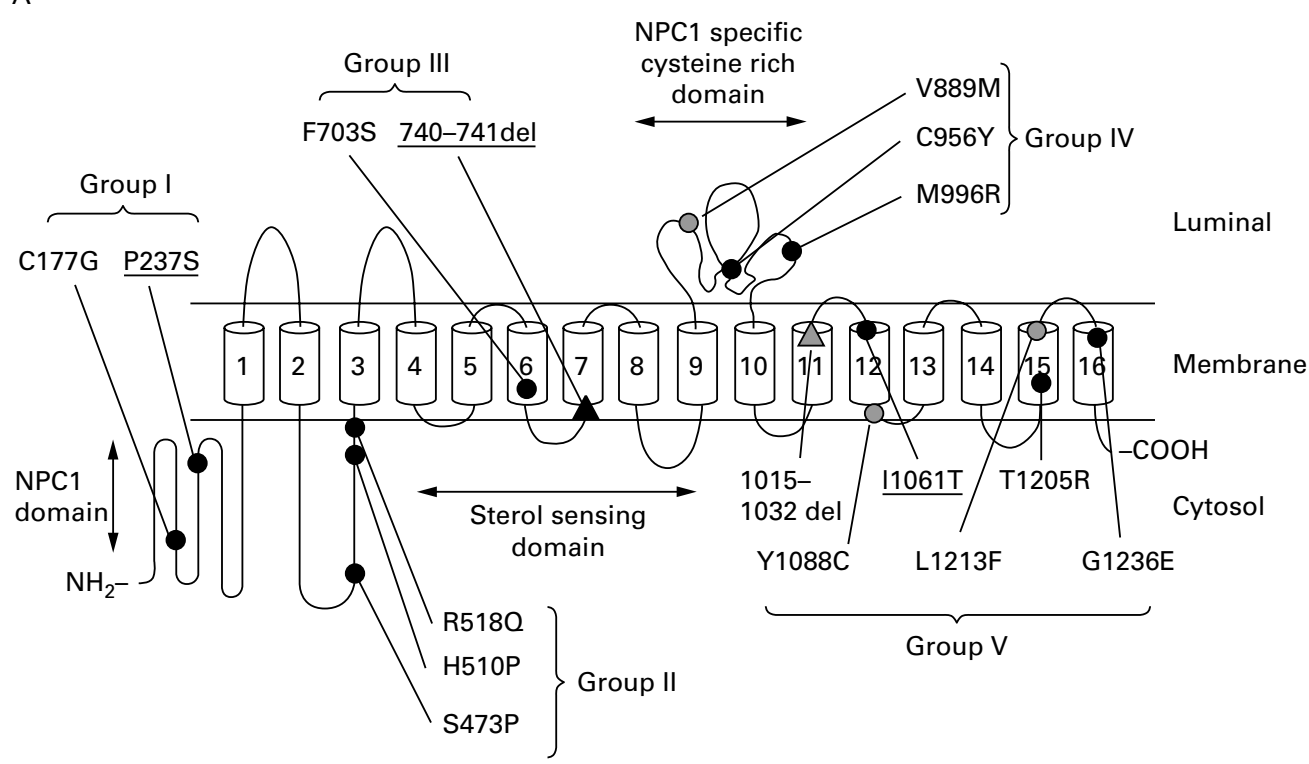

B

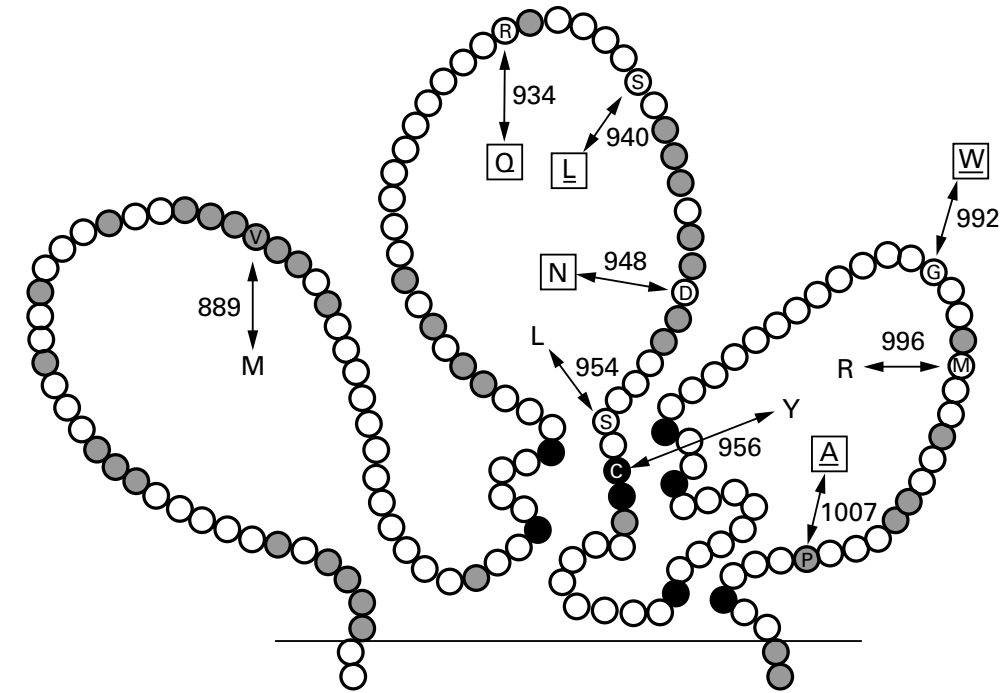

Figure 1 Distribution of mutations in NPC1. (A) Missense mutations and in frame deletions identified in this study are depicted. Circles and triangles indicate missense mutations and in frame deletions, respectively. Black circles and triangles are the mutations found in late infantile form patients and grey ones are from juvenile and adult form patients. Underlined are mutations found in white cell lines. (B) Mutations in NPC1 specific cysteine rich domain. Black circles are cysteines that may form disulphide bonds and grey ones are conserved amino acids. Squares are mutations reported by Greer et al. ${ }^{7}$ Underlined are mutations found in patients with moderate or mild phenotypes. The model for the organisation of NPC1 is according to Greer et al. ${ }^{9}$ Still tentative, it may have to be slightly altered in the future. ${ }^{19}$

group II are located in the sterol sensing domain. Second, four mutations in group VI are located in the cysteine rich extracellular loop. Interestingly, C956Y is the mutation of the cysteine residue itself that is supposed to be involved in the secondary structure formation and the other two mutations (V889M and M996R) were located in the conserved motif sequences in this loop (fig 1B). Thus, the mutations in groups III and IV appear to reinforce the functional significance of SSD and the cysteine rich domain, respectively. By analogy, one may infer the presence of functionally important domains that correspond to groups I, II, and V mutations and this should be the subject of a future study. No wild type mutations were found in the NPC domain, although the functional importance of this domain is obvious from mutagenesis studies. ${ }^{17}$
To investigate the impact of mutations on expression of the translation product, we quantified the levels of NPC1 protein in membrane preparations from cultured fibroblasts by anti-NPC1 immunoblotting ${ }^{18}$ (fig 2). The anti-NPC1 detected two bands on the blot of the control membrane preparations, a major band at $\sim 170 \mathrm{kDa}$ and a minor band at $\sim 190 \mathrm{kDa}$. These two bands have been shown to represent the same protein with differential glycosylation. ${ }^{16}$

In NPC1 cell lines, there appeared to be a distinct difference in the NPC1 protein levels between the late infantile and juvenile/adult forms. In the late infantile forms, there was a clear reduction of the NPC1 protein level regardless of the type of mutation, and five fibroblast lines (MUR, OHS, SHI, GM3123, and GM110) expressed undetectable levels of NPC1 protein. An exception was 

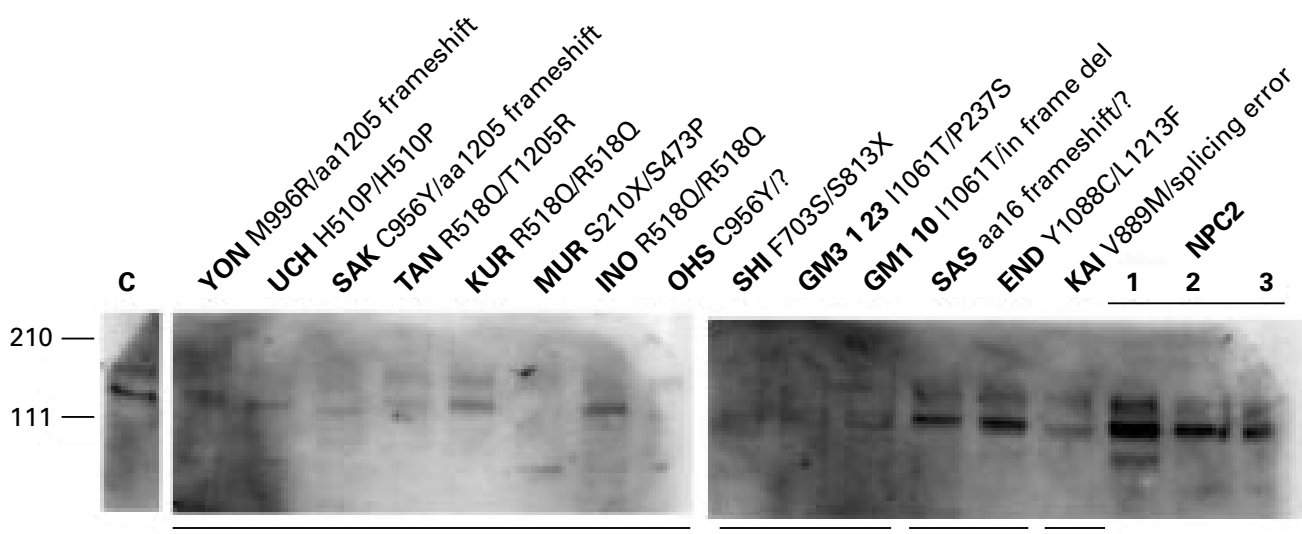

Late infantile

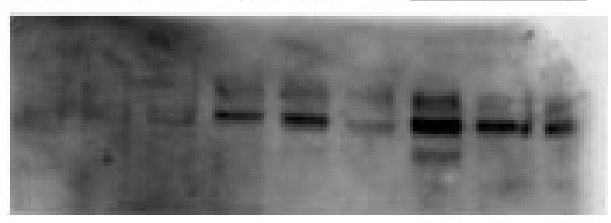

$\overline{\text { Late infantile }} \overline{\text { Juvenile }} \overline{\text { Adult }}$

Figure 2 Western blot of membrane proteins extracted from skin fibroblasts of NP-C patients and normal controls (C). Numbers 1 to 3 indicate NPC2 patients. Molecular weight $(k D a)$ is given on the left. A rabbit polyclonal anti-NPC1 antibody was a kind gift from Dr SC Patel and was used at 1:100.

KUR and INO, both of whom have R518Q homozygous mutations and levels of NPC1 protein in their fibroblasts were close to those of controls.

Patients with a late clinical onset were distinct in that all of their skin fibroblasts expressed considerable levels of mutant NPC1 protein (fig 2). Two of the three patients (END and $\mathrm{KAI})$ with a late clinical onset were compound heterozygotes for the groups IV and V mutations, whereas at least one allelic mutation of the 14 patients with a late infantile form belonged to group I, II, or III (fig 1A). In another study, skin fibroblasts from a patient with an adult neurological onset (homozygous for a V950M mutation) ${ }^{11}$ appeared to retain normal expression of NPC1 protein (G Millat, M T Vanier, C Tomasetto, unpublished data). These results led us to form a tentative conclusion that the relatively mild form of NPC1 is caused by mutations located on the C-terminal side of the transcript that do not interfere with expression/ turnover of the translation product. Future studies with an increased number of patients will verify this conclusion.

Finally, we also found that NPC2 fibroblasts expressed normal, or rather increased levels of NPC1. Similar results were achieved in a parallel study conducted with another antibody (G Millat, M T Vanier, C Tomasetto, unpublished data). Because of the identical biochemical phenotype of NPC1 and NPC2, the NPC2 protein is assumed to be located close to NPC1 both spatially and functionally. At one extreme, there has been a hypothesis that the biochemical phenotype of NPC2 is the result of the secondary absence of $\mathrm{NPC} 1 .^{2-4}$ Our findings clearly exclude this hypothesis but do not exclude that NPC2 is required for the normal function of NPC1.

We thank Dr Shutish C Patel for providing us with a rabbit polyclonal We thank Dr Shutish $\mathrm{C}$ Patel for providing us with a rabbit polyclonal
anti-NPC1 antibody. ${ }^{18}$ We also thank Drs Eto and Ida for referring patients. This work was supported in parts by a grant in aid for Scientific Research from This work was supported in parts by a grant in aid for Scientific Research from
the Ministry of Education, Science and Culture, by a research grant for Nervous and Mental Disorders from the Ministry of Health and Welfare, Japan, and ous and Mental Disorders from the Ministry of Health and
by the INSERM/JSPS cooperation programme 1998-1999.

TOSHIYUKI YAMAMOTO* HARUAKI NINOMIYA $†$ MICHIKA MATSUMOTO YASUTOSHI OHTA* EIJI NANBA* YUKIE TSUTSUMI KAZUHIRO YAMAKAWA GILLES MILLATS MARIE T VANIERS

PETER G PENTCHEV KOUSAKU OHNO +

${ }^{\star}$ Gene Research Center, Tottori University, 86 Nishi-machi, Yonago 683-8503, Fapan

†Department of Neurobiology, School of Life Sciences, Faculty of Medicine, Tottori University, 86 Nishi-machi, Yonago 683-8503, Japan $\ddagger$ Laboratory for Neurogenetics, Brain Science Institute, RIKEN, Wako 351-0198, fapan
\$INSERM Unit 189, Lyon-Sud Medical School, and Fondation Gillet-Merieux, Lyon-Sud Hospital, 69921 Oullins, France

-National Institute of Neurological Disorders and Stroke, NIH, Bethesda, MD 20892, USA

Correspondence to: Dr Yamamoto, tyamamot@grape.med.tottori-u.ac.jp

1 Pentchev PG, Vanier MT, Suzuki K, Patterson MC. Niemann-Pick disease type C: a cellular cholesterol lipidosis. In: Scriver SR, Beaudet AL, Sly WS, Valle D, eds. The metabolic and molecular bases of inherited disease. 7th ed. New York: McGraw-Hill, 1995:2625-39

2 Vanier MT, Suzuki K. Niemann-Pick diseases. In: Vinken PJ, Bruyn GW, eds. Handbook of clinical neurology. Neurodystrophies and neurolipidoses. Revised Series Vol 22. Amsterdam: Elsevier Science, 1996:133-62.

3 Vanier MT, Duthel S, Rodriguez-Lafrasse C, Pentchev P, Carstea ED. Genetic heterogeneity in Niemann-Pick C disease: a study using somatic cell hybridization and linkage analysis. Am f Hum Genet 1996;58:118-25.

4 Vanier MT, Suzuki K. Recent advances in elucidating Niemann-Pick C disease. Brain Pathol 1998;8:163-74.

5 Carstea ED, Morris JA, Coleman KG, Loftus SK, Zhang D, Cummings C, Gu J, Rosenfeld MA, Pavan WJ, Krizman DB, Nagle J, Polymeropoulos $\mathrm{MH}$, and 26 others. Niemann-Pick C1 disease gene: homology to $\mathrm{MH}$, and 26 others. Niemann-Pick Cl disease gene: ho
mediators of cholesterol homeostasis. Science 1997;277:228-31.

6 Morris JA, Carstea ED. Niemann-Pick C disease: cholesterol handling gone away. Mol Med Today 1998;4:525-31.

7 Greer WL, Riddell DC, Gillan TL, Girouard GS, Sparrow SM, Byers DM, Dobson MJ, Neumann PE. The Nova Scotia (type D) form of Niemann-Pick disease is caused by a G3097T transversion in NPC1. Am $\mathcal{F}$ Hum Genet 1998;63:52-4.

8 Yamamoto T, Nanba E, Ninomiya H, Higaki K, Taniguchi $M$, Zhang H, Akaboshi S, Watanabe Y, Takeshima T, Inui K, Okada S, Tanaka A, Sakuragawa N, Millat G, Vanier MT, Morris JA, Pentchev PG, Ohno K. NPC1 gene mutations in Japanese patients with Niemann-Pick disease type C. Hum Genet 1999;105:10-16.

9 Greer WL, Dobson MJ, Girouard GS, Byers DM, Riddell DC, Neumann PE. Mutations in NPC1 highlight a conserved NPC1-specific cysteine-rich domain. Am F Hum Genet 1999;65:1252-60.

10 Millat G, Marçais C, Rafi MA, Yamamoto T, Morris JA, Pentchev PG, Ohno K, Wenger DA, Vanier MT. Niemann-Pick C1 disease: the I1061T substitution is a frequent mutant allele in patients of western European descent and correlates with a classical juvenile phenotype. Am f Hum Genet descent and corre

11 Vanier MT, Millat G, Marçais C, Rafi M, Yamamoto T, Morris JA, Pentchev PG, Nanba E, Wenger DA. Niemann-Pick C disease: mutational spectrum in NPC1 gene and genotype/phenotype correlations. Am $\mathcal{F}$ Hum Genet Suppl 1999;65:A495.

12 Zhang ZX, Wakamatsu N, Mules EH, Thomas GH, Gravel RA. Impact of premature stop codons on mRNA levels in infantile Sandhoff disease. Hum Mol Genet 1994;3:139-45.

13 Maquat LE. Defects in RNA splicing and the consequence of shortened translational reading. Am f Hum Genet 1996;59:279-86.

14 Morris JA, Zhang D, Coleman KG, Nagle J, Pentchev PG, Carstea ED. The genomic organization and polymorphism analysis of the human NiemannPick C1 gene. Biochem Biophys Res Commun 1999;261:493-8.

15 Ohno K, Nanba E, Nakano T, Inui K, Okada S, Takeshita K. Altered sensitivities to potential inhibitors of cholesterol biosynthesis in Niemann-Pick tivities to potential inhibitors of cholesterol biosynthe
type C fibroblasts. Cell Struct Funct 1993;18:231-40.

16 Watari H, Blanchette-Mackie EJ, Dwyer NK, Watari M, Neufeld EB, Patel S, Pentchev PG, Strauss JF. Mutations in the leucine zipper motif and sterol-sensing domain inactivate the Niemann-Pick C1 glycoprotein. $f$ Biol Chem 1999;274:21861-6.

17 Watari H, Blanchette-Mackie EJ, Dwyer NK, Glick JM, Patel S, Neufeld EB, Brady RO, Pentchev PG, Strauss JF. Niemann-Pick C1 protein: obligatory roles for $\mathrm{N}$-terminal domains and lysosomal targeting in cholesterol mobilization. Proc Natl Acad Sci USA 1999;96:805-10.

18 Patel SC, Suresh S, Kumar U, Hu CY, Cooney A, Blanchette-Mackie EJ, Neufeld EB, Patel RC, Brady RO, Patel YC, Pentchev PG, Ong WY. Localization of Niemann-Pick C1 protein in astrocytes: implications for neuronal degeneration in Niemann-Pick type C disease. Proc Natl Acad Sci USA 1999;96:1657-62.

19 Davies JP, Gordon R, Ioannou I. Topological analysis of the polytopic membrane glycoprotein Niemann-Pick C1. Am f Hum Genet Suppl 1999;65:A234. 


\section{Crigler-Najiar syndrome type II resulting from three different mutations in the bilirubin uridine 5'-diphosphate-glucuronosyltransferase (UGT1A1) gene}

EDITOR-Crigler-Najjar syndromes (CN, MIM 218800) are inborn errors of metabolism characterised by unconjugated hyperbilirubinaemia resulting from the defective activity of the hepatic enzyme bilirubin uridine 5'diphosphate-glucuronosyltransferase (B-UGT).

$\mathrm{CN}$ syndrome has been classified into two types according to the degree of hyperbilirubinaemia and to the response to phenobarbital administration. The more severe CN type I is characterised by severe chronic non-haemolytic unconjugated hyperbilirubinaemia with high levels of serum bilirubin owing to the absence of bilirubin UGT activity. In the milder CN type II, bilirubin UGT activity is only decreased and a consistently significant reduction is obtained with phenobarbital treatment, which does not occur in CN I.

Like other members of the UGT isozyme family, the two human liver bilirubin UGT isozymes, UGT1A1 and UGT1D, are encoded by the UGT1 gene complex through a mechanism of alternative splicing. Each gene has a unique promoter and a unique exon 1 , while exons 2-5 are common to both genes. ${ }^{1}$ Most of the enzymatic activity results from the expression of the UGT1A1 gene.

At the molecular level, CN I results from a number of different defects; nonsense (or frameshift) and missense mutations are represented in almost the same amounts both in homozygosity and in the compound heterozygous state. ${ }^{34}$ The milder phenotype in CN II patients seems to be mainly the result of homozygosity for missense mutations ${ }^{5}$ and more rarely of the genetic compound for nonsense (or frameshift) and missense mutations or an interaction between missense mutations and a homozygous TA insertion in the TATAA promoter element, $\mathrm{A}(\mathrm{TA})_{7} \mathrm{TAA}$, instead of the normal $\mathrm{A}(\mathrm{TA})_{6}$ TAA. $^{6}$ The presence of the TA insertion in the TATAA promoter element of the $U G T 1 A 1$ gene reduces the expression of bilirubin-UDP-glucuronosyltransferase. ${ }^{7}$ Homozygosity for the TA insertion has proved to be associated with Gilbert's syndrome. ${ }^{\text {? }}$

Here, we report a case of CN II, which appears to be the result of the interaction of two different mutations and homozygosity for the promoter polymorphism (TA) ${ }_{7}$.

Blood samples were collected, after informed consent, from a 13 year old male CN type II patient, from both his parents, his older brother, and from 100 unrelated normal subjects as controls. The patient was born after a 40 week gestation to clinically normal, non-consanguineous parents. His weight at birth was $3450 \mathrm{~g}$. Jaundice requiring phototherapy appeared during the neonatal period. At 8 days of age, the total, direct, and indirect bilirubin levels were 204, 20, and $184 \mu \mathrm{mol} / \mathrm{l}$, respectively. During infancy and childhood, the indirect bilirubin levels ranged between 170 and $284 \mu \mathrm{mol} / \mathrm{l}$. The highest values were related to episodes of stress and intercurrent acute illness.

Serum bilirubin levels (STB) were lowered to $30 \mu \mathrm{mol} / 1$ ( $80 \%$ less than the steady state level) by administration of phenobarbital $(10 \mathrm{mg} / \mathrm{kg} /$ day $)$ for 40 days. The proband showed normal somatic and developmental milestones. $\mathrm{He}$ had no complaints except for jaundice. The bilirubin levels of the other family members were in the normal range and are shown in table 1 .
Table 1 Clinical and molecular data

\begin{tabular}{lllll}
\hline & Father & Mother & Proband & Brother \\
\hline TSB $(\mu \mathrm{mol} / \mathrm{l})$ & 27,2 & 18,7 & 308,1 & 20 \\
Mutation & $\mathrm{AG}_{\mathrm{Gel}}$ & $\mathrm{V}^{2} 24 \mathrm{G}$ & $\mathrm{AG} \mathrm{del} / \mathrm{V} 224 \mathrm{G}$ & AG del \\
TATAA box & $\mathrm{TA}_{6} / \mathrm{TA}_{7}$ & $\mathrm{TA}_{6} / \mathrm{A}_{7}$ & $\mathrm{TA}_{7} / \mathrm{TA}_{7}$ & $\mathrm{TA}_{6} / \mathrm{TA}_{7}$ \\
\hline
\end{tabular}

By sequence analysis of both strands of the UGT1A1 gene, including the promoter region from nucleotide -227 and all the exons, ${ }^{8}$ the patient was found to be a genetic compound for two novel mutations, a $\mathrm{T} \rightarrow \mathrm{G}$ transition at codon 224 (V224G) and a 2 bp deletion (-AG) at codons 238-239-240. Both mutations reside in the specific exon 1 of $U G T 1 A 1$. This finding is consistent with the notion that $U G T 1 A 1$ codes for the only relevant enzymatic isoform in bilirubin glucuronidation.

The AG deletion is easily detectable by polyacrylamide gel electrophoresis of a PCR product (fig 1A). For the molecular screening of the V224G mutation we set up an allele specific PCR using primers shown in fig $1 \mathrm{~B}$.

The proband inherited the GTG $\rightarrow$ GGG transition from his mother and the deletion (-AG) at codons 239/240/241 from his father (table 1). Furthermore, he was found to be homozygous for the sequence variation (TA $)_{7}$ in the promoter region. This means that the mutated UGT1A1 alleles in both parents are in cis to the $(\mathrm{TA})_{7}$ variation.

His healthy brother proved to be heterozygous for both the AG deletion and the $(\mathrm{TA})_{7}$ variation.

Analysis of the UGT1D sequence showed a neutral polymorphism at codon 157 (TGC $\rightarrow$ TGT).
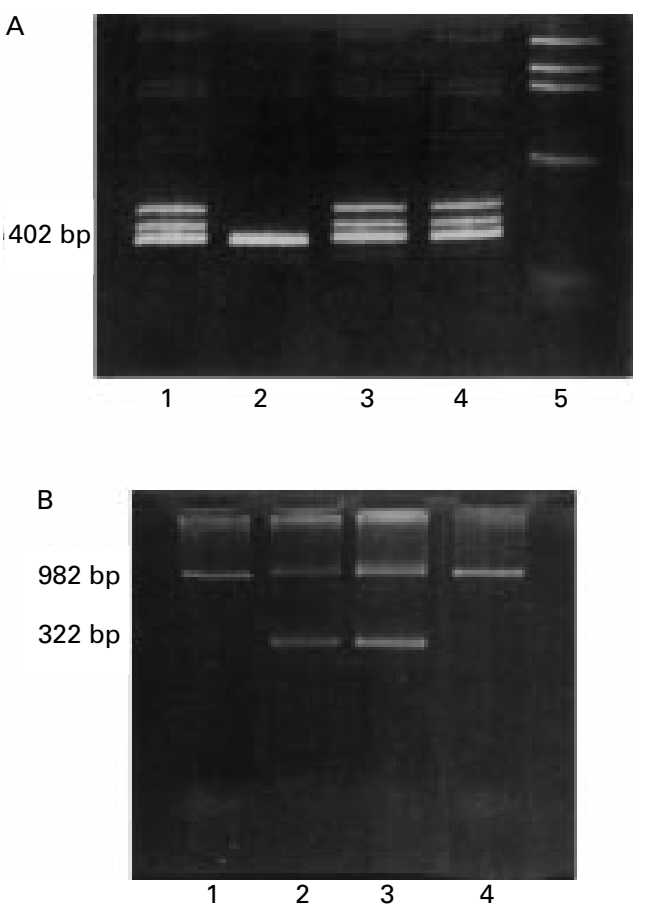

Figure 1 (A) Polyacrylamide gel electrophoresis of a 402 bp amplified DNA fragment containing the AG deletion at codons 239/240/241 of exon 1 of the UGT1A1 gene. Lanes 1, 3 4: father, proband, and brother, respectively, showing the heteroduplexes owing to heterozygosity for the AG deletion. Lane 2: mother, without the AG deletion. (B) Allele specific amplification (ARMS) to detect the V224G mutation. DNA from normal subjects (father and brother, lanes 1 and 4) does not give a 322 bp PCR product when amplified with a mutant primer complementary to the mutation (sense mutant primer: TGCCTTTTCACAGAACTTTCTGTG $C G A G G G$; antisense primer: TCTCAGAATGCTTGCTCAG). Using the same primers, DNA from the mother (lane 2) and proband (lane 3) shows a 322 bp PCR product indicating the presence of the V224G mutation. A 982 bp PCR fragment is simultaneously amplified as a control. 
One hundred normal subjects from the same area were analysed but none was found to carry the V224G mutation. The fact that we did not find normal subjects with the V224G substitution could suggest that it is a disease causing mutation. A comparative analysis of the sequence of the B-UGT protein in man, mouse, and rat indicate that the valine residue is highly conserved. Furthermore, from an analysis of the GOR secondary structure prediction, ${ }^{9}$ it seems that Val-Gly substitution could lead to loss of the beta sheet structure. For these reasons, it can be postulated that V224G can affect the function of bilirubin-UDP-glucuronosyltransferase 1 by reducing its activity, thus causing a decrease in bilirubin glucuronidation.

The deletional event that was found in the paternal allele causes the premature appearance of a stop signal after 15-17 codons. This mutation does not exert any dominant negative effect, probably because of the very short truncated encoded protein. Moreover, as for other mutations, it is silent at the heterozygous level as shown by the normal STB of the mother.

The brother, in spite of inheriting the chromosome carrying both the AG deletion and the in cis (TA $)_{7}$ variation, was normal. We can hypothesise that the presence of the (TA), polymorphism in cis to the missense mutation could reduce its negative effect.

The number of cases studied so far are very heterogeneous both at the clinical and at the molecular level making genotype-phenotype analysis very difficult. In our case, the CN II phenotype is the result of the additive effect of the interaction of a deletional event and the missense mutation V224G in association with the (TA) $)_{7}$ promoter polymorphism.

This work was partially supported by Telethon (E-675) and by Assessorato Igiene e Sanità Regione Sardegna (L R No 11, 30 April 1990)
ACHILLE IOLASCON* ALESSANDRA MELONI $\dagger$ BRIGIDA COPPOLA ${ }^{\star}$

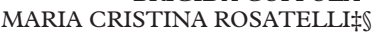

${ }^{\star}$ Dipartimento di Biomedicina dell'Età Evolutiva, Università di Bari, Bari, Italy

†Istituto di Ricerca per le Talassemie ed Anemie Mediterranee, CNR

Cagliari, Italy

$¥$ Istituto di Clinica e Biologia dell’Età Evolutiva, Università di Cagliari,

Via fenner s/n, 09121 Cagliari, Italy

$§$ Dipartimento di Biochimica e Fisiologia Umana, Università di Cagliari, Italy

Correspondence to: Dr Rosatelli, <crosatel@mcweb.unica.it>

1 Ritter JK, Crawford JM, Owens IS. Cloning of two human liver bilirubin UDP-glucuronosyl-transferase cDNAs with expression in COS-1 cells. $\mathcal{F}$ Biol Chem 1991;266:1043-7.

2 Bosma PJ, Seppen J, Goldhoorn B, Bakker C, Oude Elferink RPJ, Roy Chowdhury J, Roy Chowdhury N, Jansen PLM. Bilirubin-UDPglucuronosyltransferase 1 is the only relevant bilirubin glucuronidating isoform in man. $\mathcal{F}$ Biol Chem 1994;269:17960-4.

3 Bosma PJ, Roy Chowdhury N, Goldhoorn BG, Hofker MH, Oude Elferink RPJ, Jansen PLM, Roy Chowdhury J. Sequence of exons and the flanking regions of human bilirubin-UDP-glucuronosyltransferase gene complex and identification of a genetic mutation in a patient with Crigler-Najjar syndrome, type I. Hepatology 1992;15:941-7.

4 Labrune P, Myara A, Hadchouel M, Ronchi F, Bernard O, Trivin F, Roy Chowdhury N, Roy Chowdhury J, Munnich A, Odievre M. Genetic heterogeneity of Crigler-Najjar syndrome type I: a study of 14 cases. Hum Genet 1994;94:693-7.

5 Seppen J, Steenken E, Lindhout D, Bosma PJ, Oude Elferink RPJ. A mutation which disrupts the hydrophobic core of the signal peptide of bilirubin
UDP-glucuronosyltransferase, an endoplasmic reticulum membrane proUDP-glucuronosyltransferase, an endoplasmic reticulum mem
tein, causes Crigler-Najjar type II. FEBS Lett 1996;390:294-8.

6 Yamamoto K, Soeda Y, Kamisako T, Hosaka H, Fukano M, Sato H, Fujiyama Y, Adachi Y, Satoh Y, Bamba T. Analysis of the bilirubin uridine 5'-diphosphate (UDP)-glucuronosyltransferase gene mutations in seven patients with Crigler-Najjar syndrome type II. fpn $\mathcal{F}$ Hum Genet 1998;43:111-14.

7 Bosma PJ, Roy Chowdhury J, Bakker C, Gantla S, De Boer A, Oostra BA, Lindhout D, Tytgat GNJ, Jansen PLM, Oude Elferink RPJ, Roy Chowdhury NR. The genetic basis of the reduced expression of bilirubin UDP-glucuronyltransferase 1 in Gilbert's syndrome. $N$ Engl $\mathcal{f}$ Med 1995;333:1171-5.

8 Rosatelli MC, Meloni A, Faà V, Saba L, Crisponi G, Clemente MG, Meloni G, Piga MT, Cao A. Molecular analysis of patients of Sardinian descent with Crigler-Najiar syndrome type I. $\mathcal{f}$ Med Genet 1997;34:122-5.

9 Garnier J, Gibrat JF, Robson B. GOR secondary structure prediction method version IV. Methods Enzymol 1996;266:540-53.
EDITOR-Familial hypercholesterolaemia $(\mathrm{FH})$ is an autosomal dominant inherited lipoprotein disorder characterised by raised plasma low density lipoprotein (LDL) levels, xanthomas, premature coronary heart disease, and a family history of one or more of these. Homozygous $\mathrm{FH}$ occurs in one in a million people and they are severely affected, while heterozygotes are moderately affected and occur at a frequency of 1 in 500 in genetically heterogeneous populations. $\mathrm{FH}$ is caused by a mutation in the LDL receptor gene $(L D L R)$ and over 700 have been reported ${ }^{1}$ (http:// www.ucl.ac.uk/fh). Among these, a missense mutation, T705I in exon 15 (FH Paris-9), was originally reported in a compound heterozygote ("homozygous" FH subject) of French-American origin, ${ }^{2}$ but has now been observed in several heterozygotes who also carry another mutation in the coding region of the LDL receptor protein. ${ }^{34}$ The presence of the I705 variant has also been reported in two normocholesterolaemic subjects in the heterozygous and homozygous form, which led to the suggestion that the T705I change is a non-FH causing variation. ${ }^{5}$ The most recent report of this variation was in a Spanish family where the hypercholesterolaemia segregated with the I705 substitution and no other mutation was identified. ${ }^{6}$ Possible explanations for these contradictory findings have been that the exon 15 variant is only pathogenic when another environmental or genetic factor is present, or that in some subjects the I705 variant is in linkage disequilibrium with a second, as yet unidentified causative mutation.

We have set up a clinical genetic diagnostic service for $\mathrm{FH}^{78}$ and the $\mathrm{I} 705$ variant was identified in a subject with a clinical diagnosis of possible $\mathrm{FH}$ who was referred for $\mathrm{FH}$ genetic testing (data not shown). To investigate the pathogenicity of the amino acid substitution at codon 705 , we have determined the frequency of the I705 variant in 2287 healthy UK men and examined the effect of this variant on plasma lipid levels.

An assay was designed for the T705I substitution where an $\mathrm{Nsi}$ I restriction site was introduced into the rare $\mathrm{C}$ allele (I) by a mismatch in the sense primer (underlined): sense primer: 5'-CAG TGG CCA CCC AGG AGA CAT GCA-3' and antisense primer: 5'-ATC TCC ACC GTG GTG AGC CCA-3'. PCR conditions were as described previously, the $N s i$ enzyme was added directly to the PCR product, and the products $(139 \mathrm{bp}$ uncut $=\mathrm{T} 705$ and 115 bp + (non-detected) 14 bp cut) were separated on a $7.5 \%$ MADGE $^{9}$ and stained with ethidium bromide. The I705 carriers were then analysed for the 1061-8C variation in intron 7 by a natural EarI restriction digest, after amplification of exon 8 (197 bp) with primers FH119 (FH website) and $\mathrm{FH} 27$ ( $\mathrm{FH}$ website) and reaction conditions as previously described. ${ }^{8} \mathrm{~A}$ restriction site was lost in the 
Table 1 Characteristics (mean) (SD) of 1705 carriers and non-carriers in 2287 healthy white men from NPHS-II

\begin{tabular}{llll}
\hline T705I group & $T T$ & $T I$ & p value \\
\hline Age $(\mathrm{y})$ & $\begin{array}{l}56.1(0.15) \\
(\mathrm{n}=2256)\end{array}$ & $\begin{array}{l}55.0(1.30) \\
(\mathrm{n}=30)\end{array}$ & 0.09 \\
BMI $\left(\mathrm{kg} / \mathrm{m}^{2}\right)$ & $\begin{array}{l}26.4(0.15) \\
(\mathrm{n}=2255)\end{array}$ & $\begin{array}{l}26.8(1.20) \\
(\mathrm{n}=30)\end{array}$ & 0.56 \\
Total cholesterol (mmol/1) & $\begin{array}{l}5.75(1.02) \\
(\mathrm{n}=2241)\end{array}$ & $\begin{array}{l}5.66(1.08) \\
(\mathrm{n}=30)\end{array}$ & 0.60 \\
Triglycerides (mmol/1) $(95 \% \mathrm{CI})$ & $\begin{array}{l}1.81^{\star}(1.77-1.85) \\
(\mathrm{n}=2242)\end{array}$ & $\begin{array}{l}1.62^{\star}(1.35-1.96) \\
(\mathrm{n}=30)\end{array}$ & 0.27 \\
\hline
\end{tabular}

${ }^{\star}$ Geometric means and $95 \%$ confidence limits as triglycerides were log transformed for the analysis.

A one way analysis of variance was used to compare the lipid levels between the I705 carriers and non-carriers. The data were analysed using STATA (Intercooled Stata 5.0).

rare C allele but a control constant cut site exists for confirmation of digestion. Fragments were analysed on a $10 \%$ acrylamide gel as above giving fragments of $183 \mathrm{bp}$ (1061$8 \mathrm{C})$ and $153 \mathrm{bp}+30 \mathrm{bp}$ (non-detected) (1061-8T).

The sample studied consisted of 2287 white men from the Northwick Park Heart Study (NPHS-II). ${ }^{10}$ Exclusion criteria included non-whites, a history of unstable angina or myocardial infarction, regular medication with aspirin or anticoagulants, cerebrovascular disease, malignancy (except skin cancer other than melanoma), diseases exposing staff to risk of infection, mental disorder or other conditions precluding informed consent, or regular attendance for examination. ${ }^{10}$ Plasma cholesterol and triglycerides were measured as previously reported ${ }^{10}$ and genomic DNA was isolated by standard methods. ${ }^{11}$

As shown in table 1, 30 carriers were found, and thus the carrier frequency of the I705 variant was $1.3 \%$. In a study from The Netherlands, 100 normolipidaemic controls were screened by DGGE and sequencing and the I705 variant was found in two subjects, one heterozygous carrier and one homozygote. ${ }^{3}$ Therefore, the carrier frequency of the I705 allele was $2 \%$ which is very similar to the estimate in the larger group of UK men. All but two I705 carriers from the NPHS-II group carried the $1061-8 \mathrm{C}$ variation in intron 7, which has been associated with this exon 15 variation. ${ }^{4}$ The $1061-8 \mathrm{C}$ variant was screened in 200 men from the NPSH-II group and the variant was only detected in the I705 carriers, so the carrier frequency was estimated to be $\sim 1.3 \%$ in the general population. No statistically significant differences were observed between the mean total cholesterol and triglyceride levels of the I705 carriers and the non-carriers.

These data strongly suggest that the $\mathrm{I} 705$ variant is not having a major effect on LDL receptor function. It is the second "non-functional" variant described to date, with only the A370T being previously known. T370 occurs at a frequency of $6 \%$ in the $\mathrm{UK}^{12}$ and is associated with, at most, only a modest effect on plasma lipid levels. ${ }^{13}$ Cell studies have not detected a significant impairment of LDL receptor function of the T370 substitution. ${ }^{13}$

In the original report of this mutation, the T705I substitution in the coding region of $L D L R$ was thought to be one of the defective alleles in a compound heterozygote, while the second mutation remained undetected. ${ }^{2}$ It is reasonable to assume from the Dutch and our data that neither defect in this homozygote had been identified. The second case occurred in a 40 year old man who had a very high total cholesterol of $17.78 \mathrm{mmol} / 1 .{ }^{35}$ A splice site mutation $(313+1 \mathrm{G}>\mathrm{A})$ was inherited from his hypercholesterolaemic mother, while the I705 variant came from his normolipidaemic father. A proposed explanation for these observations is that the I705 variant is only expressed when another $L D L R$ defect is present, but two of the proband's younger sibs also had slightly raised cholesterol yet did not share an $L D L R$ haplotype with their normocholesterolae- mic sib, that is, they did not carry either of the $L D L R$ variants. Thus, another variation in $L D L R$ or in another gene may be responsible for the hypercholesterolaemia in these two sibs and would also explain the high cholesterol level in the proband. In the most recent report, ${ }^{6}$ the I705 substitution tracked with the hypercholesterolaemia phenotype, but again this could be explained by the presence of an unidentified mutation which may or may not be in linkage disequilibrium with the I705 variation. The intron 7 T1061-8C sequence change would be a candidate for such a mutation, since the rare alleles have been shown previously to occur together ${ }^{4}$ and strong allelic association has been confirmed in this sample of men. However, since carriers of the 1061-8C allele do not have raised plasma cholesterol levels it appears unlikely that this sequence change is of functional importance.

Exon 15 consists of 171 nucleotides which encode 57 amino acids, of which 18 are threonine or serine residues, ${ }^{14}{ }^{15}$ and most of the $\mathrm{O}$ linked sugars of the LDL receptor are attached to these threonine and serine residues. ${ }^{15}$ A similar region is also conserved in the LDL receptors of other mammals. ${ }^{15}$ The functional role of this domain was investigated by Davis et $a l^{15}$ using site directed mutagenesis, where a portion of exon 15 was deleted and then expressed by transfection into fibroblast cell lines. The mutated cDNA coded for a receptor protein which was functionally indistinguishable from the normal receptor. ${ }^{15}$ Subjects carrying a similar natural deletion of exon $15(\mathrm{FH}$ Espoo) have LDL levels which are relatively low and a mild form of $\mathrm{FH} .{ }^{16}$ Thus, a major rearrangement is actually a mild mutation, suggesting that mutations in this region may only have a mild effect on receptor function and therefore on lipid levels. Only six point mutations or single base deletions have been described in exon 15 (http://www.ucl.ac.uk/ $\mathrm{fh}$ ), two point mutations resulting in a stop codon, a minor deletion predicted to result in frameshift, and a splice donor site mutation, and all of these are highly likely to be pathogenic. In addition to the T705I substitution, two missense mutations have been reported, T721 I ${ }^{17}$ and R723Q. ${ }^{18}{ }^{19}$ LDL binding studies showed that the Q723 mutation had $70 \%$ of normal activity and is therefore a mild LDLR mutation. No details are known about the I721 mutation. It may be functional in that an $\mathrm{O}$ linked sugar may attach at this site but it may be non-pathogenic as with T705, which involves the same amino acid substitution.

Thus, from the available data on the reported exon 15 mutations, missense mutations, and $\mathrm{FH}$ Espoo, they appear to have a mild effect on the LDL receptor protein. Ideally, cellular studies should be carried out on all novel mutations but this is often not feasible. However, at the very least 100 normal subjects from the particular ethnic group should be screened for any novel mutation to determine frequency, and if any carriers are detected association studies should be performed. In particular, care should be taken in reporting missense mutations identified in exon 15 
of $L D L R$ as $\mathrm{FH}$ causing, as they appear to have a modest effect on LDL receptor function. Karen Heath is a PhD student sponsored by the John Pinto Foundation and
financial support is from British Heart Foundation grants (RG95007 and RG93008)

KAREN E HEATH* ${ }^{\star}+$ ROS A WHITTAL * GEORGE J MILLER $\ddagger$ STEVE E HUMPHRIES * ${ }^{\star}$ Centre for Cardiovascular Genetics, The Rayne Institute, University College Hospital Medical School, University College London, 5 University Street, London WC1E 67F, UK

†Unit of Clinical Molecular Genetics, Camelia Botnar Laboratories, Great Ormond Street Hospital for Children NHS Trust, Great Ormond Street, London WC1N 3FH, UK

$\ddagger$ Medical Research Council Epidemiology and Medical Care Unit, Wolfson Institute of Preventative Medicine, Medical College of St Bartholomew's Hospital, Charterhouse Square, London EC1M 6BQ, UK Correspondence to: Dr Heath, rmhaseh@ucl.ac.uk

1 Wilson DJ, Gahan M, Haddad L, Heath K, Whittall RA, Williams RR, Humphries SE, Day INM. A World Wide Web site for low-density lipoprotein receptor gene mutations in familial hypercholesterolaemia: sequence based, tabular and direct submission data handling. Am $\mathcal{f}$ Cardiol 1998;81:1509-11.

2 Hobbs HH, Brown MS, Goldstein JL. Molecular genetics of the LDL receptor gene in familial hypercholesterolaemia. Hum Mutat 1992;1:445-66.

3 Lombardi P, Sijbrands EJG, van de Giessen K, Smelt AHM, Kastelein JJP, Frants RR, Havekes LM. Mutations in the low density lipoprotein receptor gene of familial hypercholesterolaemic patients detected by denaturing gradient gel electrophoresis and direct sequencing. F Lipid Res 1995;36:860-7.

4 Jensen HK, Jensen LG, Hansen PS, Faergeman O, Gregerson N. High sensitivity of the single-strand conformation polymorphism method for detectsitivity of the single-strand conformation polymorphism method for detecting sequence variations in the low-density lipoprotein

5 Lom Lombardi P, Sijbrands EJG, Kamerling S, Leuven JAG, Havekes LM. The T705I mutation of the low density lipoprotein receptor gene (FH Paris-9)

6 Arca M, Jokinen E. Low density lipoprotein receptor mutations in a selected population of individuals with moderate hypercholesterolaemia. Atherosclerosis 1998;136:187-94.
7 Heath KE, Humphries SE. Rapid genetic testing of three polymorphisms in the low-density lipoprotein receptor gene and their use in a clinical genetic diagnostic service. Clin Genet 1999;55:212-14.

8 Heath KE, Humphries SE. Rapid detection of polymorphisms in exon 10, 11 and 12 of the low density lipoprotein receptor gene (LDLR) and their use in a clinical genetic diagnostic setting. Clin Genet 1999;55:212-14.

9 Day INM, Humphries SE, Richards S, Norton D, Reid M. High-throughput genotyping using horizontal polyacrylamide gels with wells arranged for microplate array diagonal gel electrophoresis (MADGE). Biotechniques 1995;19:830-5.

10 Miller GJ, Bauer KA, Barzegar S, Cooper JA, Rosenberg RD. Increased activation of the haemostatic system in men at high risk of fatal coronary heart disease. Thromb Haemostas 1996;75:767-71.

11 Nicolaides NC, Stoeckert CJ. A simple, efficient method for the separate isolation of RNA and DNA from the same cells. Biotechniques 1990;8:154-6.

12 Taylor R, Jeenah M, Seed M, Humphries SE. Four DNA polymorphisms in the LDL receptor gene: their genetic relationship and use in the study of variation at the LDL receptor locus. F Med Genet 1988;25:653-9.

13 Gudnason V, Patel D, Sun XM, Humphries S, Soutar AK, Knight BL. Effect of the StuI polymorphism in the LDL receptor gene (Ala 370 to Thr) on lipid levels in healthy individuals. Clin Genet 1995;47:68-74.

14 Yamamoto T, Davis CG, Brown MS, Schneider WJ, Casey ML, Goldstein JL, Russell DW. The human LDL receptor: a cysteine-rich protein with multiple Alu sequences in its mRNA. Cell 1984;39:27-38.

15 Davis CG, Ellhammer A, Russell DW, Schneider WJ, Kornfeld S, Brown MS, Goldstein JL. Deletion of clustered O-linked carbohydrates does not impair function of low denstiy lipoprotein receptor in transfected fibroblsts. 7 Biol Chem 1986;261:2828-38.

16 Koivisto PVI, Koivisto UM, Kovanen PT, Gylling H, Miettinen TA, Kontula K. Deletion of exon 15 of the LDL receptor gene is associated with a mild form of familial hypercholesterolaemia (FH Espoo). Arterioscler Thromb 1993;13:1680-8.

17 Nauck M, Scharnag H, Koster W, Nissen H, Nauck M, Marz W. Mutations in the genes encoding the low-density lipoprotein receptor and apolipoprotein B in southwest Germany. Atherosclerosis 1997;134:257.

18 Sun XM, Neuwirth C, Patel DD, Knight BL, Soutar AK with the Familial Hypercholesterolaemia Regression Study Group. Comparison of the genetic defect with LDL-receptor activity in cultured cells from patients with a clinical diagnosis of heterozygous familial hypercholesterolaemia. Arterioscler Thromb Vasc Biol 1997; 17:3092-101.

19 Sun XM, Neuwirth C, Patel DD, Knight BL, Soutar AK with the Familial Hypercholesterolaemia Regression Study Group. Influence of genotype at the low density lipoprotein (LDL) receptor gene locus on the clinical phenotype and response to lipid-lowering drug therapy in heterozygous familial hypercholesterolaemia. Atherosclerosis 1998;136:175-85.

\section{Absence of germline mutations in MINPP1, a phosphatase encoding gene centromeric of PTEN, in patients with Cowden and Bannayan-Riley- Ruvalcaba syndrome without germline PTEN mutations}

EdITOR-Germline mutations in the dual specificity phosphatase gene PTEN (also known as MMAC1 or TEP1) have been associated with susceptibility to two related hamartomatous disorders, Cowden syndrome (CS, MIM 158350) and Bannayan-Riley-Ruvalcaba syndrome (BRR, MIM 153480). ${ }^{12}$ It has recently been established that PTEN functions as a 3-phosphatase towards phospholipid substrates in the phosphatidylinositol 3-kinase (PI-3 kinase) pathway. ${ }^{3}$ Lack of PTEN results in the accumulation of phosphatidylinositol- $(3,4,5)-\mathrm{P}_{3}$, which is required for activation of protein kinase $\mathrm{B}$ (PKB)/Akt, a downstream target of PI3-kinase and a known cell survival factor. ${ }^{4-8}$

While up to $81 \%$ of CS and approximately $60 \%$ of BRR cases have detectable PTEN germline mutations, no mutations in the coding region or exon-intron boundaries of PTEN have been found in the remaining affected subjects. ${ }^{29-13}$ Informative PTEN mutation negative families have been shown to be linked to the 10 q23 region, where PTEN lies, ${ }^{214}$ although recently there has been a report of two CS families in which linkage to $10 \mathrm{q} 23$ has been excluded. ${ }^{9}$ This has raised the possibility that either a regu- latory region of the PTEN gene not included in previous studies, such as the promoter region, or another, closely located gene might be responsible for the CS and BRR cases in which no PTEN mutation has been found. The first alternative is unlikely to represent the majority of such cases, as no evidence of PTEN transcriptional silencing has been detected in the tissue of affected CS subjects in which no PTEN mutation was identified (Dahia and Eng, unpublished observations). Transcription levels of PTEN were found to be similar in affected and unaffected tissues of at least three unrelated CS patients and were equivalent to those of normal subjects. This suggests that methylation of the promoter or mutation within the promoter affecting transcription of PTEN does not occur in at least a subset of these PTEN mutation negative CS and BRR cases. To investigate the possibility that a closely mapped gene was the target of such mutations, we examined the coding region of a recently identified gene mapping to $10 \mathrm{q} 23$, next to D10S579, a marker estimated to lie no more than $1 \mathrm{Mb}$ centromeric of PTEN. ${ }^{15}$ The multiple inositol polyphosphate phosphatase, known as MINPP1 or MIPP, has been cloned and shown to encode a conserved domain common to histidine phosphatases. ${ }^{15}{ }^{16}$ MINPP1 codes for an approximately $52 \mathrm{kDa}$ enzyme with the ability to remove the 3-phosphate from inositol phosphate substrates, such as Ins $(1,3,4,5) \mathrm{P}_{4}$, as well as other inositol moieties. It has been shown that human MINPP1 has a wide tissue distribution pattern and its subcellular localisation appears to be targeted to the endoplasmic reticulum (ER). ${ }^{15}{ }^{16}$ While little is known about the human MINPP1 function, its most well studied homologue, chick HiPER1, has a more restricted tissue distribution and appears to be critical to regulate the transition 
Table 1 Primer sequences and annealing temperature used in PCRs of the MINPP1 gene

\begin{tabular}{|c|c|c|c|}
\hline MINPP1 exon & Forward sequence & Reverse sequence & $\begin{array}{l}\text { Annealing temperature } \\
\text { used for PCR }\end{array}$ \\
\hline $1-\mathrm{A}$ & $\begin{array}{l}\text { MINPP1 5'UTRF } \\
\text { CTCCACTGACCGTCCCGA }\end{array}$ & $\begin{array}{l}\text { MINPP1-296R } \\
\text { ATCTGTTTGACCGTGGGGTA }\end{array}$ & 54 \\
\hline $1-B$ & $\begin{array}{l}\text { MINPP1-145F } \\
\text { ACCAAGACTCGCTACGAGGA }\end{array}$ & $\begin{array}{l}\text { MINPP1-556R } \\
\text { GTGCTTGGAACTGGTGATGA }\end{array}$ & 54 \\
\hline $1-\mathrm{C}$ & $\begin{array}{l}\text { MINPP1-535F } \\
\text { CTCATCACCAGTTCCAAGCA }\end{array}$ & $\begin{array}{l}\text { MINPP1-I-1R: } \\
\text { AGGACCGGGACAGCACAC }\end{array}$ & 61 \\
\hline 2 & $\begin{array}{l}\text { MINPP1-I-2F: } \\
\text { CGGCTGTGCGGATTAGTAAG }\end{array}$ & $\begin{array}{l}\text { MINPP1-I-2R: } \\
\text { TCCTTATGTTTCATTTTCACAGTTC }\end{array}$ & 54 \\
\hline 3 & $\begin{array}{l}\text { MINPP1-I-3F: } \\
\text { TCCCCAAACTGAAGATGTCC }\end{array}$ & $\begin{array}{l}\text { MINPP1-I-3R: } \\
\text { AACCAAATGCAAACAAGCAA }\end{array}$ & 54 \\
\hline 4 & $\begin{array}{l}\text { MINPP1-I-4F: } \\
\text { TCAGGGAATCTTGTTATATTTTTGAA }\end{array}$ & $\begin{array}{l}\text { MINPP1-I-4R: } \\
\text { TGGGTAGAGTGGAAGGTTCG }\end{array}$ & 54 \\
\hline $6^{\star}$ & $\begin{array}{l}\text { MINPP1-1093F } \\
\text { ATCCTCCAGTTTGGTCATGC } \\
\text { or } \\
\text { GTCTCAGCCAATTTCTTCTC }\end{array}$ & $\begin{array}{l}\text { MINPP1-1464R } \\
\text { TCATAGTTCATCAGATGTACTGTT }\end{array}$ & 54 \\
\hline
\end{tabular}

^In the chick MINPP1 homologue, HiPER1, an extra exon, dubbed exon 5, and not seen in humans, precedes the final exon, named therefore exon 6.

of growth plate chondrocytes from proliferation to hypertrophy. ${ }^{17}$ It is presumed that human MINPP1 plays a role in differentiation and apoptosis, although details on the pathways involved in such signalling are as yet unknown. Thus, owing to its chromosomal location and to the fact that, like PTEN, it encodes a phosphatase with activity towards lipid substrates, we sought to investigate whether mutations in MINPP1 would account for cases of CS and BRR without detectable PTEN mutations.

We obtained DNA from 36 subjects who met stringent criteria for the diagnosis of CS $(n=14)$ and BRR $(n=22)$ and in whom no PTEN mutation had been detected. ${ }^{12}{ }^{13}$ In at least one of the families, linkage data were compatible with linkage of the CS phenotype with the $10 \mathrm{q} 23$ region. ${ }^{14}$ The rest of the cases were isolated or belonged to small families where linkage analysis was impossible. Informed consent was obtained from all subjects enrolled in this study, according to institutional Human Subjects Protection Committee protocols. All samples were screened for mutations in the coding region of MINPP1 and most intron-exon boundaries of the gene by PCR based (primer sequences and PCR conditions in table 1) direct sequence analysis, as previously described. ${ }^{18}$ No MINPP1 mutations were found in germline DNA from any of the subjects examined in the present study. In particular, no mutations were found at the highly conserved histidine phosphatase motif, RHGxRxP, which defines members of the histidine acid phosphatase family. In addition, a second highly conserved site in this group of phosphatases comprising a histidine residue located at position 370 was found to be intact in all samples examined. This represents a proton donor site at the carboxy-terminal region of the protein which appears to be critical for full catalytic activity of this group of enzymes. ${ }^{15}{ }^{16}$ We identified five variations from the reference MINPP1 sequence from the database in all samples, as well as in three normal controls (GenBank accession number AF046914). All of these sequence variants were identical to the reference MINPP2 sequence (GenBank accession number AF084943). A sixth variant, c. $444 \mathrm{~A} \rightarrow \mathrm{G}$, was noted in all our sequences which is in agreement with the MINPP1 reference sequence, but at odds with that of MINPP2. It is likely, therefore, that these variations might represent errors in sequence entry on the database, rather than being associated with any particular phenotype, as they were identical in all samples, including the normal controls.

While described as independent hamartoma syndromes with shared clinical features until recently, it has been generally accepted that only CS bears a higher susceptibility to malignancies. ${ }^{1920} \mathrm{~A}$ broad analysis of genotype-phenotype data in the largest series of both CS and BRR recently undertaken in our laboratory has suggested that they might in fact represent distinct spectra of the same primary disorder. ${ }^{13}$ These findings have clear implications for the follow up of affected subjects, in which systematic cancer surveillance is now recommended for both disorders, and not only for patients with CS.

In several human malignancies, such as breast, prostate, and thyroid cancer with loss of heterozygosity of $10 \mathrm{q}$ and in which no PTEN mutations have been found, it has been suggested that a region proximal to PTEN might be the main target in the tumorigenesis pathway. ${ }^{181-24}$ It remains to be determined whether somatic abnormalities of MINPP1 might be related to any of these sporadic tumours.

In conclusion, we have excluded an important candidate gene as the primary genetic abnormality underlying CS and $\mathrm{BRR}$ in subjects without identifiable PTEN mutation. It is possible that some degree of genetic heterogeneity exists, as suggested by a study that has excluded linkage to 10q23 in two PTEN mutation negative CS families. ${ }^{9}$ The major genetic defect responsible for CS and BRR in cases without detectable PTEN mutation still remains to be established.

This work was partially supported by the US Army Breast Cancer Research Program (to CE) and P30CA16058 from the National Cancer Institute, Bethesda, MD (Ohio State University Comprehensive Cancer Center). PLMD is a Susan G Komen Breast Cancer Research Foundation Postdoctoral Research Fellow (to CE) and OG a Fellow of the DFG.

PATRICIA $M$ DAHIA ${ }^{\star}+$ OLIVER GIMM* HONGOBO CHI DEBBIE J MARSH*+S PAUL R REYNOLDS $\ddagger$ CHARIS ENG*ף

${ }^{\star}$ Clinical Cancer Genetics and Human Cancer Genetics Programs, Ohio State University Comprehensive Cancer Center, 420 W 12th Avenue, Room 690C MRF, Columbus, OH 43210, USA

†Dana-Farber Cancer Institute, Harvard Medical School, Boston, MA, USA

$\ddagger$ Department of Orthopaedics, University of Rochester School of Medicine, Rochester, NY, USA

\CRC Human Cancer Genetics Research Group, University of

Cambridge, Cambridge, UK

Correspondence to: Professor Eng, eng-1@medctr.osu.edu

§resent address: Cancer Genetics Laboratory, Kolling Institute for Medical Research, Department of Medicine, University of Sydney, St Leonards, NSW, Australia

1 Marsh DJ, Dahia PL, Zheng Z, Liaw D, Parsons R, Gorlin RJ, Eng C. Germline mutations in PTEN are present in Bannayan-Zonana syndrome. Nat Genet 1997;16:333-4.

2 Liaw D, Marsh DJ, Li J, Dahia PL, Wang SI, Zheng Z, Bose S, Call KM, Tsou HC, Peacocke M, Eng C, Parsons R. Germline mutations of the PTEN gene in Cowden disease, an inherited breast and thyroid cancer syndrome. Nat Genet 1997;16:64-7.

3 Maehama T, Dixon JE. The tumor suppressor, PTEN/MMAC1, dephosphorylates the lipid second messenger, phosphatidylinositol 3,4,5trisphosphate. F Biol Chem 1998;273:13375-8.

4 Stambolic V, Suzuki A, de la Pompa JL, Brothers GM, Mirtsos C, Sasaki T, Ruland J, Penninger JM, Siderovski DP, Mak TW. Negative regulation of $\mathrm{PKB} /$ Akt-dependent cell survival by the tumor suppressor PTEN. Cell 1998;95:29-39. 
5 Haas-Kogan D, Shalev N, Wong M, Mills G, Yount G, Stokoe D. Protein kinase B (PKB/Akt) activity is elevated in glioblastoma cells due to
mutation of the tumor suppressor PTEN/MMAC. Curr Biol 1998;8:1195mutat

6 Myers MP, Pass I, Batty IH, Van der Kaay J, Stolarov JP, Hemmings BA, Wigler MH, Downes CP, Tonks NK. The lipid phosphatase activity of PTEN is critical for its tumor suppressor function. Proc Natl Acad Sci USA 1998;95:13513-18.

7 Davies MA, Lu Y, Sano T, Fang X, Tang P, LaPushin R, Koul D, Bookstein R, Stokoe D, Yung WK, Mills GB, Steck PA. Adenoviral transgene expression of MMAC/PTEN in human glioma cells inhibits Akt activation and induces anoikis. Cancer Res 1998;58:5285-90.

$8 \mathrm{Li} \mathrm{DM}$, Sun H. PTEN/MMAC1/TEP1 suppresses the tumorigenicity and induces G1 cell cycle arrest in human glioblastoma cells. Proc Natl Acad Sci USA 1998;95:15406-11.

9 Tsou HC, Teng DH, Ping XL, Brancolini V, Davis T, Hu R, Xie XX, Gruener AC, Schrager CA, Christiano AM, Eng C, Steck P, Ott J, Tavtigian SV, Peacocke M. The role of MMAC1 mutations in early-onset breast SV, Peacocke $M$. The role of $M M A C 1$ mutations in early-onset breast cancer: causative in association with Cowden syndrome a

10 Nelen MR, van Staveren WC, Peeters EA, Hassel MB, Gorlin RJ, Hamm H, Lindboe CF, Fryns JP, Sijmons RH, Woods DG, Mariman EC, Padberg Lindboe CF, Fryns JP, Sijmons RH, Woods DG, Mariman EC, Padberg
GW, Kremer H. Germline mutations in the PTEN/MMAC1 gene in GW, Kremer H. Germline mutations in the PTEN/MMAC1

11 Longy M, Coulon V, Duboue B, David A, Larregue M, Eng C, Amati P, Kraimps JL, Bottani A, Lacombe D, Bonneau D. Mutations of PTEN in patients with Bannayan-Riley-Ruvalcaba phenotype. F Med Genet 1998;35: 886-9.

12 Marsh DJ, Coulon V, Lunetta KL, Rocca-Serra P, Dahia PL, Zheng Z, Liaw D, Caron S, Duboue B, Lin AY, Richardson AL, Bonnetblanc JM, Bressieux JM, Cabarrot-Moreau A, Chompret A, Demange L, Eeles RA, Yahanda AM, Fearon ER, Fricker JP, Gorlin RJ, Hodgson SV, Huson S, Lacombe D, LePrat F, Odent S, Toulouse C, Olopade OI, Sobol H, Tishler S, Woods CG, Robinson BG, Weber HC, Parsons R, Peacocke M, Longy M, Eng C. Mutation spectrum and genotype-phenotype analyses in Longy $M$, Eng C. Mutation spectrum and genotype-phenotype analyses in Cowden disease and Bannayan-Zonana syndrome, two hamartoma $507-15$

13 Marsh DJ, Kum JB, Lunetta KL, Bennett MJ, Gorlin RJ, Ahmed SF, Bodurtha J, Crowe C, Curtis MA, Dasouki M, Dunn T, Feit H, Geraghty MT, urtha J, Crowe C, Curtis MA, Dasouki M, Dunn T, Feit H, Geraghty MT, S, Murday VA, Nathanson KL, Parisi M, Pober B, Romano C, Tolmie JL, Trembath R, Winter RM, Zackai EH, Zori RT, Weng LP, Dahia PL, Eng C.
PTEN mutation spectrum and genotype-phenotype correlations in Bannayan-Riley-Ruvalcaba syndrome suggest a single entity with Cowden syndrome. Hum Mol Genet 1999:8:1461-72.

14 Nelen MR, Padberg GW, Peeters EAJ, Lin AY, van den Helm B, Frants RR, Coulon V, Goldstein AM, van Reen MMM, Easton DF, Eeles RA, Hodg son S, Mulvihill JJ, Murday VA, Tucker MA, Mariman ECM, Starink TM, Ponder BAJ, Ropers HH, Kremer H, Longy M, Eng C. Localization of the gene for Cowden disease to 10q22-23. Nat Genet 1996;13:114-16.

15 Chi H, Tiller GE, Dasouki MJ, Romano PR, Wang J, O'Keefe R J, Puzas JE, Rosier RN, Reynolds PR. Multiple inositol polyphosphate phosphatase: evolution as a distinct group within the histidine phosphatase family and chromosomal localization of the human and mouse genes to chromosomes 10q23 and 19. Genomics 1999;56:324-36.

16 Caffrey JJ, Hidaka K, Matsuda M, Hirata M, Shears SB. The human and rat forms of multiple inositol polyphosphate phosphatase: functional homology with a histidine acid phosphatase up-regulated during endochondral ossification. FEBS Lett 1999;442:99-104.

17 Romano PR, Wang J, O'Keefe RJ, Puzas JE, Rosier RN, Reynolds PR. HiPER1, a phosphatase of the endoplasmic reticulum with a role in chondrocyte maturation. $f$ Cell Sci 1998;111:803-13.

18 Dahia PL, Marsh DJ, Zheng Z, Zedenius J, Komminoth P, Frisk T, Wallin G, Parsons R, Longy M, Larsson C, Eng C. Somatic deletions and mutations in the Cowden disease gene, PTEN, in sporadic thyroid tumors. Cancer Res 1997;57:4710-13.

19 Eng C. Cowden syndrome. F Genet Counsel 1997;6:181-91.

20 Eng C. Genetics of Cowden syndrome: through the looking glass of oncology. Int F Oncol 1998;12:701-10.

21 Marsh DJ, Zheng Z, Zedenius J, Kremer H, Padberg GW, Larsson C, Longy $M$, Eng C. Differential loss of heterozygosity in the region of the Cowden locus within 10q22-23 in follicular thyroid adenomas and carcinomas. Cancer Res 1997;57:500-3.

22 Feilotter HE, Nagai MA, Boag AH, Eng C, Mulligan LM. Analysis of PTEN and the $10 \mathrm{q} 23$ region in primary prostate carcinomas. Oncogen 1998;16:1743-8.

23 Feilotter HE, Coulon V, McVeigh JL, Boag AH, Dorion-Bonnet F, Duboue B, Latham WC, Eng C, Mulligan LM, Longy M. Analysis of the 10q23 chromosomal region and the PTEN gene in human sporadic breast carcinoma. Br 7 Cancer 1999;79:718-23.

24 Yeh JJ, Marsh DJ, Zedenius J, Dwight T, Robinson BG, Mutter G, Eng C. Fine structure deletion analysis of 10q22-24 demonstrates regions of loss and suggests that sporadic follicular thyroid adenomas and follicular thyroid carcinomas develop along distinct parallel neoplastic pathways. Genes Chrom Cancer 1999;26:322-8.

\section{Mosaicism in Alport syndrome and genetic counselling}

EDITOR-Alport syndrome is characterised by a progressive glomerulonephritis with typical ultrastructural changes in the glomerular basement membrane. The most frequent, semidominant, $\mathrm{X}$ linked type is the result of a variety of mutations (either point mutations or intragenic deletions) of the $C O L 4 A 5$ gene encoding the $\alpha 5$ chain of type IV collagen. ${ }^{1}$

During SSCP scanning of the COL $4 A 5$ gene, a shift in a segment including exon 44 and flanking intronic sequences was found in a 19 year old proband showing typical ultrastructural changes of the glomerular basement membrane (III.3 in fig 1). Sequence analysis showed a $\mathrm{G} \rightarrow \mathrm{C}$ transversion in the $5^{\prime}$ splice site of intron 44 (position $4271+1$ ). The mutation introduced an AluI restriction site which divided a $66 \mathrm{bp}$ fragment into two fragments of $39+27 \mathrm{bp}$. All 18 family members were tested using this restriction assay and the mutation was found in the proband's affected brother, his cousin, his mother, and two maternal aunts. Surprisingly, the proband's grandmother was a normal homozygote. The proband's grandfather was dead, but true paternity of all daughters could be (indirectly) ascertained by polymorphic markers. ${ }^{4}$

In this family the mutation is associated with juvenile Alport syndrome in males, suggesting that the splicing defect results in a low level or absence of the protein, in agreement with our previous findings on genotypephenotype correlations. ${ }^{1}$ Interestingly, we noted considerable clinical variability among heterozygous females $(n=4)$, ranging from ESRD at 27 years to absence of microscopic haematuria at 37 years.

Our data strongly suggest mosaicism in the germ cells of either grandparent. Mosaicism in germ cells may be the result of either a mutation in a germ cell that thereafter undergoes mitotic divisions (giving rise to mosaicism confined to germ cells), or an early postzygotic mutation before separation of the somatic/germ cells (giving rise to mosaicism in both the tissues and germline). In the latter case, the phenotype may or may not be expressed in the mosaic subjects, depending on the proportion of mutated cells in the relevant tissues. In order to verify mosaicism in somatic tissues of the living grandmother (I.1 in fig 1), we used Amplification Refractory Mutation System (ARMSPCR), a tool able to detect known mutations even when present in a low fraction of template molecules. ${ }^{5}$ The primer sense for exon $44^{1}$ was used in combination with the following specific antisense primers: normal (5'GGTATAACTATCTTCAGGAATAAGTCTTAC-3') and mutant (5'- GGTATAACTATCTTCAGGAATAAGTCT TAG-3'). We performed ARMS-PCR on DNA extracted from grandmaternal peripheral blood using progressively lower stringency by lowering the temperature or increasing the PCR cycle number or both, with the aim of reaching a condition where even the very few mutated molecules present in the blood sample would be amplified. This condition was never reached, as the grandmother's DNA always gave the same results as normal homozygous female controls (data not shown).

On analysis of Xq22 DNA polymorphisms, the three carrier females in the second generation were homozygous for one of the maternal haplotypes, which therefore must have been present in the dead grandfather as well, while the single non-carrier female and the unaffected male carried the other maternal haplotype. These data might suggest that the mutation was present in the grandmaternal gonads on 


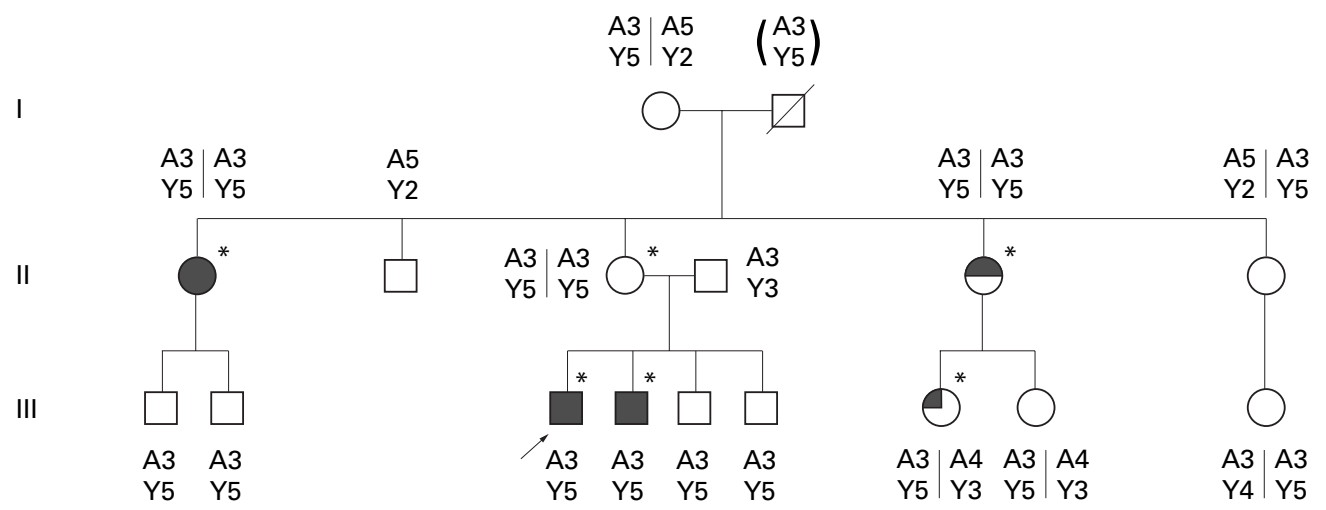

$$
\begin{aligned}
& \text { Microscopic haematuria } \\
& \text { Chronic renal failure at } 21 \text { years } \\
& \text { Dialysis at } 28 \text { years } \\
& \square \text { Dialysis at } 17 \text { years and deafness }
\end{aligned}
$$

Figure 1 Pedigree of the family and haplotype analysis at the COL4A5/COL $4 A 6$ locus. ${ }^{*}$ Presence of mutation $G \rightarrow C$ at $4271+1$ of intron 44. For haplotype analysis: $A=2 B 6$ polymorphism at the $3^{\prime}$ end of the $C O L 4 A 5$ gene $; Y=A 6 Y U 2$ polymorphism in intron 31 of COL $4 A 6 .^{3}$

haplotype A3Y5, and that the mutated germ cells were indeed preponderant, since it was transmitted to all daughters sharing this haplotype. When mosaicism in the germline is diagnosed because of the birth of more than one affected child to apparently healthy parents, it has been reported that in $50 \%$ of the cases the mutation can be found in somatic cells. ${ }^{6}$ The absence of the mutation in the blood of the grandmother suggests that she carried germline mosaicism only. However, since only blood was tested and some cases are reported in which a mutation not found in blood was shown in other tissues, such as muscle, buccal smear, or hair, somatic mosaicism cannot be completely excluded. ${ }^{78}$

An alternative explanation for the above results is mosaicism in the dead grandfather (I.2 in fig 1). Somatic mosaicism is not excluded even if he did not himself express Alport syndrome, and germline mosaicism would be compatible with transmission of a mutated COL $4 A 5$ gene to three females and of a normal gene to one female; in fact, it is critical for the model that the latter subject, II.5, does not carry the mutation. In order unambiguously to assign the mutation to a paternal or a maternal haplotype, it would be necessary to discriminate which haplotype the three carrier females transmitted to the next generation, but unfortunately they were homozygous for all markers tested. Given these data, mosaicism in either the grandmother or the grandfather might be considered equally likely; both are asymptomatic and no difference in gender of mosaic subjects has been reported. ${ }^{6}$

Mosaicism is a well known phenomenon observed in several Mendelian diseases. Mosaicism of parental somatic/germ cells is reported at a rate of $6 \%$ in osteogenesis imperfecta type II, 5-10\% in campomelic dysplasia, and at an even higher rate in facioscapulohumeral dystrophy, Duchenne muscular dystrophy, and haemophilia A and $\mathrm{B}(11-20 \%) .{ }^{6} \mathrm{~A}$ recent review reports a rate of about $10 \%$ of somatic and germline mosaicism in retinoblastoma patients. ${ }^{9}$ In contrast, in other diseases like achondroplasia and Apert syndrome, mosaicism was never detected in large series of cases, despite the high de novo mutation rate.

In agreement with a low fitness of male Alport syndrome patients, it is well known that a definite proportion is caused by new or recent mutations. ${ }^{10}$ Among a sample of 16 (unpublished) mutations in which at least the parental DNA was tested, the present case was the only one with a large family available in which we could show that the mutation had originated in a previous generation. Of the remaining cases, one arose de novo in the grandfather who showed no evidence of mosaicism and 14 were inherited. From these proportions, it is hard to establish the frequency of mosaicism among parents of Alport syndrome patients. Additional cases, similar to the one we report here which originates from mosaic subjects in recent generations, may have gone undetected. In a recent communication by Plant et al, ${ }^{11}$ somatic mosaicism was reported in 3/28 Alport syndrome families with a known COL $4 A 5$ mutation $(10.7 \%)$. In these three cases, the new mutation was detected as a mosaic in the blood of one parent who was oligosymptomatic (two cases) or asymptomatic (one case). In the same series, five de novo mutations were reported ${ }^{12}$; thus, the incidence of mosaicism among sporadic cases was $1 / 6(16.6 \%)$. Since no cases of mosaicism had been reported in Alport syndrome until recently, it was current practice in genetic counselling to reassure parents when an apparently de novo mutation was found. Given our results and somatic mosaicism detected by others, more cautious counselling would be advisable in all cases with an apparently de novo mutation.

This work was supported by Cofin 98 (MURST) to Mario De Marchi. We thank Giuseppe Novelli for paternity ascertainment.

MIRELLA BRUTTINI* FRANCESCA VITELLI* ILARIA MELONI* GIUSEPPE RIZZARI + MARIO DELLA VOLPE $\ddagger$ GIANNA MAZZUCCOS MARIO DE MARCHI ALESSANDRA RENIERI*

^Genetica Medica, Policlinico Le Scotte, Universita’di Siena, 53100 Siena, Italy

†Ambulatorio Nisseno di Emodialisi, Caltanissetta, Italy

$\ddagger$ Nefrologia, Az Osp S S Antonio e Biagio e C Arrigo, Alessandria, Italy $₫$ Dipartimento di Scienze Biomediche e Oncologia Umana, Universita' di Torino, Italy

ๆDip Scienze Cliniche e Biologiche, Ospedale San Luigi Universita’ di Torino, Italy

Correspondence to: Dr Renieri, renieri@unisi.it 
1 Renieri A, Bruttini M, Galli L, Zanelli P, Neri T, Rossetti S, Turco A, Heiskari N, Zhou J, Gusmano R, Massella L, Banfi G, Scolari F, Sessa A, Rizzoni G, Tryggvason K, Pignatti PF, Savi M, Ballabio A, De Marchi M. $\mathrm{X}$-linked Alport syndrome: an SSCP-based mutation survey over all 51 exons of the COL4A5 gene. Am $\mathcal{F}$ Hum Genet 1996;58:1192-204.

2 Barker D, Cleverly J, Fain PR. Two CA-dinucleotide polymorphisms at the COL4A5 (Alport syndrome) gene in Xq22. Nucleic Acids Res 1992;20:929. 3 Oohashi T, Yasuyoshi U, Manabu S, Yoshifumi N. Isolation and structure of the COL4A6 gene encoding the human $\alpha 6($ IV) collagen chain and comparison with other type IV collagen genes. F Biol Chem 1995;270: 26863-7.

4 Gasparini P, Mandich P, Novelli G, Bellone E, Sangiuolo F, De Stefano F, Potenza L, Trabetti E, Marigo M, Pignatti PF, Dallapiccola B, Ajmar F. Forensic applications of molecular genetic analysis: an Italian collaborative study on paternity testing by the determination of variable number of tandem repeat DNA polymorphisms. Hum Hered 1991;41:174-81

5 Newton CR Ga polymorphisms. Hum Hered 1991,41:174-81. Newton CR, Graham A, Heptinstall LE, Powell SJ, Summers C, Kalsheker $\mathrm{N}$, Smith JC, Markham AF. Analysis of any point mutation in DNA. The 17:2503-16.
6 Zlotogora J. Germ line mosaicism. Hum Genet 1998;102:381-6.

7 Putnam EA, Park ES, Aalfs CM, Hennekam RC, Milewicz DM. Parental somatic and germ-line mosaicism for a FBN2 mutation and analysis of FBN2 transcript levels in dermal fibroblasts. Am $\mathcal{f}$ Hum Genet 1997;60:818-27.

8 Voit T, Neuen-Jacob E, Mahler, Jauch A, Cremer M. Somatic mosaicism for a deletion of the dystrophin gene in a carrier of Becker muscular dystrophy. Eur 7 Pediatr 1992;151:112-16.

9 Sippel K, Fraioli R, Smith G, Schalkoff M, Sutherland J, Gallie B, Dryja T. Frequency of somatic and germ-line mosaicism in retinoblastoma: implications for genetic counseling. Am f Hum Genet 1998;62:610-19.

10 Renieri A, Seri M, Myers JC, Pihlajaniemi T, Massella L, Rizzoni G, De Marchi M. De novo mutation in the COL4A5 gene converting glycine 325 to glutamic acid in Alport syndrome. Hum Mol Genet 1992;1:127-9.

11 Plant KE, Boye E, Green PM, Vetrie D, Flinter FA. Somatic mosaicism associated with a mild Alport syndrome phenotype. Fourth International Workshop on Alport Syndrome, Salt Lake City, Utah, 15-17 April 1999.

12 Plant KE, Green PM, Vetrie D, Flinter FA. Detection of mutations in COL4A5 in patients with Alport syndrome. Hum Mutat 1999;13:124-32.
EDITOR - The ear, patella, short stature syndrome (EPS or Meier-Gorlin syndrome) is a rare disorder characterised by microtia, absent or hypoplastic patellae, and proportionate pre- and postnatal growth retardation. In 1994, published reports of the disorder were reviewed by Boles et al. ${ }^{1}$ To date, over 17 patients have been described.$^{1-5}$ Inheritance is autosomal recessive as evidenced by an almost equal number of male and female patients, as well as affected sibs, occurrence of consanguineous matings, and the absence of clinical abnormalities in the parents. Here, we describe two unrelated patients with the EPS syndrome and breast hypoplasia. This is a hitherto unreported

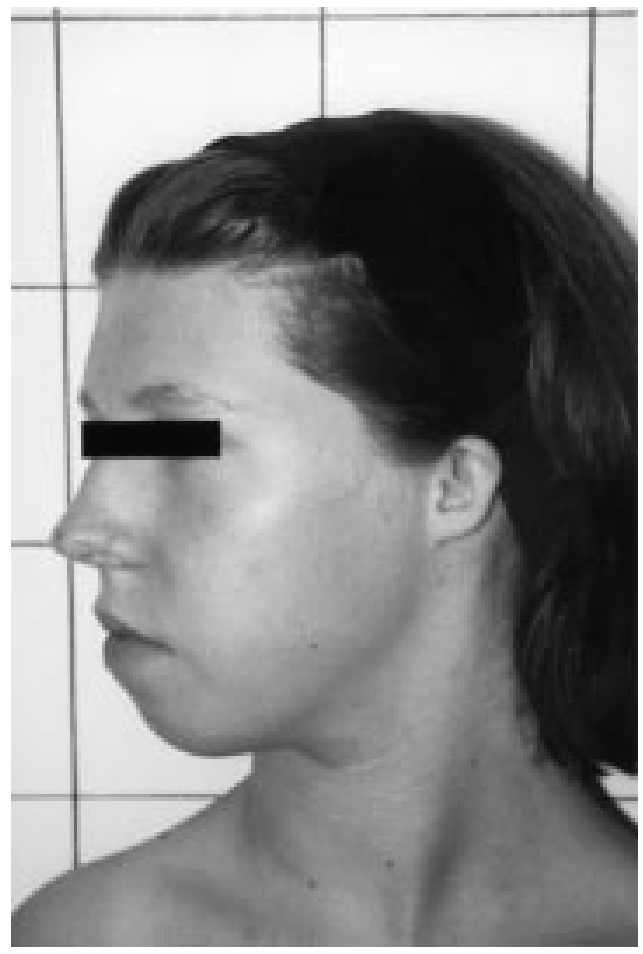

Figure 1 Case 1 aged 14 years. Note microtia and micrognathia. finding that may be a part of the syndrome in adult females. Furthermore, the disproportionate short stature which was present in our patients may be a skeletal manifestation of the EPS syndrome.

Patient 1 was the first child of non-consanguineous parents. Clitoral hypertrophy and hypoplastic labia minora were noted after birth. She was referred at the age of 14 years because of dysmorphic features and delayed breast development. Her menarche started at the age of 12 years and she had regular periods. Psychomotor development had been satisfactory. Hearing was normal. Physical examination showed disproportionate short stature (height 1.47 $\mathrm{m}$ (<3rd centile), arm span $1.33 \mathrm{~m}$, arm span for height $<<3$ rd centile). Head circumference was $53.3 \mathrm{~cm}$ (25th centile). There was microtia (ear length $<3$ rd centile) and micrognathia (fig 1). She had a narrow thorax. Puberty was Tanner stage P5M1 (fig 2). A skeletal survey showed bilateral absent patellae. Endocrine studies were normal. She had been treated with ethinyloestradiol which resulted in minimal breast development.

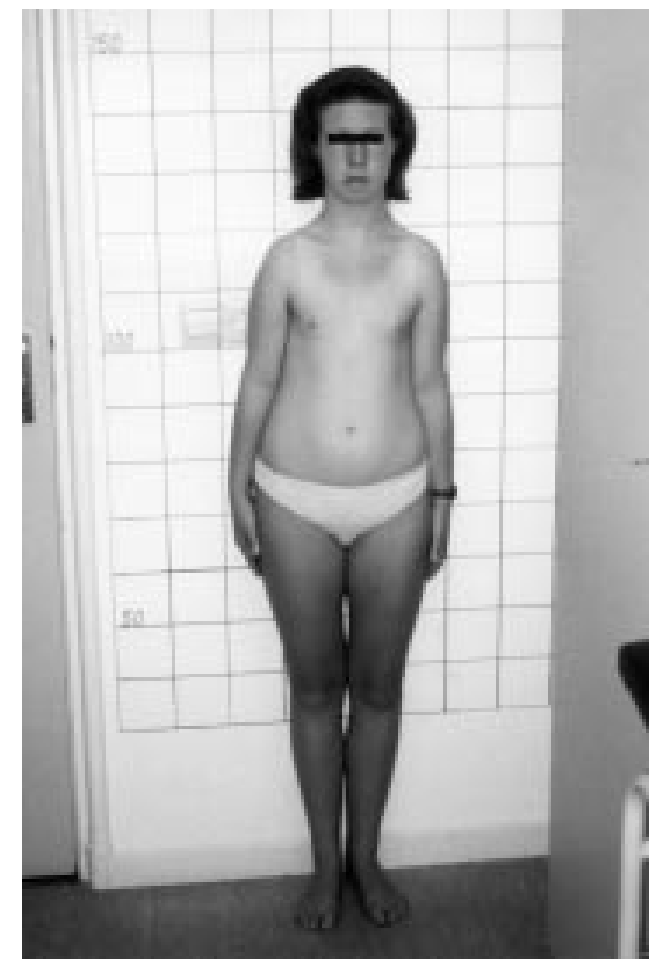

Figure 2 Case 1 aged 14 years. Note disproportionate short stature and breast hypoplasia. 


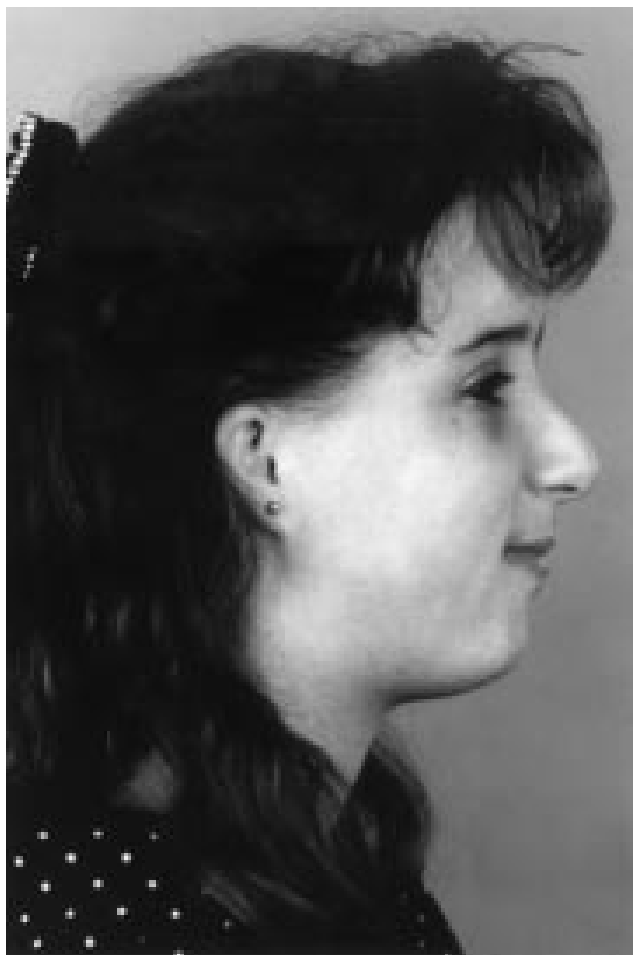

Figure 3 Case 2 aged 15 years. Note microtia and beaked nose.

Patient 2 was also the first child of non-consanguineous parents. At the age of 5 years, she had surgery on her coronary sutures because of craniosynostosis. The girl was lost to follow up until the age of 15 when she was referred for evaluation of short stature and absence of breast development. Menarche had occurred at 13 years and she had regular periods. Psychomotor development was satisfactory. Hearing was normal. Physical examination showed an adolescent female with disproportionate short stature (height $1.43 \mathrm{~m}$ (<3rd centile), arm span $1.32 \mathrm{~m}$, arm span for height $<<3$ rd centile). Head circumference was 51.5 $\mathrm{cm}$ (<3rd centile). She had small, round ears, a beaked nose, and a small mouth (fig 3 ). Narrow shoulders with hypoplastic breasts were noted (fig 4). Puberty was Tanner stage P5M1. A skeletal survey showed bilateral hypoplastic patellae. Chromosome analysis showed no abnormalities and endocrine studies were normal. She underwent plastic surgery for enlargement of her breasts.

Both our patients showed microtia, short stature, and absent or hypoplastic patellae, which are all characteristic of the EPS syndrome (table 1), but we found our patients' breast hypoplasia and disproportionate build remarkable. It is possible that these two features may have been overlooked in previously reported patients. Alternatively, it cannot be excluded that they represent uncommon features present in only a subset of patients with EPS syndrome. To date, nine males and eight females with EPS syndrome have been reported (table 1). Six of the female patients were younger than 10 years. One female at the age of 17 had small breasts ${ }^{3}$ and the other female aged 55 had normal secondary sexual characteristics. ${ }^{2}$

In both our patients, arm span for height was far below the $3 \mathrm{rd}$ centile, which is indicative of disproportionate short stature. Most other patients were reported to have proportionate short stature. ${ }^{14}$ However, details about arm span, sitting height, or subischial leg length are not available except for two patients described by Cohen et al. ${ }^{6}$

In 1994, Lacombe et al postulated that the EPS syndrome could be the human equivalent of the short-ear

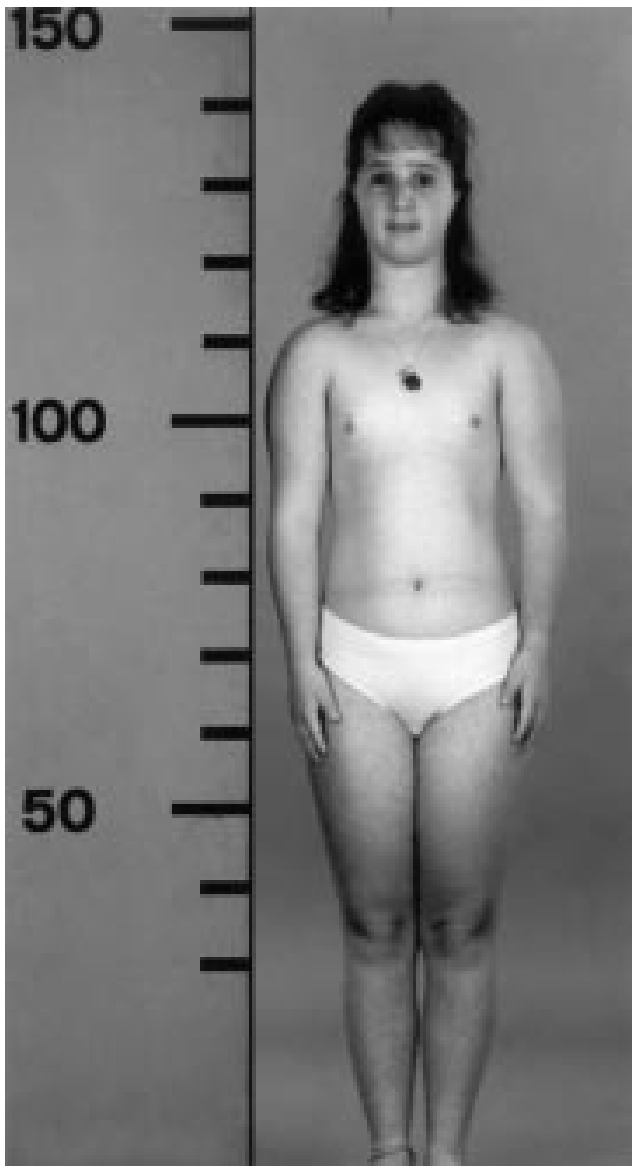

Figure 4 Case 2 aged 15 years. Note disproportionate short stature, narrow shoulders, and absence of breast development.

murine disorder resulting from mutations in the bone morphogenetic protein 5 gene $(B M P-5)$. This hypothesis has not yet been tested by molecular studies. Experiments showed that BMP-5 deficient mice have a lower cross sectional geometry and a significant reduction in length of the femora. ${ }^{7}$ In theory, this growth reduction, if present in the humeri, could lead to disproportionate short stature with reduced arm span. We hypothesise that disproportionate short stature in humans with EPS syndrome may result from a molecular defect in the BMP-5 gene. However, underdevelopment of breast tissue is, to our knowledge, not a feature of $B M P-5$ deficient mice. Additional studies may yield further information about the role of the BMP-5 gene in the EPS syndrome.

We have described two females with EPS syndrome in which both breast hypoplasia and disproportionate short

Table 1 Clinical features of the EPS syndrome

\begin{tabular}{llll}
\hline Features & Published reports & Patient 1 & Patient 2 \\
\hline Sex & 9 male/8 female & $\mathrm{F}$ & $\mathrm{F}$ \\
Height <3rd centile & $12 / 17^{\star}$ & + & + \\
Proportionate short stature & $2 / 15 \dagger$ & - & - \\
Disproportionate short stature & & + & + \\
Microtia & $17 / 17$ & + & + \\
Absent or hypoplastic patellae & $11 / 17 \ddagger$ & + & + \\
Early closure or prominent cranial sutures & $6 / 175$ & - & + \\
Clitoromegaly & $3 / 8$ & + & - \\
Breast hypoplasia & & + & +
\end{tabular}

$\star$ Height $>3$ rd centile was noted in three patients; in two patients height was not reported.

†Seven other reported patients had proportionate short stature. However, span measurements were not reported.

$\ddagger$ Three other patients had normal patellae.

\$Three patients had normal sutures; no information on the other eight patients. Tone patient had small breasts, seven of nine female patients were too young to notice breast hypoplasia. 
stature were present. These features may be associated with the EPS syndrome. Identification of other patients with EPS syndrome and breast hypoplasia and disproportionate short stature may further support this suggested association.

The authors wish to thank the probands and their parents for their cooperation and Dr S Faries for performing endocrinological investigations in our second patient.

P A TERHAL *

$M$ G E M AUSEMS*

Y VAN BEVER+

L P TEN KATE†

P F DIJKSTRA

G M C KUIJPERSS

${ }^{\star}$ Department of Medical Genetics, University Medical Centre Utrecht,

Utrecht, The Netherlands

tDepartment of Clinical Genetics and Human Genetics, Academic

Hospital, Free University, Amsterdam, The Netherlands

$\ddagger$ Department of Radiology, Jan van Breemen Institute, Amsterdam, The

Netherlands
$\$$ Department of Pediatric Endocrinology, University Medical Centre

Utrecht, Utrecht, The Netherlands

Correspondence to: Dr Terhal, P.A.Terhal@dmg.azu.nl

1 Boles RG, Teebi AS, Schwartz D, Harper JF. Further delineation of the ear, patella, short stature syndrome (Meier-Gorlin syndrome). Clin Dysmorphol

2 Fryns JP. Meier-Gorlin syndrome: the adult phenotype. Clin Dysmorphol 1998;7:231-2.

3 Lacombe D, Toutain A, Gorlin RJ, Oley CA, Battin J. Clinical identification of a human equivalent to the short ear (se) murine phenotype. Ann Genet 1994;37:184-91

4 Loeys BL, Lemmerling MM, Van Mol CE, Leroy JG. The Meier-Gorlin syndrome, or ear, patella, short stature syndrome, in sibs. Am f Med Genet 1999;84:61-7.

5 Verhallen JTCM, van der Lely N, Kant SG. Het syndroom van Meier-Gorlin. Tijdschr Kindergeneesk 1999;67:32-5.

6 Cohen B, Temple IK, Symons JC, Hall CM, Shaw DG, Bhamra M, Jackson AM, Pembrey ME. Microtia and short stature: a new syndrome. 7 Med Genet 1991;28:786-90.

7 Mikic B, Van der Meulen MC, Kingsley DM, Carter DR. Mechanical and geometric changes in the growing femora of BMP-5 deficient mice. Bone 1996;18:601-7.

\section{Pili torti et canaliculi and agenesis of the teeth: report of a new "pure" hair-tooth ectodermal dysplasia in a Norwegian family}

EDITOR-The ectodermal dysplasias comprise a heterogeneous group of inherited developmental disorders affecting tissue and organs of ectodermal origin. Their classification was developed by Freire-Maia and Pinheiro, ${ }^{1}$ with malformations of the hair, teeth, nails, and sweat glands as the major criteria. Ectodermal dysplasias are thus divided into 11 subgroups based on a minimum of two ectodermal signs with or without other developmental defects.

A Norwegian family with structural hair abnormalities associated with agenesis of the teeth is reported. The mode of inheritance is consistent with an autosomal dominant pattern.

The investigation for hair and tooth abnormalities in the family started with a then 16 year old boy (IV.3, fig 1), who was under dermatological treatment for an $\mathrm{X}$ linked ichthyosis. Blood lipoprotein electrophoresis showed increased migration of the low density lipoprotein (LDL) fraction compared to normal, consistent with steroid sulphatase deficiency. Interestingly, the blood LDL fraction in his mother, who suffered from dry skin, also showed increased migration, pointing towards carrier status for $\mathrm{X}$ linked ichthyosis. ${ }^{2}$ His maternal grandfather was said also to have suffered from scaly skin. He had, however, died several years ago and clinical examination was therefore not possible. No other person in the family suffered from ichthyosis.

Further, it had been recognised that several persons on the paternal side of his family suffered from stiff and rough hair that seemed to break easily.

The boy had preferred to keep his hair short because it then was easier to treat the scaling of the scalp. He had therefore not been aware of increased breakage of hair. However, his hair felt rough and stiff (fig 2), and there was a discrete area of partial alopecia on the top of his head. Scanning electron microscopy of his hair showed twisted hair shafts combined with longitudinal grooves, pili torti et canaliculi (fig 3). He also had agenesis of the lower premolar teeth (35 and 45) (fig 4). There was no gingival fibrosis and no nail abnormality. The boy was of normal intelligence, had normal sweating and normal hearing, no generalised hypertrichosis, and no ophthalmological abnormalities.

The younger of his two sisters (IV.5, fig 1) had neither hair abnormalities nor agenesis of the teeth. The older of his two sisters (IV.4) also had agenesis of the teeth (12 and 22) (fig 5). She had no problems with breakage of hair and scanning electron microscopy of her hair showed no structural hair changes.

Hair samples from his mother showed no alterations. However, hair samples from both his father (III.2) (fig 6)

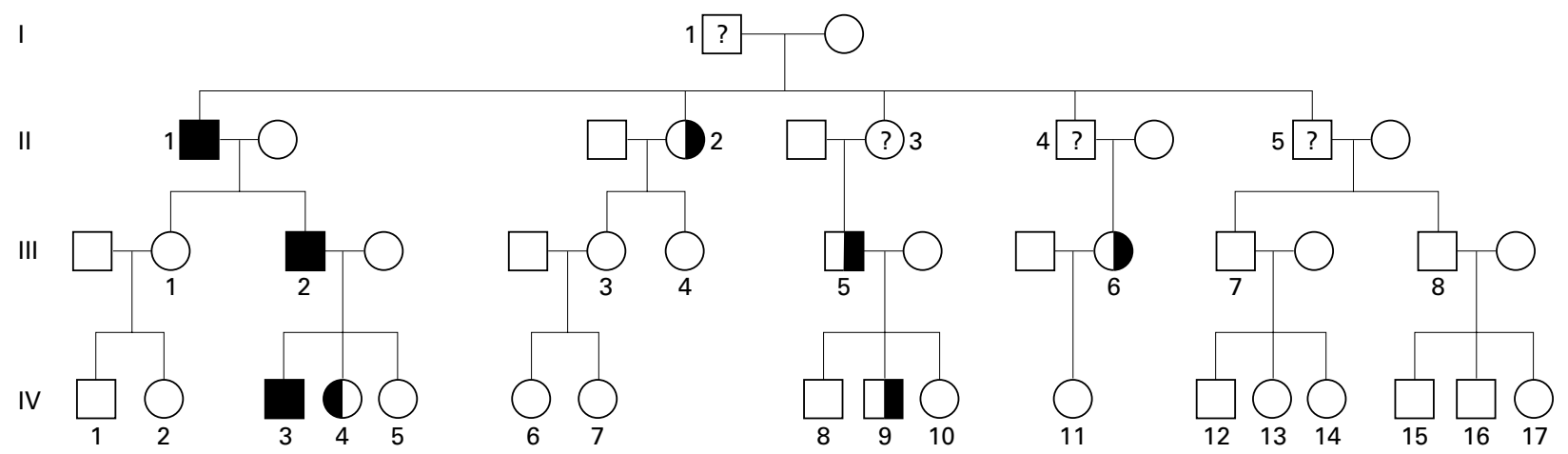

\footnotetext{
$\square$ Pili torti et canaliculi
$\square \bigcirc$ Tooth agenesis
}

Figure 1 Family pedigree. 


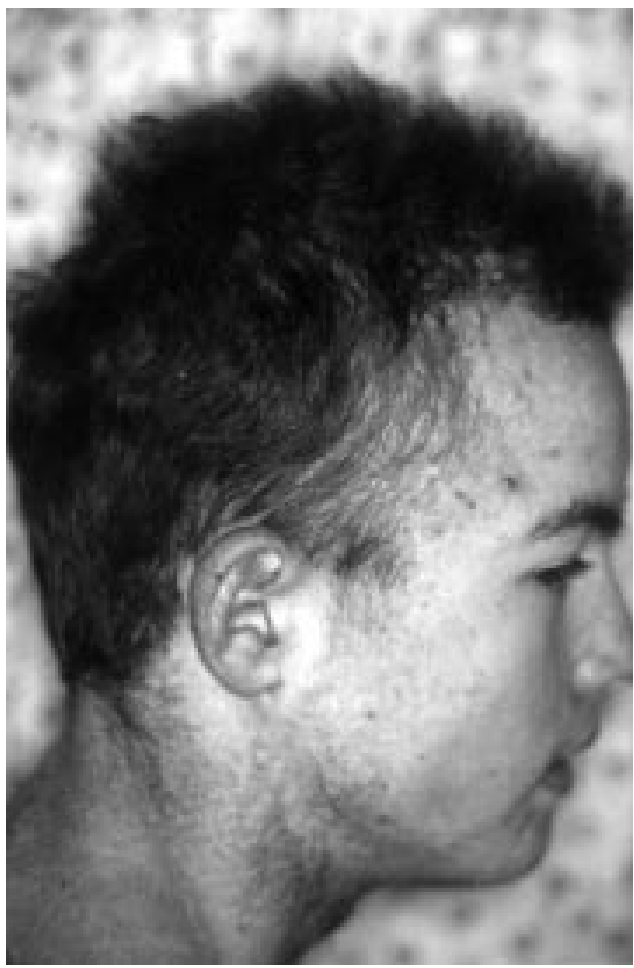

Figure 2 Short, stubby hair of patient IV.3. Ichthyotic skin changes consistent with $X$ linked ichthyosis. (Photograph reproduced with permission.)

and his paternal grandfather (II.1) (fig 7) showed pili torti et canaliculi. They also both had agenesis of the upper lateral teeth (12 and 22).

His great grandfather (I.1), the father of his paternal grandfather, was also said to have had stiff and rough hair and absence of teeth.

His paternal grandfather had four sibs, two sisters and two brothers. The hair of the only remaining sister (II.2) showed pili canaliculi and she also had dental abnormalities. She was not examined clinically, but provided hair samples for scanning electron microscopy. The hair and teeth of both her children, two sisters, were normal. Two out of three of the children of the remaining sibs, III.5 and III.6, showed similar hair abnormalities, pili torti et canaliculi (fig 8). They were said to have certain teeth missing. The son of III. 5 had pili torti et canaliculi and agenesis of certain teeth.

The hair samples were fixed onto probe with double sided sticky tape, coated with a $30 \mathrm{~nm}$ layer of gold/

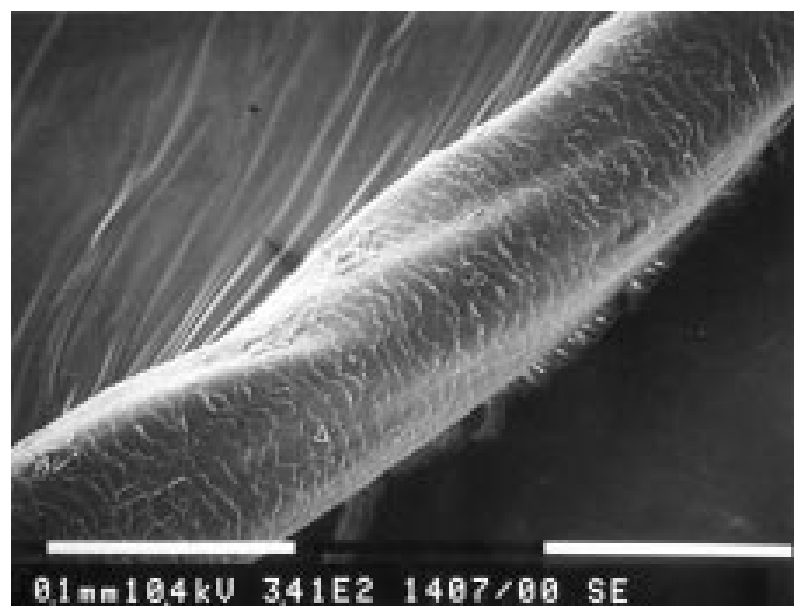

Figure 3 Scanning electron microscope picture of hair from IV.3 showing twisted hairs with longitudinal grooves, pili torti et canaliculi.

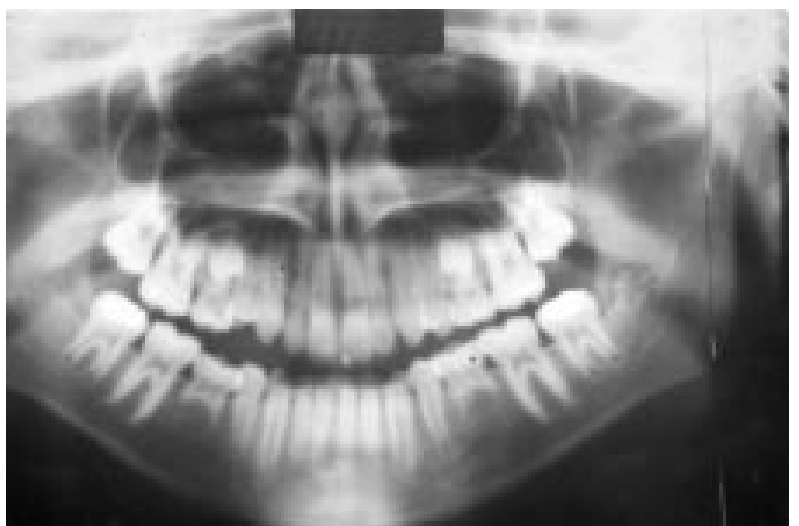

Figure 4 Dental x ray of IV.3 showing absence of premolar teeth 35 and 45.

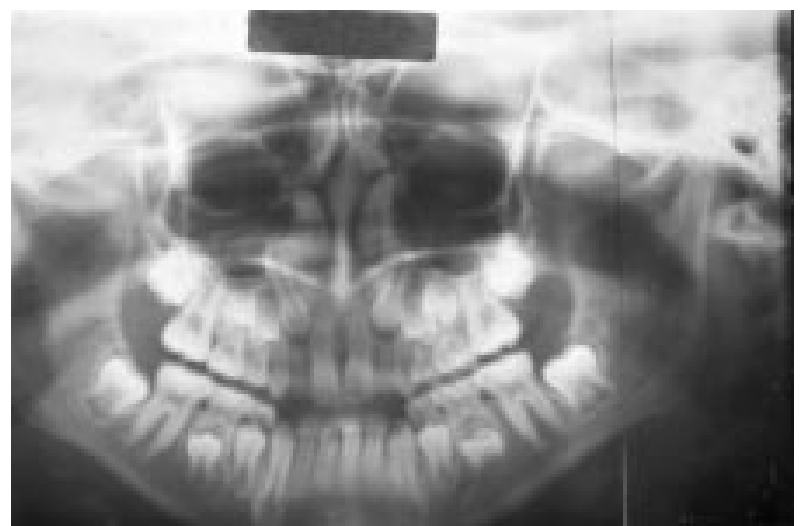

Figure 5 Dental x ray of IV.4 showing absence of 12 and 22.

palladium alloy in a Polaron E 5100 Sputter Coater (Polaron Equipment Ltd, Watford, UK), and the specimens were then examined and photographed in a Philips SEM 515 microscope (Philips, Eindhoven, The Netherlands).

So far, seven other pure ectodermal dysplasias with combined defects of hair and teeth have been described: (1) the oculodentodigital syndrome, ${ }^{3}$ (2) hypertrichosis and dental defects, (3) gingival fibromatosis and hypertrichosis, (4) trichodental dysplasia, ${ }^{4-6}$ (5) ectrodactylyectodermal dysplasia with normal lip and palate, (6) uncombable hair-retinal pigmentary dystrophy-juvenile cataract-brachymetacarpia, and (7) familial clefting syndrome with ectropion and dental anomaly.

The absence of pathological findings in tissue/organs other than the hair and teeth rules out the oculodentodigital syndrome, gingival fibromatosis and hypertrichosis

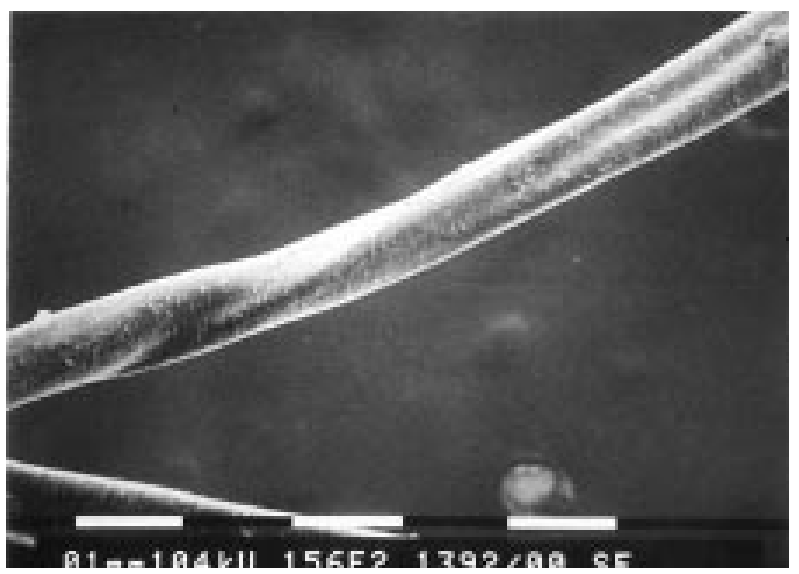

Figure 6 Scanning electron microscope picture of hair from III. 2 showing pili torti et canaliculi. 


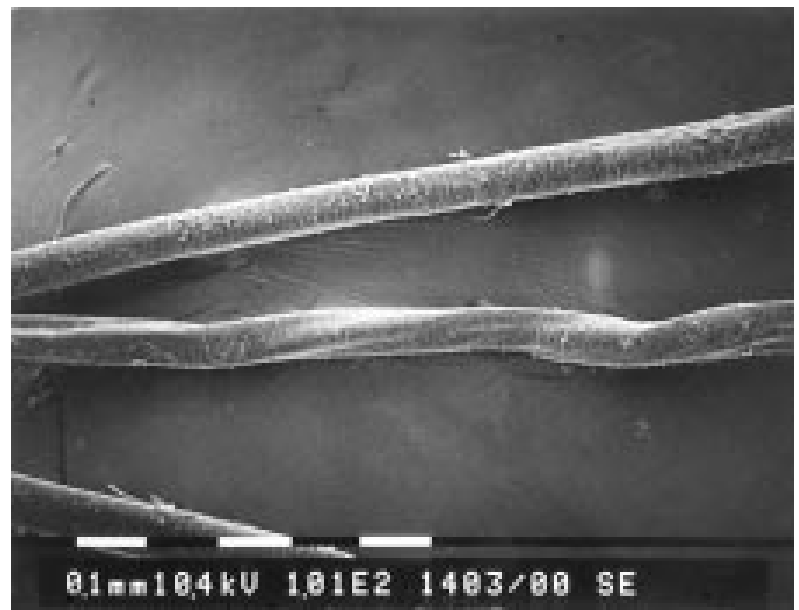

Figure 7 Scanning electron microscope picture of hair from II. 1 showing pili torti et canaliculi.

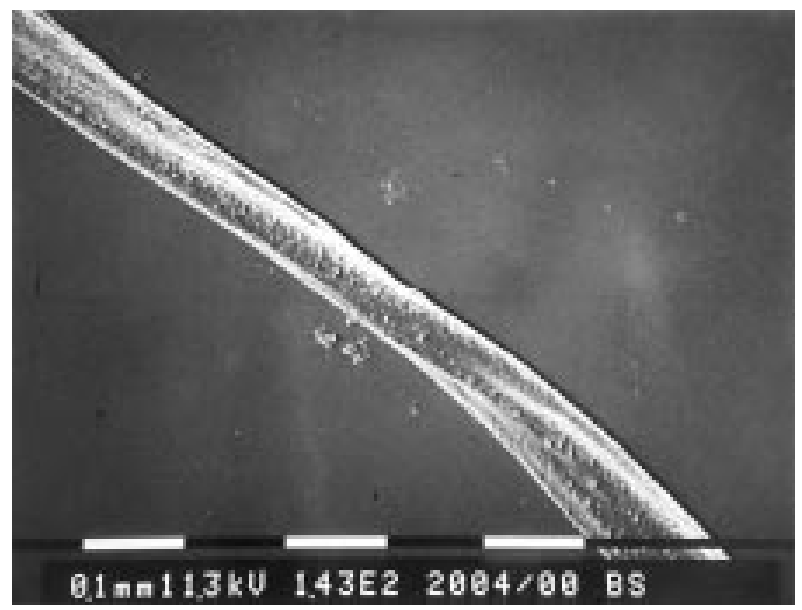

Figure 8 Scanning electron microscope picture of hair from III. 6 showing pili torti et canaliculi.

syndrome, ectrodactyly-ectodermal dysplasia with normal lip and palate, uncombable hair-retinal pigmentary dystrophy-juvenile cataract-brachymetacarpia, and familial clefting syndrome with ectropion and dental anomaly. The dental abnormalities in (2) consist of persistence of deciduous teeth, delayed eruption, and the hypertrichosis is localised or generalised. In (4) trichodental dysplasia, missing teeth, peg shaped incisors, and shell teeth are the most common dental abnormalities. ${ }^{4-6}$ The hair is fine, sparse, dull, and slow growing.

Congenital absence of teeth is most probably autosomal dominantly inherited. ${ }^{7}$ It has been speculated that a common genetic defect may give rise to different phenotypic manifestations, including missing, malformed, and even ectopic and malpositioned teeth. The maxillary teeth that develop in the critical marginal areas of the dental lamina, namely the lateral incisors, canines, and second premolars, seem most susceptible. ${ }^{8}$

The findings in our patients, with different phenotypic manifestations of agenesis of the premolars or lateral incisors, point towards an autosomal dominant mode of inheritance. The sister IV.4 of patient IV.3 only showed agenesis of certain teeth and no pili torti et canaliculi on scanning electron microscopy. This is probably the result of variable expression of the ectodermal dysplasia.

Congenital pili torti et canaliculi is a hair shaft abnormality that has previously been described in Marie Unna hypotrichosis, and together with cleft lip/palate in the EEC-syndrome. The alopecia in Marie Unna hypotrichosis resembles androgenetic alopecia, but, in addition, hair loss occurs at the perimeter of the scalp as well, giving the patients monk-like features. ${ }^{9}$ In the EEC syndrome, several other pathological findings are present, ${ }^{10}$ not seen in any of our patients.

In conclusion, the combination of pili torti et canaliculi and dental abnormalities has not been described before and could represent a new pure hair-tooth ectodermal dysplasia.

EDGAR SELVAAG

Department of Dermatology, Ullevål Hospital, University of Oslo, Norway

Correspondence to: Dr Selvaag, Department of Dermatology, University of

Copenhagen, Bispebjerg Hospital, Bispebjerg Bakke 23, DK-2400

Copenhagen, Denmark

1 Freire-Maia N, Pinheiro M. Ectodermal dysplasias-some recollections and a classification. Birth Defects 1988;24:3-14.

Paller AS. Laboratory tests for ichthyosis. Dermatol Clin 1994;12:99-107.

3 Gillespie FD. A hereditary syndrome: 'dysplasia oculodentodigitalis'. Arch Ophthalmol 1964;71:187-92.

4 Salinas CF, Spector M. Tricho-dental syndrome. In: Brown AC, Crounse RG, eds. Hair, trace elements, and human illness. New York: Praeger, 1980:240-56.

5 Kersey PJW. Tricho-dental syndrome: a disorder with a short hair cycle. $\mathrm{Br}$ f Dermatol 1987;116:259-63.

6 Eteson DJ, Clark RD. A new autosomal dominant tricho-dental dysplasia. March of Dimes Birth Defects Conference, Baltimore, 10-13 July, 1988.

7 Graber LW. Congenital absence of teeth: a review with emphasis on inheritance patterns. FAMA 1978;96:266-75.

8 Kotsomitis N, Freer TJ. Inherited dental anomalies and abnormalities. ASDC F Dent Child 1997;64:405-8.

9 Mende B, Kreysel HW. Hypotrichosis congenita hereditaria Marie Unna mit Ehlers-Danlos-Syndrom und Atopie. Hautarzt 1987;38:532-5.

10 Trüeb RM, Spycher MA, Schumacher F, Burg G. Pili torti et canaliculi bei ektodermaler Dysplasie. Hautarzt 1994;45:372-7.
EDITOR-In the March 1999 issue of the journal, Portnoi et $a l^{1}$ reported a patient with hyperpigmentation distributed along the lines of Blaschko ${ }^{23}$ with mosaicism for partial tetrasomy for the chromosomal region 3q27-q29. Here we describe a patient who displays a very similar pattern of skin hyperpigmentation (fig $1 \mathrm{~A}, \mathrm{~B}$ ) associated with mosaicism for a small partial terminal triplication of $3 \mathrm{q}$ (fig 2) leading to functional tetrasomy with the following karyotype obtained from lymphocytes: mos 46,XY, $\operatorname{trp}$ (3) (q27.1-qter) [47]/46,XY [4]. Both parents were

\section{Skin pigmentary anomalies in a mosaic form of partial tetrasomy $3 \mathrm{q}$}

found to have a normal karyotype. The proband is a 5 year old boy, the first child of healthy, unrelated parents. During early pregnancy intrauterine growth retardation was suspected, but no anomalies were recorded during the following months except reduced fetal movements. He was born by caesarean section 3 weeks before the calculated date of birth because of HELLP syndrome. His birth weight and length were $2810 \mathrm{~g}$ and $49 \mathrm{~cm}$, respectively. Owing to his pigmentary skin anomalies, soon after birth the diagnosis of a hypomelanosis of Ito was made. He was retarded in all developmental milestones, as he was not able to sit before the age of 8 months or walk before 21 months and started to speak at about 2 years. Coarse facial features (fig 1A) with pronounced supraorbital ridges, broad nasal bridge, long philtrum, large prominent ears, and hypoplastic enamel structures were noted. He has a 

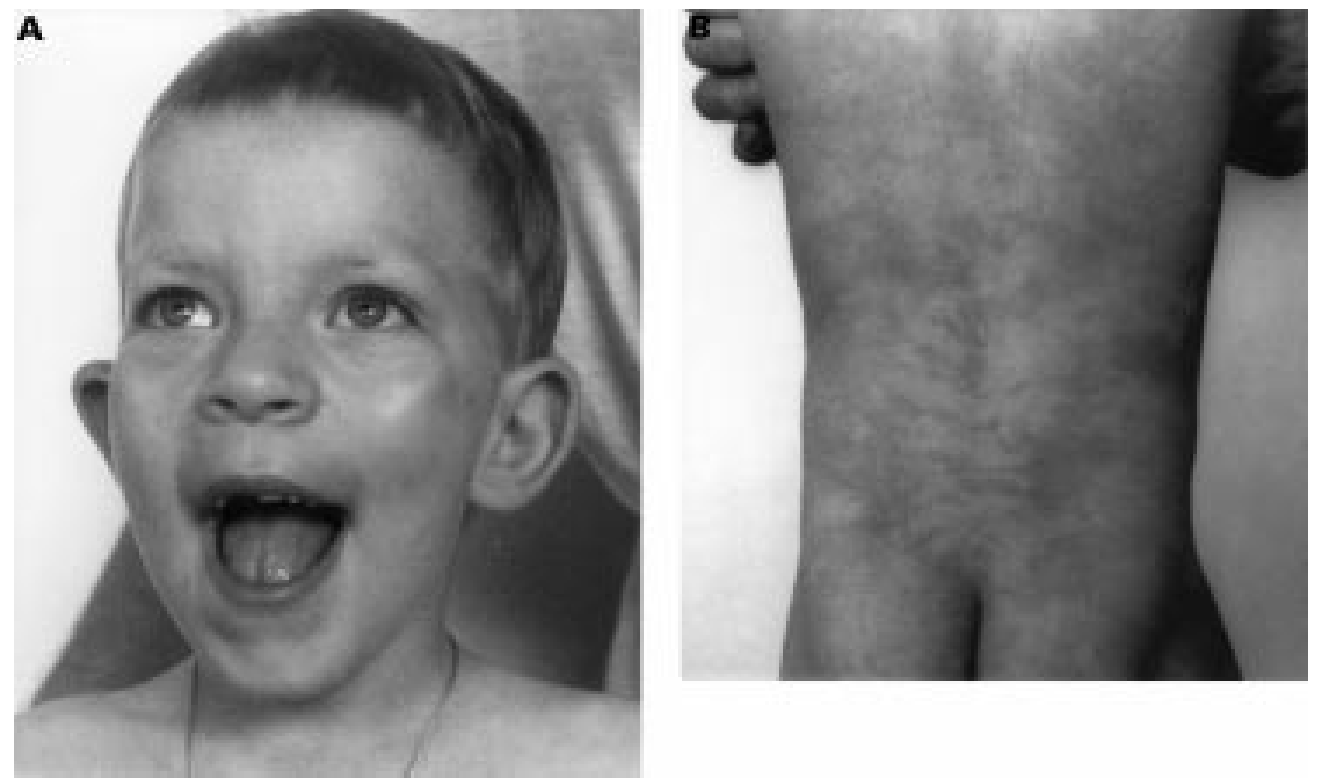

Figure 1 Clinical features of the patient aged 5 years. (A) Front view. Note hypertelorism and prominent ears.

(B) Hyperpigmentation following the lines of Blaschko.

bilateral single palmar crease, but his father shows this feature on his right hand as well. At the age of 2 years his weight of $12 \mathrm{~kg}$ (25th centile), length of $84 \mathrm{~cm}$ (10th-25th centile), and head circumference of $50.5 \mathrm{~cm}$ ( 75 th centile) indicated disproportionate growth curves. Psychomotor examination showed a general retardation of about 6-8

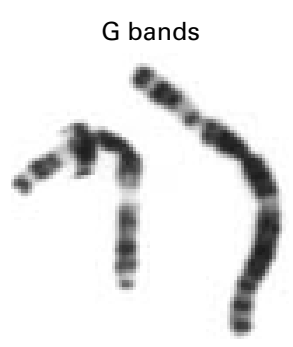

3 $\operatorname{der}(3)$

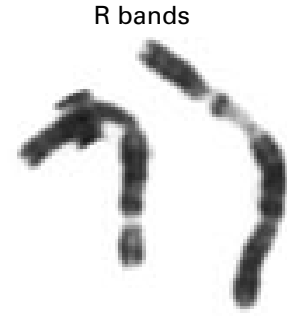

$3 \operatorname{der}(3)$
Figure 2 Partial GTG and RTG karyotype of the normal and the derivative chromosomes 3 . months. Magnetic nuclear resonance imaging of the brain showed periventricular lesions of the white matter with no further anomalies. Despite our request to perform a skin biopsy from the light and dark pigmented areas of his skin to allow cytogenetic analysis of these tissue samples as well, his parents have so far refused this. Since, currently, there is no medical necessity to perform this type of analysis, we had to respect their wishes.

At the age of 5 years the proband was investigated again. $\mathrm{He}$ is currently $113 \mathrm{~cm}$ (50th-75th centile) tall, weighs 19.5 $\mathrm{kg}$ (50th-75th centile), and his head circumference is 53.5 $\mathrm{cm}$ (90th centile). $\mathrm{He}$ is cooperative and understands questions and commands quite well but his articulation is still rather poor despite regular speech therapy. Motor development in particular with regard to fine movements is about two to three years behind normal. At the cytogenetic level, the size of the partially tetrasomic segment seems to be identical to the previously reported case. ${ }^{1}$ We performed FISH analysis using the same YAC clones (806_d_8, 760_f_3, 781_f_8, 883_d_12) as described to determine

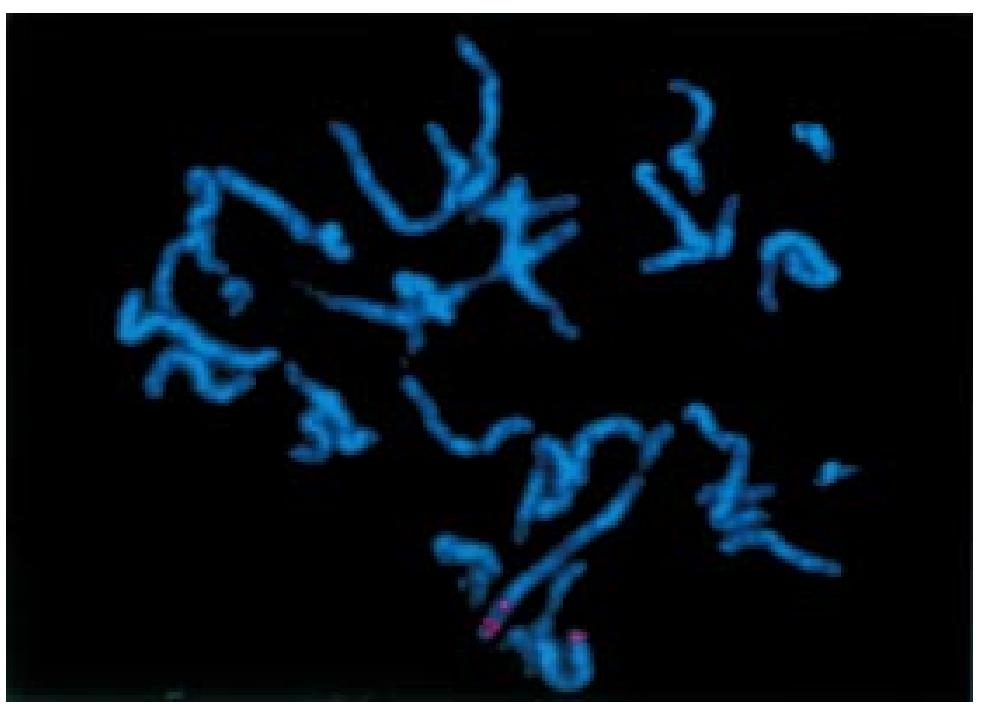

Figure 3 Partial metaphase cell showing the localisation of the YAC clone 883_d_12 on the normal and the derivative chromosome 3. Note that the inverted orientation of the inserted fragment was confirmed by the relative position of the hybridisation signals. 
how similar at the molecular level the chromosomal breakpoints are. A triplication was confirmed for two YACs (781_f_8 and 883_d_12) whereas the more proximal YAC, 806_d_8, showed only one signal on the rearranged chromosome. Furthermore, the YAC 760_f_3, which is just a few megabases proximal to 781_f_8, does not map to the triplicated region. This indicates that the breakpoint in $3 \mathrm{q} 27.1$ is not identical at the molecular level in both patients, but is more distal in our proband. From the hybridisation pattern of the triplicated YAC clones it can be concluded that the terminal triplication on the derivative chromosome 3 occurred because of an insertional inverted duplication (fig 3). FISH analysis using a probe specific for the subtelomeric region of the long arm of chromosome 3 (Vysis) showed additional interstitial signals on the derivative chromosome 3 (results not shown).

The patient described by Portnoi et al $l^{1}$ was claimed to be the first with a pure partial tetrasomy of $3 \mathrm{q}$ but he is of normal intelligence and does not show dysmorphic features. As can be judged from the distribution of normal versus abnormal cells in lymphocytes and skin fibroblasts, in particular from the dark pigmented areas, the percentage of partially tetrasomic cells in their patient is much lower than in our case. This could be the explanation why the proband described here exhibits psychomotor retardation and dysmorphic features. However, the observation of Portnoi et $a l^{1}$ that in the partial tetrasomic cells for 3q27.1qter a more intensive skin pigmentation is obvious can clearly be confirmed in the unique karyotype-phenotype constellation present here. It was proposed that because of a gene dosage effect caused by the partial tetrasomy, one or more genes involved in skin pigmentation are responsible for the hyperpigmented brown streaks following the lines of Blaschko (fig 1B). No obvious candidate gene responsible for this effect has been mapped so far to this chromosomal segment; however, the melanoma associated antigen $p 97$ gene $^{4}$ might be involved. Although the partial tetrasomy 3q27.1-qter in both patients is caused by different chromosomal rearrangements, a break in band $3 \mathrm{q} 27.1$ must have occurred in both of them during the first postzygotic cell divisions. Molecular studies with mapping of chromosomal breakpoints allowed us to exclude the involvement of a single gene in both affected subjects. In conclusion, partial tetrasomies for an autosomal segment are rare and deserve more attention when they are associated with an unusual phenotype.

PETER MICHAEL KROISEL ERWIN PETEK KLAUS WAGNER

Institute of Medical Biology and Human Genetics, University of Graz, Harrachgasse 21/8, A-8010 Graz, Austria

Correspondence to: Dr Kroisel, peter.kroisel@kfunigraz.ac.at

1 Portnoi MF, Boutchnei S, Bouscarat F, Morlier G, Nizard S, Dersarkissian H, Crickx B, Nouchy M, Taillemite JL, Belaich S. Skin pigmentary anomalies and mosaicism for an acentric marker chromosome originating from 3q. F Med Genet 1999;36:246-50.

2 Happle R. Lyonization and the lines of Blaschko. Hum Genet 1985;70:2006.

3 Kalter DC, Griffiths WA, Atherton DY. Linear and whorled hypermelanosis. f Am Acad Dermatol 1994;suppl 5:141-3.

4 Plowman GD, Brown JP, Enns CA, Schroder J, Nikinmaa B, Sussman HH,

Hellstrom KE, Hellstrom I. Assignment of the gene for human melanomaassociated antigen p97 to chromosome 3. Nature 1983;303:70-2.
EDITOR-Primary lymphoedema (MIM 153200) is a chronic tissue swelling, most frequently of the lower limbs, which occurs as a consequence of a failure of lymph drainage. ${ }^{1}$ It arises from an intrinsic abnormality of the lymphatic system and generally shows an autosomal dominant pattern of inheritance with reduced penetrance, variable expression, and variable age of onset. ${ }^{2}$ There is a strong genetic input into primary lymphoedema, with 35\% of all patients showing a positive family history. ${ }^{34}$ The swelling can be present at birth, as in Milroy disease, but more commonly it becomes clinically apparent during puberty, which is known as Meige disease..$^{5-7}$

A variant of pubertal onset lymphoedema is lymphoedema-distichiasis (LD) (MIM 153400). This syndrome is a rare form of primary lymphoedema which is associated with distichiasis, a congenital anomaly in which aberrant eyelashes arise inappropriately from the site of the meibomian gland openings. ${ }^{48}$ The disease shows an autosomal dominant pattern of inheritance with incomplete penetrance. ${ }^{9}$ A recent study of three families by our group reported linkage of LD to chromosome $16 \mathrm{q} 24.3 .{ }^{10}$ The locus was placed between the markers D16S422 and D16S3074, a distance of $\sim 16 \mathrm{cM}$ according to the Généthon sex averaged map.

Subsequently, more members of family 3 have been ascertained (fig 1) along with an additional family with an affected father and three affected children (not shown). All subjects were carefully phenotyped based on the presence of distichiasis, which provides a clear criterion with which to define affected status. This was established following slit lamp examination by an ophthalmologist unaware of any other clinical signs. DNA of the newly ascertained subjects was extracted from peripheral venous blood by a standard procedure using a Nucleon genomic DNA extraction kit (Nucleon Biosciences, Strathclyde, UK). Polymorphic microsatellite markers were PCR amplified and electrophoresed through an $8 \%$ denaturing polyacrylamide gel on a conventional gel rig. Gels were run at a constant $50 \mathrm{~mA}$ and the DNA bands were visualised with silver staining. ${ }^{11}$

The microsatellite markers D16S511, D16S422, D16S402, D16S3037, D16S520, and D16S3074 were PCR amplified in the newly ascertained subjects from family 3 and for the new family. The latter was consistent with linkage to the LD locus. All newly ascertained subjects from family 3 were consistent with linkage, using distichiasis as the sign of affected status. Fig 1 shows the expanded pedigree, with the same numbering for the previously typed subjects as in our original publication. ${ }^{10}$ It is of interest that IV.5 (fig 1), who was assumed to be unaffected and non-penetrant in the previous study, was found by slit lamp examination to have limited distichiasis. There are therefore no members of any of the four families we have studied who carry the "affected" haplotype but have no signs.

Analysis of an additional six markers within the LD locus, D16S486, D16S498, D16S543, D16S2625, D16S539, and D16S3061, produced a reduction in the distal interval by $\sim 2 \mathrm{cM}$ as a result of a recombination event in an affected family member (fig 1, IV.4). Another subject (III.5) was included as of unknown status in the initial report. He had a slightly abnormal lymphoscintigraphy result at 30 minutes, which was well within normal limits at 60 minutes, but no lymphoedema. Recent examination has 
Family 3

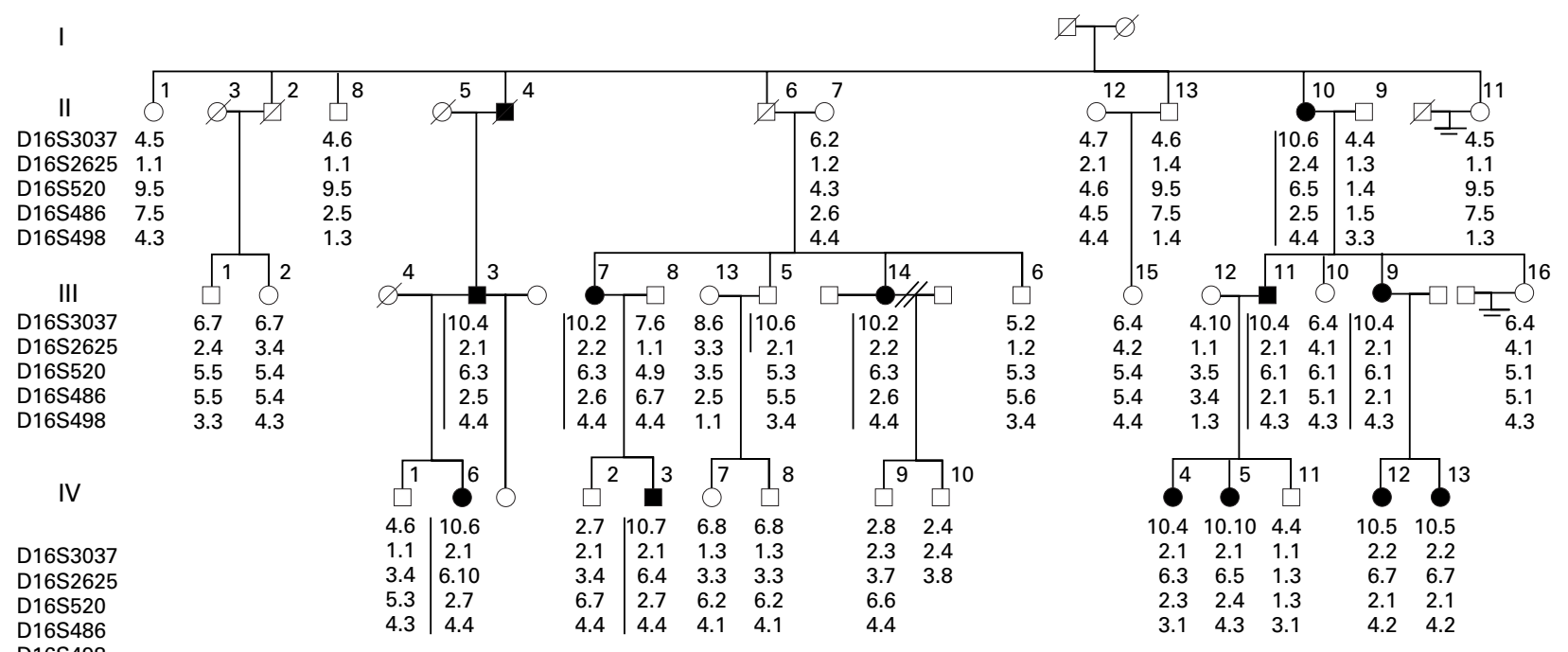

Figure 1 Pedigree of family 3 with haplotypes for the markers shown. Newly ascertained subjects are numbered 12-13 in generation II, 13-16 in generation III, and 6-13 in generation IV. All other family members are numbered as they appeared in the initial report. ${ }^{10}$

shown him to have no trace of distichiasis, which is unlike all the other carriers of the affected haplotype in the four families analysed. We therefore concluded that he is clinically unaffected and does not carry the mutated gene, rather than being a case of non-penetrance. Analysis of the additional six markers in this subject showed a recombination proximally which removed $\sim 10 \mathrm{cM}$ from the locus. The flanking recombinant markers are now D16S3037 (proximal) and D16S498 (distal), with D16S520 and D16S486 non-recombinant between these two, which is a genetic distance of $\sim 4 \mathrm{cM}$ according to the Généthon sex averaged map. Mapping these markers on a mouse/human somatic cell panel ${ }^{12}$ locates the flanking microsatellite markers between the breakpoints in the hybrids CY120 to CY112. This suggests that the physical distance is $1-2 \mathrm{Mb}$.

This interval is not very gene rich or physically well characterised, although it does contain the homologue of the Drosophila transcription factor gene FKHL5. Sequence analysis of BAC RP11-463O9 (AC009108) shows it to contain both D16S520 and FKHL5, placing the gene clearly in the critical region. However, initial analysis of this gene by single stranded conformational polymorphism (SSCP) analysis has shown no mutations in its two exons.

$$
\begin{array}{r}
\text { R BELL* } \\
\text { G BRICE } \\
\text { A H CHILD } \\
\text { V A MURDAY } \\
\text { S MANSOUR } \\
\text { C J SANDY } \\
\text { J R O COLLIN } \\
\text { P MORTIMERS } \\
\text { D F CALLEN } \\
\text { K BURNAND } \\
\text { S JEFFERY } \\
\text { ` }
\end{array}
$$

${ }^{\star}$ Medical Genetics Unit, St George's Hospital Medical School, Cranmer Terrace, London SW17 ORE, UK
†Department of Cardiological Sciences, St George's Hospital Medical School, London SW17 ORE, UK

$\ddagger$ Moorfields Eye Hospital, London, UK

$\$$ Department of Dermatology, St George's Medical School, London SW17 ORE, UK

\Department of Cytogenetics and Molecular Genetics, Women and Children's Hospital, North Adelaide, South Australia

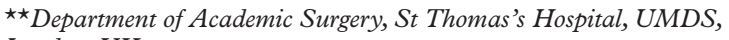
London, UK

Correspondence to: Dr Jeffery, sggt100@sghms.ac.uk

1 Mortimer PS. Managing lymphoedema. Clin Exp Dermatol 1995;20:98-106. 2 Greenlee R, Hoyme H, Witte M, Crowe P, Witte C. Developmental disorders of the lymphatic system. Lymphology 1993;26:156-68.

3 Witte MH. Genetic alterations in lymphoedema. Lymphology 1997;16:1925.

4 Dale RF. The inheritance of primary lymphoedema. F Med Genet 1985;22: 274-8.

5 Goodman RM. Familial lymphoedema of the Meige's type. Am f Med 1962; 32:651-6.

6 Wheeler ES, Chan V, Wassman R, Rimoin DL, Lesavoy MA. Familial lymphoedema praecox: Meige's disease. Plast Reconstr Surg 1981;67:362-4.

7 Herbert FA, Bowen PA. Hereditary late-onset lymphoedema with pleural effusion and laryngeal edema. Arch Intern Med 1983;143:913-15.

8 Robinow M, Johnson GF, Verhagen AD. Distichiasis-lymphedema: a Robinow M, Johnson GF, Verhagen AD. Distichiasis-lymphedema: a
hereditary syndrome of multiple congenital defects. Am $\mathcal{f}$ Dis Child hereditary syndrom

9 Rosbotham JL, Brice GW, Child AH, Nunan TO, Mortimer PS, Burnand KG. Distichiasis-lymphoedema: clinical features, venous function and lymphoscintigraphy. Br f Dermatol 2000;142:148-52.

10 Mangion J, Rahman N, Mansour S, Brice G, Rosbotham J, Child AH, Murday VA, Mortimer PS, Barfoot R, Sigurdsson A, Edkins S, Sarfarazi M, Burnand K, Evans AL, Nunan TO, Stratton MR, Jeffery S. A gene for lymphoedema-distichiasis maps to 16q24.3. Am f Hum Genet 1999;65: 427-32.

11 Jeffery S, Saggar-Malik AK, Moragan S, MacGregor GA. A family with autosomal dominant polycystic kidney disease not linked to chromosome 16p13.3. Clin Genet 1993;44:173-6.

12 Callen DF, Lane SA, Kozman H, Kremmidiotis G, Whitmore SA, Lowenstein M, Doggett NA, Kenmochi N, Page DC, Maglott DR, Nierman WC, Murakawa K, Berry R, Sikela JM, Houlgate R, Auffray C, Sutherland GR. Integration of transcript and genetic maps of chromosome 16 at near-1-Mb
resolution; demonstration of a "hot spot" for recombination at $16 \mathrm{p} 12$. resolution; demonstration
Genomics 1995;29:503-11. 